\title{
A novel corrosion resistant repair technique for existing Reinforced Concrete (RC) elements using Polyvinyl Alcohol Fibre Reinforced Geopolymer Concrete (PVAFRGC)
}

\author{
Mohammed Haloob Al-Majidi ${ }^{1,2}$, Andreas P. Lampropoulos ${ }^{1}$, Andrew B. Cundy ${ }^{3}$, Ourania T. \\ Tsioulou ${ }^{1}$, Salam Al-Rekabi ${ }^{4}$ \\ ${ }^{1}$ School of Environment and Technology, University of Brighton, Moulsecoomb, Brighton BN2 4GJ, UK \\ ${ }^{2}$ Department of Civil Engineering, College of Engineering, University of Basrah, Basrah, Iraq \\ ${ }^{3}$ School of Ocean and Earth Science, University of Southampton, Southampton SO14 3ZH, UK. \\ ${ }^{4}$ Department of Civil Engineering, Al-Mustaqbal University College, Babylon, Iraq.
}

\begin{abstract}
Strain hardening fibre reinforced geopolymer concrete, which utilises waste material rather than primary mineral products and is suitable for cast-in-place applications, shows considerable potential as a resistant, more environmentally friendly, concrete repair material. This study assesses the corrosion protection performance of polyvinyl alcoholic fibre reinforced geopolymer concrete as a repair material. The applicability of polyvinyl alcoholic fibre reinforced geopolymer concrete as a repair material for preventing steel corrosion was investigated using specimens that simulated surface coating repair. Large scale beam repair was conducted using beams where part of the concrete cover at various depths $(12.5 \%$ and $25 \%$ of the total beam depth) was replaced by polyvinyl alcoholic fibre reinforced geopolymer concrete. Accelerated corrosion tests were performed using an induced current technique by applying a nominal $300 \mathrm{~mA} / \mathrm{cm}^{2}$ constant anodic current for approximately 90 days. Results from flexural strength tests showed significant improvements in the structural performance of the reinforced concrete beams repaired with polyvinyl alcoholic fibre reinforced geopolymer concrete following accelerated corrosion. The results can be summarised as follows: surface coating with polyvinyl alcoholic fibre reinforced geopolymer concrete significantly reduced corrosion damage in terms of mass loss, crack distributions and structural performance, while differences in surface coating thickness also considerably affected the corrosion resistance of the repaired beams.
\end{abstract}

Keywords; corrosion resistance; fibre reinforced geopolymer concrete; repair material; reinforced concrete beams.

\section{Introduction}

Reinforced concrete (RC) structures in marine and coastal areas are continuously exposed to a chloride-rich environment, which leads to deterioration of the concrete and its reinforcement bars [1-3]. Corrosion of steel reinforcement bars causes a reduction in their cross-sectional area, and produces corrosion products with a higher volume than the original 
steel leading to cracking of the concrete cover. The cracking also increases the corrosion rate, and decreases the bond effectiveness between steel bars and concrete, leading to a reduction in load carrying capacity and the safety performance of the concrete structure $[4,5]$. In recent years, RC structure deterioration has motivated the development of innovative and new materials and techniques for structural repair, as replacement of existing structures would be very costly, and in most cases prohibitively expensive [1]. In this study an induced current testing technique was employed to accelerate corrosion over a relatively short period (i.e. 90 days) in order to make comparisons between specimens with a significant degree of corrosion. This technique has been widely used in previous studies, which have proven that the induced current method can accurately simulate the effect of corrosion over short (experimental) periods $[6.7,8]$.

A range of research studies have focused on the repair of existing structures. Most of this research uses a traditional patch repair method which applies polymer cement mortar (PCM) to repair concrete structures, or uses repair techniques based on externally bonded steel plates, reinforced concrete jacketing [9, 10], or use of externally bonded Fibre Reinforced Polymer (FRP). While all of these methods and materials have been used relatively successfully for the rehabilitation of reinforced concrete structures and are yielding excellent results for some specific applications, there is still a need to develop a material capable of extending structure service life in severe environmental conditions with a minimum of maintenance. In particular, the use of externally glued FRPs as well as steel plates can have issues around fire resistance. The use of reinforced concrete jacketing systems needs to apply concrete layers with thicknesses larger than $60-70 \mathrm{~mm}$ as the presence of reinforcing bar requires a minimum concrete cover [11]. Moreover, these repair techniques cannot protect repaired concrete structures damaged by chloride attack from re-deterioration processes, due to physical and electrochemical incompatibilities between the repair material and substrate concrete [12].

Fibre reinforced cementitious composites (FRCC) are materials composed of a cement-based matrix with short discontinuous fibres. Generally, the addition of fibres to a concrete mix considerably enhances many of the mechanical properties of concrete such as flexural, impact, tensile, and abrasion strength, cracking distribution and post cracking behaviour [13, 14]. While numerous cracks can be generated under tensile stress following fibre addition, these cracks have low permeability to chloride, oxygen and moisture ingress since crack width is very small. While steel fibres are the most commonly used type of fibre, Polyvinyl Alcohol (PVA) fibres have also been successfully used for the enhancement of the 
mechanical properties of conventional concrete in previous studies [15-18]. Li et al., (2001) [18] studied the strain hardening performance of fibre reinforced mortar containing $2 \%$ PVA fibre with a surface oil coating. The strong chemical bond between the cementitious matrix and the oiled PVA fibres led to the rupture of bridging fibres rather than their pull-out during the opening of a matrix crack. Therefore, a fibre surface oiling was applied to weaken the bond and provide 'pseudo' strain hardening characteristics. Lee et al., (2012) [19] examined the strain-hardening behaviour of a PVA fibre reinforced cement-less mortar with Alkali Activated Slag (AAS). Test results showed a significant improvement in tensile strain values, which reached up to $4.7 \%$ (and which were considerably higher compared to the respective values for the unreinforced matrix, which were around $0.02 \%$ ).

Regarding cost, the PVA fibres have similar cost per weight compared to steel fibres. However, the quantity of PVA fibre used is six times less than steel fibre at the same volume fraction, therefore the cost of PVA fibre reinforced concrete mixture is considerably lower compared to the cost of the respective material reinforced with steel fibres. Moreover, in the current study the cost of the geopolymer matrix material is further reduced by lowering the potassium silicate content and avoiding heat curing treatment [14].

These fibre-rich materials therefore show potential as a more resilient repair and strengthening material, particularly under chemically aggressive environmental conditions. Recently, novel techniques using fibre reinforced concrete (FRC) layers or jackets have been proposed to improve the performance of existing structural members [11, 20-22]. Simultaneously, fibre reinforced geopolymer concretes (FRGC) have emerged as novel engineering materials with the potential to form a substantial element of an environmentally sustainable construction and building products industry [23]. Fibre reinforced geopolymer composites with higher ductility and strain hardening behaviour have been developed in our previous work $[14,23]$. Based on the earlier phases of the material development, PolyVinyl Alcoholic Fibre Reinforced Geopolymer Concrete (PVAFRGC) materials showed superior durability characteristics in term of resistance to sulphuric acid attack, corrosion resistance and chloride penetration which is in agreement with previous studies on the durability properties of geopolymer mortar and geopolymer concrete [24-26]. The FRGC matrix composition is similar to that of normal mortar and concrete therefore, FRGC materials are expected to be highly applicable as surface coating or patch repair materials for the repair and preventive maintenance of reinforced concrete structures that have already deteriorated, or that will deteriorate due to steel corrosion. However, research on FRGC has mainly focused on its mechanical performance, such as its tensile strength and post cracking behaviour and, to date, there are no published studies on the evaluation of the structural performance of FRGC, and its applicability for repair of and preventive maintenance against steel corrosion, in comparison to untreated reinforced concrete beams. Recently, the usage of geopolymer matrix as a repairing layer or as a binding agent to ensure the adhesion between fibre reinforced sheets/ strips and the concrete substrate has been investigated with favourable 
results [27, 28]. However, there are not any published studies to date on the use of unreinforced geopolymer mortars for repair applications since the high shrinkage strain values may lead to de-bonding of the new mortar. Also, there are not any published studies to date on the durability performance of RC elements strengthened or repaired with geopolymer concrete.

Electrochemical incompatibilities of RC and repair mortar affect the initiation of macrocell corrosion between the repair material and the substrate. Electrochemical compatibilities are attributed to the electrochemical potential imbalance when the two materials (i.e. repair material and substrate) due to the variations of the physical and chemical properties of the two materials [29]. The electrochemical incompatibilities of RC and PVAFRGC have not been examined in the current study, and this could be part of a future investigation in this field.

The main aim of this study was to investigate the corrosion protection performance of FRGC (specifically PVAFRGC) used as repair material of varying thickness $(12.5 \%$ and $25 \%$ of the total RC beam depth). Two different depths of the repair layer were examined in order to evaluate the effect of the thickness of the repair layer on the durability and on the structural performance of the elements. These two values were selected as two characteristic cases of repair techniques by simply replacing the concrete cover ( $12.5 \%$ of the total RC beam depth) or by also replacing existing concrete around the reinforcement bars $(25 \%$ of the total $\mathrm{RC}$ beam depth).

For comparison, monolithic RC beams made entirely using normal (conventional) concrete with a cross section of $100 \times 200 \mathrm{~mm}$ were used as controls. Accelerated corrosion studies were undertaken using an induced current technique by applying a nominal $300 \mathrm{~mA} / \mathrm{cm}^{2}$ constant anodic current for 90 days. The effect of accelerated corrosion on the mass loss of the steel reinforcements, failure mode, crack distribution, load carrying capacity and interface slip measurement between the substrate and the repair layer, was examined.

\section{Experimental Program.}

\subsection{Materials, mixture proportions and mechanical properties.}

Geopolymer concretes can be synthesized by mixing an alkaline solution with industrial aluminosilicate waste materials, and their adoption could considerably reduce the carbon dioxide emissions associated with the manufacturing of conventional Portland cement. However, based on previous studies [30-32], FA-based geopolymer concretes require elevated temperature treatment to obtain comparable performance (in terms of physical, 
mechanical and durability characteristics) to conventional concrete. This heat treatment leads to increased cost, effects the material sustainability, and generates practical production and handling issues, preventing in situ application of geopolymer concrete at large scales [31, 33, 34]. Preliminary work has however been performed to develop fibre reinforced geopolymer concretes with improved strain hardening performance and which can be cured at ambient temperature $[14,23,35]$. This study assesses the application of these ambient temperature cured geopolymer materials as a practical repair material for $\mathrm{RC}$ structures exposed to aggressive marine environments. The geopolymer matrix was produced by using a ternary binder (fly ash, slag and silica fume) mixture with potassium silicate alkaline activator (details of the mix proportions are given in Table 1). Polyvinyl alcohol (PVA) fibres at 2\% volume fraction were used in this study as fibre reinforcement (mechanical and geometrical properties of the PVA fibres are shown in Table 2). The mixing procedures (steps and time) and curing conditions have been described in detail in a previous published study [14].

Three different tests were carried out to measure the mechanical properties of the PVAFRGC mixture; compression tests, flexural strength tests and direct tensile tests. Standard cube compressive tests (100 mm cube side) were conducted, and the mean compressive strength at the time of structural testing (120 days after casting) was equal to $45 \pm 2 \mathrm{MPa}$. The cubes were covered with plastic sheets to prevent moisture loss and cured at room temperature up to the testing date. Regarding the workability of PVAFRGC, this has not been examined in this study and so values are not available for this specific mix, but the mix used was quite workable and could easily pass through the reinforcement without need for compaction. Flow tests have been conducted for the plain geopolymer mix (without the PVA fibres) following the ASTM C230 [36] procedure, and a slump of $150 \mathrm{~mm}$ was measured.

Direct tensile strength was determined using "dog-bone" shaped specimens of $13 \mathrm{~mm}$ (mid cross section) by $50 \mathrm{~mm}$ (Figure 1a) [14, 23]. Flexural strength was assessed by testing standard prismatic specimens $(100 \times 100 \times 500 \mathrm{~mm})$ at 28 days curing using an Instron testing machine (the flexural test setup is shown in Figure 1b). It should be noted that these tests have been conducted in order to evaluate the flexural and tensile strength characteristics of the examined material, and these characteristics may vary from the actual characteristics of the repair layers which have different geometry compared to the standard beams and therefore different fibre orientation. Details of the testing set up are described in a previously published study [14]. 
An average stress-strain curve was calculated and the average strength was found equal to 3 MPa (Figure 2a). This strength value refers to the ultimate tensile strength of the material obtained by the direct tensile (dog-bone) tests which occurs at a strain approximately equal to 0.004 , a value which varies for the various examined specimens since there is a quite significant plateau where the ultimate stress remains almost constant (Figure 2a). The maximum stress value is similar to the tensile strength of conventional mortars, however PVAFRGC shows significantly enhanced stress-strain hardening characteristics as opposed to conventional mortars which are characterised by brittle behaviour. The Young's modulus was experimentally obtained from the slope of the initial linear part of the stress-strain graph and a value of $25 \mathrm{GPa}$ was calculated. The experimental results in Figure $2 \mathrm{~b}$ indicate strain hardening behaviour as the second peak load is greater than that at the first cracking load, and there is a large deflection gap between first and second peak loads. The load deflection curve further showed that after initial cracking, load increased with deflection with a low slope due to the fibre bridging action at the interface of cracks, up to the point at which slip between the fibres and matrix occurred. After this stage, the maximum load was achieved which was then followed by tension softening and load reduction which is attributed to crack opening, which is significantly increased at this stage. The enhanced strain hardening characteristics of the material, which are clearly illustrated in the stress strain (Figure 2a) and load-deflection (Figure 2b) curves, is attributed to the strong bonds between the PVA fibres and the geopolymer matrix [14, 23].

\subsection{Reinforced concrete beam geometry, preparation and material properties.}

In total 12 reinforced concrete beams were constructed for this study, four as reference beams (without treatment), and eight for repair using different thicknesses of PVAFRGC layer. The test beams were classified into two series, the beams in series 1 are the control specimens (non-corroded beams) while the beams in series 2 are the RC beams exposed to corrosion. Figure 3 shows the dimensions of the beams where the length is $1400 \mathrm{~mm}$, breadth is $200 \mathrm{~mm}$ and the width is $100 \mathrm{~mm}$. The reinforcement consisted of two deform bars with a diameter of $10 \mathrm{~mm}(2 \Phi 10)$ made of steel with a characteristic yielding stress value of $530 \mathrm{MPa}$ in the tensile side. Stirrups of $8 \mathrm{~mm}$ deformed bars diameter (Ф8) were used in the shear span at an interval of $90 \mathrm{~mm}$ with a measured yield strength stress value of $350 \mathrm{MPa}$ and spacing 90 $\mathrm{mm}$. The ultimate strengths for the $\Phi 8$ and $\Phi 10$ bars were $414 \mathrm{MPa}$ and $640 \mathrm{MPa}$, respectively. The specimens were fabricated from ordinary Portland cement. Coarse aggregates having particle size $<10 \mathrm{~mm}$ as well as fine aggregates of $5 \mathrm{~mm}$ were used to 
prepare the ordinary concrete. During casting, concrete cubes with side dimension of $100 \mathrm{~mm}$ were sampled and tested for compressive strength, which at the time of structural testing (210 days after casting) was equal to $32 \mathrm{MPa}$.

\subsection{Repair of reinforced concrete beams.}

The RC beams with ordinary concrete were cast in a wooden mould up to $150 \mathrm{~mm}$ and 175 $\mathrm{mm}$ depths for PVAFRGC-50R and PVAFRGC-25R, respectively (Figure 4). Then the specimens were demoulded after 2 days and left to mature for 3 months. Since the concrete cover of deteriorated RC beams must be removed before the surface coating or the repair material is applied on actual deteriorated structures, in this study FRGC was overlaid on RC beams without initial deterioration of the reinforcement bars. The exposed steel reinforcements were cleaned using a steel brush (Figure 5), and an air chipping hammer was used for roughening the concrete surfaces followed by washing with a high-pressure water-jet to clean the surface of dust and to remove the weak layer of dry cement paste and loose aggregate. After 3 months, a $25 \mathrm{~mm}$ or $50 \mathrm{~mm}$ layer of PVAFRGC was cast directly on the concrete beam surface by overturning the RC beam upside down (Figure 6) in order to have repaired specimens with identical cross section with the control specimens $(100 \times 200 \mathrm{~mm})$, which facilitates direct comparisons of the experimental results. The repaired thicknesses of $25 \mathrm{~mm}$ and $50 \mathrm{~mm}$ (Figure 7) correspond to the waterproofing layer of structural elements [37]. Since the curing of PVAFRGC was carried out at ambient temperature and humidity, a plastic sheet was placed on the surface in order to limit water evaporation.

The differential shrinkage between the new mortar and the existing substrate is a crucial parameter for the performance of the repaired and/or strengthened RC elements. When a new mortar is applied to an existing concrete element, the new material tends to shrink during the drying process while part of the moisture is also transferred to the existing dry substrate. This moisture transfer mechanism results in a differential shrinkage strain and subsequent shear stresses at the new mortar - to--existing substrate interface which may lead to de-bonding of the new mortar and failure of the repaired and or strengthened element [38, 39]. Standard practice in these applications employed to avoid this phenomenon include the appropriate design of the mortar mixes in order to reduce the shrinkage strain values, and use of wet curing during the initial period after casting in order to mitigate the shrinkage strain development and reduce the risk of de-bonding. 
In the current study, a plastic sheet was placed on the surface after casting in order to limit water evaporation. After demoulding, the PVAFRGC surface was kept under wet conditions by water spray curing for the first 10 days, to avoid cracking resulting from restrained shrinkage. Also the addition of PVA fibres to the mortar has effectively reduced the shrinkage strain of the geopolymer mortars as presented in a previous study [40].

\subsection{Corrosion acceleration and mass loss measurements.}

An induced accelerated corrosion test was employed to simulate the corrosion of steel reinforcement in concrete (Figure 8). Six RC beams were corroded by an accelerated corrosion system, and six specimens were left un-corroded to act as reference beams (Table 3). RC beams were first immersed in a 5\% sodium chloride solution which was placed up to a $5 \mathrm{~cm}$ height from the bottom side of the beams (Figure 8). The corrosion process was then accelerated by applying a constant current of $300 \mathrm{~mA}$ for 90 days between the reinforcement bar (anode) and a copper mesh (cathode) at the bottom surface of the container connected to the negative terminal of the DC power supply, as shown in Figure 9.

After 90 days of accelerated corrosion, extensive cracks appeared especially in the control specimen with conventional concrete where crack localization also appeared. The targeting degree of induced corrosion (10\%) was theoretically calculated according to Faraday's law as follows:

$$
M_{t h}=\frac{W I_{a p p} T}{F}
$$

where:

$M_{t h} \quad$ is theoretical mass of rust per unit surface area of the bar $\left(\mathrm{g} / \mathrm{cm}^{2}\right)$,

$W \quad$ is the equivalent weight of steel which is taken as the ratio of atomic weight of iron to the valency of iron $(27.925 \mathrm{~g})$,

$I_{\text {app }} \quad$ is the applied current density $\left(\mathrm{A} / \mathrm{cm}^{2}\right)$,

$T \quad$ is the duration of induced corrosion (s), and

$F \quad$ is the Faraday's constant (96.487 A-s).

After testing of the RC beams to failure, coupons of corroded steel reinforcement were removed from the tested beams to evaluate the mass loss of steel at the end of corrosion exposure. To remove the corrosion products from the steel, a number of chemical, mechanical and electrolytic techniques are described in the ASTM Standard G1-90. To ensure that the steel bar was free from any adhering corrosion products the rusted steel bars 
were mechanically cleaned using a stiff metal brush. Stages of removal and cleaning of the corroded steel coupons are shown in Figure 10. The reinforcing bar was then weighed and the percentage mass loss was calculated using Eq. (2).

$$
\text { corrosion mass loss }=\frac{\text { initial mass }- \text { final mass }}{\text { initial mass }} \cdot 100
$$

\subsection{Mechanical test setup.}

All tested specimens (initial and repaired RC beams) were loaded under four-point bending with an imposed deflection rate of $0.004 \mathrm{~mm} / \mathrm{s}$ (with an effective span equal to $1200 \mathrm{~mm}$ ) using a Zwick testing machine (Figure 11). The displacement of the specimens was measured using Linear Variable Displacement Transducers (LVDT) placed at the centre of the specimen on each side. The results observed include the mode of failure, load carrying capacity and slipping at the interface.

The lateral LVDTs give an indication of the interface slip between the repair overlaid material and the substrate RC beam during bending with an applied load, as reported by Tsioulou et al. [41]. Six lateral LVDTs were fixed longitudinally to the interface. The LVDTs were attached symmetrically to the beams, three on each side of the load set up (Figure 12). The lateral LVDTs were mounted on the concrete surface at the supports and then at incremental distances of $250 \mathrm{~mm}$ towards the centre. Each LVDT was glued to the substrate beam and was in contact with a metal angle section that was glued to the strengthened/ repair layer (Figure 13). All readings were continuously collected by data-acquisition systems during the test until failure of the beam. It should be mentioned that the fixed (rather than roller) supports of the lateral LVDTs result in additional induced recordings during the bending of the beams. However, this method can give a relatively accurate indication of the interface slip and the recorded data can be corrected taking into account the rotation of the beams at the support during bending, as also noted by Tsioulou et al. [41].

\section{$3 \quad$ Analysis and discussion of results.}

\subsection{Corrosion damage of control and repaired RC beams.}

Visual inspection of the corroded specimens showed that the control specimens had multiple corrosion stains and cracking on the tensile side. During the induced current test, it is 
assumed that the current applied to the steel bar attracted negatively charged chloride ions from the $\mathrm{NaCl}$ solution into the concrete specimens, towards the positively charged reinforcements. As the chloride ions reached the steel-concrete interface above threshold concentrations, the steel surface began to corrode [5]. The expansive reaction products of the corrosion imposed tensile stresses on the conventional concrete / FRGC cover, resulting in cracking when the tensile stresses exceeded the tensile strength of the cover material. No delamination or spalling of concrete cover was observed. The RC beams repaired with PVAFRGC at different thicknesses $(25 \mathrm{~mm}$ and $50 \mathrm{~mm})$ showed small and relatively few corrosion stains on the repaired layer as shown in Figure 14. Visual inspection confirmed that the majority of the corrosion stains occurred at locations where initial hairline cracks were present, resulting from differential shrinkage. After the flexural test and removal of the overlay repair material, corrosion product stains from rusted steel bars distributed at the interfacial zone of RC beams repaired with $25 \mathrm{~mm}$ of PVAFRGC were more common than those for the RC beams repaired with $50 \mathrm{~mm}$ of PVAFRGC (Figure 15).

After demolition of the specimens, the extracted tensile steel reinforcement coupons were cleaned, measured and compared to the non-corroded coupons. The average percentage of steel mass loss was at $8.5 \%, 7 \%$ and $5.5 \%$ for the control beam and RC beams repaired with $25 \mathrm{~mm}$ and $50 \mathrm{~mm}$ of PVAFRGC, respectively. The targeting degree of corrosion (10\%) was close to the achieved mass loss for the control specimens $(8.5 \%)$ so it can be concluded that targeted corrosion levels can be reached with the accelerated corrosion duration calculated in accordance with Faraday's equation. The differences in the mass loss values for the specimens repaired with PVAFRGC are attributed to differences between the crack distribution and crack width formed in the control and repaired RC beams during the applied induced current. Large localized cracks formed in the control specimens, allowing easier migration of corrosion products, which was evidenced by excessive rust concentration on the cracked surfaces of the severely damaged specimens (Figure 16a). From the other side, hair cracks only were observed visually at the surface of the repaired RC beams with PVAFRGC. The reduced crack width for RC beams repaired with PVAFRGC reduced movement of the corrosion products, which was evidenced by the concentration of the corrosion products only on the interface between the old and the new material (Figure 16b).

\subsection{Mode of Failure and crack pattern of initial and repaired RC beams.}

Failure of the control and repaired RC beams at the end of testing are shown in Figure 17. Failure of unrepaired beams, both corroded and un-corroded, occurred by flexural crack 
failure followed by crushing of concrete in the compression zone as shown in Figure 17b. For the corroded unrepaired specimens, the loss of bonding due to cracking resulting from the volume expansion of the rebar after the electrical acceleration led to spalling of concrete cover at the bottom tensional face of the beam under loading. The RC beams repaired with 25 $\mathrm{mm}$ and $50 \mathrm{~mm}$ of PVAFRGC overlay failed by rupture of the PVAFRGC layer after yield of the tensile steel reinforcement followed by concrete crushing (Figure $17 \mathrm{c}-\mathrm{e}$ ). The accelerated corrosion of the RC beams did not change the failure mode of the repaired material. The same crack pattern was noticed in $25 \mathrm{~mm}$ and $50 \mathrm{~mm}$ layer thickness repaired beams under flexural loading, where multiple cracks were observed in the PVAFRGC overlay layer. The localized large cracks that developed in the substrate RC beam diffused into many fine cracks when they met the PVAFRGC layer, leading to delay in the flexural failure. The cracks started to propagate with increasing loading in a direction perpendicular to the FRGC layer. At the final stage of the loading it was observed that only one crack was completely opened. This is due to the effect of the reinforcing fibres in arresting the cracks, and their stress transfer capability, which leads to effective stress redistribution. The slipping of the steel bars was not monitored in the current study but from visual observations it was evident that there was not any significant slip in any of the examined specimens.

\subsection{Loading capacity of repaired RC specimens.}

The main loading test results are summarized in Table 4. The first crack load for each beam was the load at which the load-deflection relationship for the particular beam was no longer linear, and the failure load was determined as $85 \%$ of the maximum load. The load versus mid-span deflection curves for each beam series are presented in Figures 18-20.

The load-deflection curves of the reference corroded and non-corroded RC specimens are presented in Figure 18 (a-b).

From Figure 18 and Table 4, it can be seen that the first cracking of non-corroded RC beams occurred at a load of $9 \mathrm{kN}$ and $9.4 \mathrm{kN}$ for Ref- 1 and Ref- 2 specimens, respectively. As the loading increased further, inclined cracks were distributed across the beam with major cracking initiated close to the centre of the beam. The load dropped at $52.5 \mathrm{kN}$ and $53.4 \mathrm{kN}$ and related deflections are $9.1 \mathrm{~mm}$ and $10.65 \mathrm{~mm}$ for Ref-1 and Ref-2 specimens, respectively. Subjecting the specimens to an induced current of $300 \mathrm{~mA}$ for 90 days for steel corrosion with $8.5 \%$ steel mass loss had significant effects on the structural response of the control RC beams. The ultimate load of the corroded $\mathrm{RC}$ beams was reduced by $16 \%$ on average for Ref-corr-1 and Ref-corr-2, compared to the respective average ultimate load of the specimens without corrosion (Ref-1 and Ref-2). The deflection at the ultimate load reduced to $6.86 \mathrm{~mm}$ and $7 \mathrm{~mm}$ for Ref-cor-1 and Ref-cor-2, respectively (Figure 18b). This reduction of the ultimate load and the respective deflection is attributed to the reduction of 
the mass of the longitudinal reinforcement at the tensile side and the subsequent concrete cracking and loss of bond between the steel bars and the concrete which was observed after the application of the induced current.

The load-deflection curve of the corroded and non-corroded specimens repaired with $25 \mathrm{~mm}$ PVAFRGC overlay are presented in Figure $19(a-b)$.

As shown in Figure 19 and Table 4, the failure mode of PVAFRGC-R25 specimens was similar to that of the control RC beams. Application of a $25 \mathrm{~mm}$ thickness of PVAFRGC overlay however improved the structural performance of the RC beams. The recorded first cracking load was increased by $41 \%$ on average for PVAFRGC-R25-1 and PVAFRGC-R252 specimens compared with the respective load values for the control beams (Ref-1 and Ref2). As the loading increased further, the cracking across the substrate and the repaired layer increased, and crack width enlarged up to failure. The ultimate failure load was increased by 15\% on average for both PVAFRGC-R25-1 and PVAFRGC-R25-2 compared with the control RC beams. This ultimate load increment is attributed to the enhanced stress strain characteristics of the PVAFRGC which was placed to the tensile side of the beams and therefore led to an increase in the internal stresses of the tensile stress-strain block of the specimens' cross section, and subsequent increase of ultimate moment and load capacity. The effect of steel corrosion ( $7 \%$ steel mass loss) on the structural response of the repaired beams was considerably reduced compared with the control RC beams. For corroded specimens, the ultimate load was decreased by $11 \%$ on average for PVAFRGC-R25-corr-1 and PVAFRGCR25-corr-2 compared with the respective ultimate load value of the non-corroded repaired specimens. Despite corrosion damage and cracking at the interface between the repair overlay and the substrate (Figure 15), the ultimate loads of the corroded-repaired specimens were still higher than those of the control non-corroded beams (i.e. the Ref specimens). This improved behaviour of the PVAFRGC repaired specimens is attributed to the fact that PVAFRGC proved to be beneficial in limiting the effect of corrosion on the steel reinforcement mass loss, and also as subsequent concrete cracking at the tensile side was limited when PVAFRGC was used. This has contributed to the enhancement of the ultimate load capacity when compared to the respective results of the control specimens.

The load-deflection curve of the corroded and non-corroded specimens repaired with $50 \mathrm{~mm}$ PVAFRGC overlay are presented in Figure 20 (a-b).

For RC beams repaired with $50 \mathrm{~mm}$ thickness of PVAFRGC material overlay, the first cracking load was higher than the respective values of the average of the two control (Ref-1 and Ref-2) and the two PVAFRGC-R25 specimens (PVAFRGC-R25-1 and PVAFRGC-R25- 
2) by $63 \%$ and $15 \%$ respectively. However, increasing the repair overlay thickness from 25 $\mathrm{mm}$ to $50 \mathrm{~mm}$ did not change the ultimate load since there was not any significant change in the material of the outer tensile side, and the addition of PVAFRGC does not significantly affect the stress strain distribution at the tensile side of the specimens. With increasing load, multiple cracks in the repair layer were observed, and the crack widths were narrower than those observed in the repaired beam with $25 \mathrm{~mm}$ thickness overlay. The peak load and midspan displacement at failure were $61 \mathrm{kN}$ and $7.65 \mathrm{~mm}$ for the PVAFRGC-R50-1 specimen, and were $60 \mathrm{kN}$ and $8.33 \mathrm{~mm}$ for the PVAFRGC-R50-2 specimen, respectively. The effect of corrosion exposure on the corrosion damage, cracking and structural response of RC beams (Figure 20b) was less pronounced compared with the control and repaired beams with $25 \mathrm{~mm}$ thickness of PVAFRGC. Visual inspection of the repaired beam after demolition confirmed that no corrosion products were present at the interface between the substrate and the overlay material (Figure 16b and 20b). For corroded RC beams repaired with $50 \mathrm{~mm}$ PVAFRGC overlay material, the ultimate failure load decreased to $55.47 \mathrm{kN}$ and $56.40 \mathrm{kN}$ for PVAFRGC-R50-corr-1 and PVAFRGC-R50-corr-2, respectively, which is approximately a $8 \%$ reduction compared with the values observed for the PVAFRGC-R50 non-corroded beams (Figure 20b). The results of this section indicate that the addition of PVAFRGC can considerably limit the effect of corrosion since the average ultimate load reduction due to corrosion for the control specimens was found to be equal to $16 \%$, while the respective reduction was reduced to $11 \%$ for the $25 \mathrm{~mm}$ PVAFRGC repair layer and was further reduced to $8 \%$ for the $50 \mathrm{~mm}$ PVAFRGC repair layer

\subsubsection{Discussion of the repaired RC beams results.}

To assess the structural and corrosion resistance differences between the different thicknesses of the repaired material and the control specimens, experimental loads at three points were compared, the first crack loading point, the ultimate load point, and the failure load point of the RC beams. Individual and average test results for all RC beams are presented in Figure 21 and summarized in Figure 22.

Compared to the control RC beams, the repaired beams PVAFRGC-R25-1 and PVAFRGCR25-2 showed first crack load values which were increased by $41 \%$ on average for the two examined specimens. This means that the stiffness of the repaired RC beams was significantly improved by using $25 \mathrm{~mm}$ of PVAFRGC in the tension zone. There is also a 15 $\%$ increment of the ultimate failure load of the repaired $\mathrm{RC}$ beams for both $25 \mathrm{~mm}$ and 50 
$\mathrm{mm}$ repair thicknesses. These results show that the PVAFRGC layer thickness is not a significant factor in improving the ultimate failure load when the effect of corrosion is not taken into consideration. It can also be observed from these results that an additional onequarter initial loading carrying capacity can be achieved by using PVAFRGC with $12.5 \%$ of the total beam depth in the tensile side, without changing the quantity of longitudinal steel or the cross section of the RC beam.

Constant current applied for 90 days to accelerate the corrosion procedure reduced the ultimate carrying capacity of the control RC beams by $16 \%$ (Figure $21 \mathrm{a}$ ), and caused $8.5 \%$ mass loss of the reinforcement bars. Increasing the repair layer thickness from $25 \mathrm{~mm}$ to 50 $\mathrm{mm}$ in the corroded RC beams considerably enhanced the flexural capacity (Figure 22). These results indicate that increasing the repair material thickness improved the corrosion resistance, which was confirmed by the reduction in the mass loss of the corroded reinforcement bar from 7\% for PVAFRGC-R25 specimen to $5.5 \%$ for PVAFRGC-R50 specimen (Figure $21 \mathrm{~b}-\mathrm{c}$ ). This behaviour can be explained by two factors: firstly, the superior durability performance of the thicker repair material in terms of corrosion resistance, chloride and moisture penetrations; and secondly, the impact on the interfacial bond between the overlaid repair material and the RC beam substrate, which is the weakest and most critical section of the repaired member. The interfacial bond is influenced by the geometry (thickness) of the repair material, which subsequently effects the corrosion rate of the reinforcement bars and crack damage. A $50 \mathrm{~mm}$ thickness of repair layer ensures higher bonding with the concrete substrate by stronger embedding of the longitudinal and shear reinforcement in the repair material. On the other hand, the interfacial bond between the 25 $\mathrm{mm}$ repair layer and the concrete substrate was controlled only by adhesion through the concrete substrate's rough surface.

\subsection{Interface slip measurement of repaired specimens.}

High bond strength at the interface between concrete layers cast at different ages is vital to ensure monolithic behaviour of the strengthened and repaired reinforced concrete members $[42,43]$. Given that in an existing $\mathrm{RC}$ beam these dimensions are restricted from the geometry of the existing structure, it is important to enhance the shear strength at the interface in order to ensure that the shear stresses will be lower than the shear strength at the interface. 
Figures 23 and 24 illustrate the relationship of load slip measurements between the RC beam substrate and the overlay repair material with $25 \mathrm{~mm}$ and $50 \mathrm{~mm}$ thickness, respectively. The geometry and the loading of the beams were symmetrical and the preparation of the interface was the same along the whole beam length. A similar set up was followed for all RC beams as mentioned in section 2.5 and the slip measurement points $a_{1}, a_{2}, b_{1}, b_{2}, c_{1}$ and $c_{2}$ are presented in the results. The slip measurements at the interface between the RC beam substrate and the overlay layer presented here are only due to the bending load, and the effects of creep and shrinkage are ignored.

From Figure 23 and Figure 24, interface slip values are summarized in Table 5, which presents data for the maximum load and the respective loads at interface slip values of 0.2 $\mathrm{mm} \mathrm{P}_{(\mathrm{s}=0.2 \mathrm{~mm})}, 0.8 \mathrm{~mm} \mathrm{P}_{(\mathrm{s}=0.8 \mathrm{~mm})}$ and $1.5 \mathrm{~mm} \mathrm{P}_{(\mathrm{s}=1.5 \mathrm{~mm})}$. These are the ultimate accepted slip values for immediate occupancy, life safety and collapse prohibition behaviour levels respectively, according to GRECO [41, 44].

From the results presented above, it can be observed overall that the slip interface measurements of all beams are small, and increased as cracks began to propagate with an increase in the applied load. For instance, in beam PVAFRGC-R25-1, the interface slip measurement was very small (up to $\leq 0.2$ ) within an applied load of $33 \mathrm{kN}$, and increased to $0.75 \mathrm{~mm}$ at the maximum load of $60.75 \mathrm{kN}$ (Figure 23a and Table 5). Figure 24 illustrates that increasing the repair thickness from $25 \mathrm{~mm}$ to $50 \mathrm{~mm}$ did not have a significant effect on the interface slip measurements. However, a $50 \mathrm{~mm}$ repair thickness delays the respective loads at interface slip values of $0.2 \mathrm{~mm}$, as the first cracking load increased with repair thickness. According to slip measurements for repaired RC beams PVAFRGC-R50-1 and PVAFRGC-R50-2, the respective loads at interface slip values of $0.2 \mathrm{~mm}$ were $34 \mathrm{kN}$ and 43 $\mathrm{kN}$, respectively. Exposure of repaired RC beams to accelerated corrosion did not have a major effect on the slip measurement. It can be seen that the interface slip reaches the $1 \mathrm{~mm}$ limit only in RC beam PVAFRGC-R50-corr-2 as all specimens failed by flexural cracking, rather than by separation between the substrate beam and the repaired layer. The interface slip measurement along the beam length for RC beams repaired with $25 \mathrm{~mm}$ and $50 \mathrm{~mm}$ of PVAFRGC, respectively are presented in Figure 25 and Figure 26.

It can be observed from Figure 25 and Figure 26 that the interface slip measurements were very low (almost zero) at the supports, and greater near to the collapse cracks at the mid-span interface slip. Despite the symmetry of the RC beam and the loading conditions, the interface slip measurements were not symmetric as the interface adhesion depends on local conditions, as cracks occur asymmetrically [41]. Moreover, the debonding of the repaired layer due to 
differential shrinkage (if there is inadequate connection between the old and the overlay layer) are not included in these results and could affect the slip interface measurement.

There are several analytical models suggested by design codes for the calculation of shear strength at the concrete to concrete interface. The design codes of RC structures used to assess the shear strength at the interface in this study are GRECO [44] code, Model Code (2010) [45], Eurocode 2 [46], ACI Committee 318 [47], and CEB-FIP Model Code [48]. The interface shear strength of the repaired/ strengthened RC beams can be obtained using the following Eqs. (3 - 6).

Model code 2010 [45], Eurocode 2 [46];

$$
\begin{aligned}
\tau_{f u d}=c \cdot f_{c t d} & +\mu \cdot \sigma_{N}+\rho \cdot f_{y d} \cdot(\mu \cdot \sin \alpha+\cos \alpha) \\
& \leq 0.5 \cdot v \cdot f_{c d}
\end{aligned}
$$

ACI Committee 318 [47] code;

$$
\begin{gathered}
\tau_{f u d}=\lambda \cdot\left(1.79+0.6 \cdot \rho \cdot f_{y d}\right) \leq 3.45 \mathrm{MPa} \\
3.45 \mathrm{MPa} \leq \tau_{f u d}=\pi \cdot \rho \cdot f_{y d} \leq \min \left(0.2 \cdot f_{c d}, 5.5 \mathrm{MPa}\right) \\
\text { and } f_{y d} \leq 414 \mathrm{MPa}
\end{gathered}
$$

GRECO code [44];

$$
\tau_{f u d}= \begin{cases}0.25 \cdot f_{c t d}, & \text { smooth interface } \\ 0.75 \cdot f_{c t d}, & \text { rough interface } \\ f_{c t d}, & \text { use of shotcrete }\end{cases}
$$

CEB-FIP Model Code 1990 [48];

$$
\tau_{f u d}=\left\{\begin{array}{lr}
0.1 \cdot f_{c t d}, & \text { very smooth interface } \\
0.2 \cdot f_{c t d}, & \text { smooth interface } \\
0.4 \cdot f_{c t d}, & \text { rough interface }
\end{array}\right.
$$

Where:

$\tau_{\text {fud }}$ is the design interface shear strength,

$\mathrm{f}_{\mathrm{ctd}}$ is the design tensile strength of the concrete with the lower strength (between the old and the new concrete),

$\mathrm{f}_{\mathrm{yd}}$ is the design steel yield stress,

$\sigma_{N}$ is the external vertical to the interface stress,

$\alpha \quad$ is the angle between reinforcement and interface level,

c is the adhesion factor, and

$\mu \quad$ is the friction factor. 
In this investigation, a coefficient of friction ( $\mu$ ) equal to 0.7 and adhesion (c) $0.45 \mathrm{MPa}$ were used, values recommended by Eurocode 2 [46] for rough interfaces. The models proposed by Model code 2010 [45], Eurocode 2 [46] and ACI Committee 318 [47] (Eqs. 3 and 4) take into account the geometric rate of interface reinforcement $(\rho)$ which in this study is calculated for the specimens PVAFRGC-R50 by the number of stirrups crossing the interface, while $\lambda$ is a modification factor reflecting the reduced mechanical properties of light- weight concrete relative to normal weight concrete and equals 1 for normal weight concrete.

The respective interface shear stress can be determined according to the British standard BS 8110-1 [49] using equation (9). The respective results for each repaired beam are presented in Table 6.

$$
\tau_{x}=\frac{V_{s d}}{b \cdot z}
$$

Where $\tau_{x}$ is the interface shear stress of the examined section of the beam according to BS 8110-1 [49]. $V_{s d}$ is the shear force of the examined section of the beam, $b$ is the width of the interface, $z$ is the lever arm of the composite section.

The interface shear stress at the respective loads at interface slip values of $0.2 \mathrm{~mm}$ in all beams repaired with PVAFRGC layers (Table 6) was lower than the respective interface shear strength in all the examined models apart from CEB-FIP Model Code 1990 [48]. This can be explained the small value of the slip measurements at this point $(\mathrm{s}=0.2 \mathrm{~mm})$. The maximum shear stress was higher than the respective shear strength apart from when the ACI-318 code [47] was used (in the case of PVAFRGC-R25 specimens) and when the ACI318 code [47] and Eurocode 2 [46] were used (in the case of PVAFRGC-R50 specimens). Therefore, the low values of interface slip along the whole length of the interface were due to sufficient adhesion when repaired with PVAFRGC material. For corroded specimens, the shear stress at interface slip values of $0.2 \mathrm{~mm}$ and the maximum shear stress was lower than in the non-corroded specimens as the respective bending loads were decreased. The maximum shear stress of PVAFRGC-R50-corr is lower than the shear strength for all examined models apart from CEB-FIP Model code 1990 [48]. This can also be explained by the small interface slip measurements of the experimental investigations. Moreover, the reaction force at the support points preventing the repaired layer from slipping provides an explanation of the negligible slip measurements at the support point of the beams [41]. 


\section{$4 \quad$ Conclusions}

This paper proposed a novel repair technique using strain hardening fibre reinforced geopolymer concrete for the protection of steel reinforcement in concrete members exposed to severe environmental conditions. An experimental investigation was carried out into the performance of RC beams repaired using PVAFRGC with two variant depths $(12.5 \%$ and $25 \%$ of the total $\mathrm{RC}$ beam depth) to simulate a repair surface coating, in order to investigate the effect of overlay depth on flexural performance. The effect of severe environmental conditions on the flexural capacity of RC beams was also evaluated by exposing $\mathrm{RC}$ beams to accelerated induced current. The results from the examined specimens are summarized as follows:

- The mass loss of the reinforcement rebar due to corrosion exposure in the control RC beam was about $8.5 \%$. The repaired $\mathrm{RC}$ beams showed better corrosion resistance and increasing the thickness of the repaired layer from $25 \mathrm{~mm}$ to $50 \mathrm{~mm}$ significantly increase the corrosion resistance by reducing the mass loss from $7 \%$ to $5.5 \%$, respectively.

- A similar failure mode (i.e. flexural fracture and cracks propagating at the mid-span) was observed for the control specimens and the repaired RC beam specimens, and the corrosion cracking damage did not change the failure mode of the specimens.

- The initial cracking and ultimate load was significantly increased by repairing beams with PVAFRGC. For RC beams repaired with a $50 \mathrm{~mm}$ thickness of PVAFRGC material overlay, the first cracking load was higher than the respective values of the control specimens and the specimens with $25 \mathrm{~mm}$ thickness of PVAFRGC material overlay (PVAFRGC-R25) by $63 \%$ and $15 \%$ respectively

- The ultimate failure load was increased by $15 \%$ when a $25 \mathrm{~mm}$ repair layer of PVAFRGC was used as a replacement for conventional concrete. This ultimate load increment is attributed to the enhanced stress strain characteristics of the PVAFRGC which was placed to the tensile side of the beams. Further increases of the repair layer from $25 \mathrm{~mm}$ to $50 \mathrm{~mm}$ thickness did not have any observable effect on the ultimate load capacity of the specimens, since further addition of PVAFRGC towards the neutral axis of the beams does not significantly affect the tensile side stress distribution.

- Regarding corrosion, the addition of PVAFRGC was found to be quite effective in limiting the effects of corrosion since the average percentage of steel mass loss of 
$8.5 \%$ which was observed for the control specimens was reduced to $7 \%$ and $5.5 \%$ for the specimens with 25 and $50 \mathrm{~mm}$ PVAFRGC repair layers respectively. In terms of structural performance, the experimental results showed that the ultimate load capacity of the repaired specimens with PVAFRGC was improved, since the $16 \%$ ultimate load reduction in the control specimens due to corrosion was reduced to $11 \%$ for the $25 \mathrm{~mm}$ PVAFRGC repair layer and was further reduced to $8 \%$ for the $50 \mathrm{~mm}$ PVAFRGC repair layer. This improvement is attributed to the fact that PVAFRGC proved to be beneficial in limiting the effect of the corrosion on the steel reinforcement mass loss, and that the subsequent concrete cracking at the tensile side was limited when PVAFRGC was used.

- The interface slip measurement for the corroded and non-corroded specimens showed that in the case of the repair techniques using a new PVAFRGC layer on the tensile side, very small slip measurements were observed along the full length of the beam, which were almost zero at the supports, which means that a strong and effectively bonded interface had developed following roughening and adhesion of the PVAFRGC material to the substrate. Moreover, the slip measurements for the corroded beams indicate that there is a very limited effect of corrosion exposure on the interface slip measurements.

From the summarized points listed above, it is clear that this overlay repair technique has a strong positive effect on the stiffness, the ultimate capacity and corrosion resistance of the RC beams. Further future experimental study should be focused on the efficiency of the PVAFRGC repair layers in promoting durability improvement at various corrosion levels.

\section{Acknowledgments}

The lead author gratefully acknowledges the Iraqi Ministry of Higher Education and Scientific Research-University of Basrah and Iraqi Cultural Attaché in London for the award of a Doctoral Scholarship.

\section{References}

1. Xie, J.-h. and Hu R.-I., Experimental study on rehabilitation of corrosion-damaged reinforced concrete beams with carbon fiber reinforced polymer. Construction and Building Materials, 2013. 38: p. 708-716.

2. Sahmaran, M., Anil, O., Lachemi, M., Yildrim, G., Ashour Ashraf F., and Acar, F., Effect of Corrosion on Shear Behavior of Reinforced Engineered Cementitious Composite Beams. ACI Structural Journal, 2015. 112(6). 
3. Chen, H.-P. and Zhou X., Reinforcement Corrosion Induced Cracking and Optimised Repair Strategy for Deteriorating Concrete Structures. in 11th International Symposium on Structural Engineering (ISSE-11), 2010.

4. Ma, Y., Xu, F., Wang, L., Zhang, J., and Zhang, X., Influence of corrosion-induced cracking on structural behavior of reinforced concrete arch ribs. Engineering Structures, 2016. 117: $p$. 184-194.

5. Sahmaran, M., Li V.C., and Andrade C., Corrosion resistance performance of steel-reinforced engineered cementitious composite beams. ACI Materials Journal, 2008. 105(3): p. 243-250.

6. Ahmad, S., Techniques for inducing accelerated corrosion of steel in concrete. The Arabian Journal for Science and Engineering,, 2009. 34(2): p. 95.

7. Etman, Z.A., Reinforced Concrete Corrosion and Protection. 2012: Department of Civil Engineering , Faculty of Engineering, Mnoufiya University, EGYPT.

8. Shaikh, F.U.A. and Supit S.W.M., Compressive strength and durability properties of high volume fly ash (HVFA) concretes containing ultrafine fly ash (UFFA). Construction and Building Materials, 2015. 82: p. 192-205.

9. CEB Bulletin d'Information 162, Assessment of concrete structures and design procedures for upgrading (redesign). 1983: Losanne: CEB.

10. Cheon, H. and MacAlevey N., Experimental behaviour of jacketed reinforced concrete beams. ASCE J Struct Eng, 2000. 126: p. 692-9.

11. Martinola, G., Meda, A., Plizzari, G., and Rinaldi, Z., Strengthening and repair of RC beams with fiber reinforced concrete. Cement and Concrete Composites, 2010. 32(9): p. 731-739.

12. Kobayashi, K., lizuka T., Kurachi H., and Rokugo K, Corrosion protection performance of High Performance Fiber Reinforced Cement Composites as a repair material. Cement and Concrete Composites, 2010. 32(6): p. 411-420.

13. Uygunoğlu, T., Investigation of microstructure and flexural behavior of steel-fiber reinforced concrete. Materials and Structures, 2008. 41(8): p. 1441-1449.

14. Al-Majidi, M.H., Lampropoulos A., and Cundy A.B., Tensile properties of a novel fibre reinforced geopolymer composite with enhanced strain hardening characteristics. Composite Structures, 2017. 168: p. 402-427.

15. Natali, A., Manzia S., and Bignozzia M.C., Novel fiber-reinforced composite materials based on sustainable geopolymer matrix. Procedia Engineering, 2011. 21: p. $1124-1131$

16. Zhang Z, Yao X, Zhu H, Hua S, and Chen Y, Preparation and mechanical properties of polypropylene fiber reinforced calcined kaolin-fly ash based geopolymer. Journal of Central South University of Technology 2009. 16: p. 49- 52.

17. Shafiq, N., Ayub T., and Khan S.U., Investigating the performance of PVA and basalt fibre reinforced beams subjected to flexural action. Composite Structures, 2016. 153: p. 30-41.

18. Li, V.C., Wang, S., and Wu, C., Tensile strain-hardening of polyvinil alcohol engineering cementiious composite (PVA-ECC). ACI Materials Journal, 2001.98 (6): p. 483-492.

19. Lee, B.Y., Cho, C.G, Lim, H.J. Song, J.K., Yang, K.H., and Li V.C., Strain hardening fiber reinforced alkali-activated mortar - A feasibility study. Construction and Building Materials, 2012. 37: p. 15-20.

20. Lampropoulos, A.P., Paschalis S.A., Tsioulou O.T., and Dritsos S.E., Strengthening of reinforced concrete beams using ultra high performance fibre reinforced concrete (UHPFRC). Engineering Structures, 2016. 106: p. 370-384.

21. Hussein, M., Kunieda M., and Nakamura H., Strength and ductility of RC beams strengthened with steel-reinforced strain hardening cementitious composites. Cement and Concrete Composites, 2012. 34(9): p. 1061-1066. 
22. Farhat, F., Nicolaides, D., Kanellopoulos, A., and Karihaloo, B.L., High performance fibrereinforced cementitious composite (CARDIFRC)-Performance and application to retrofitting. Engineering fracture mechanics, 2007. 74(1): p. 151-167.

23. Al-Majidi, M.H., Lampropoulos A., and Cundy A.B., Steel fibre reinforced geopolymer concrete (SFRGC) with improved microstructure and enhanced fibre-matrix interfacial properties. Construction and Building Materials, 2017. 139: p. 286-307.

24. Song, X., Marosszeky, M., Brungs, M. and Munn, R., 2005. Durability of fly ash based geopolymer concrete against sulphuric acid attack. International Conference on Durability of Building Materials And Components, 2005, Lyon [France].

25. Wallah, S.E. and Rangan, B.V., Low-Calcium Fly Ash-Based Geopolymer Concrete: LongTerm Properties, Research Report GC2, 2006, Faculty of Engineering, Curtin University of Technology, Perth.

26. Lee, N.K. and Lee, H.K., Setting and mechanical properties of alkali-activated fly ash/slag concrete manufactured at room temperature. Construction and Building Materials, 2013, 47(0), pp. 1201-1209.

27. Menna, C., Asprone D., Ferone C., Colangelo F., Balsamo A., Prota A., Cioffi R., and Manfredi G., Use of geopolymers for composite external reinforcement of $R C$ members. Composites Part B: Engineering, 2013. 45(1): p. 1667-1676.

28. Bencardino, F. and A. Condello, Eco-friendly external strengthening system for existing reinforced concrete beams. Composites Part B: Engineering, 2016. 93: p. 163-173.

29. Gu, P., Beaudoin, J. J., Tumidajski, P. J. and Mailvaganam, N. P., Electrochemical incompatibility of patches in reinforced concrete. Concrete International, 1997. 19(8): p. 6872.

30. Davidovits, J., Geopolymer Chemistry and Applications. 3 ed. 2011: Geopolymer Institute, 2011.

31. Deb, P.S., Nath P., and Sarker P.K., The effects of ground granulated blast-furnace slag blending with fly ash and activator content on the workability and strength properties of geopolymer concrete cured at ambient temperature. Materials \& Design, 2014. 62(0): p. 3239.

32. Islam, A., Alengaram U.J., Jumaat M.Z., and Bashar I.I., The development of compressive strength of ground granulated blast furnace slag-palm oil fuel ash-fly ash based geopolymer mortar. Materials \& Design, 2014. 56(0): p. 833-841.

33. Lee, N.K. and H.K. Lee, Setting and mechanical properties of alkali-activated fly ash/slag concrete manufactured at room temperature. Construction and Building Materials, 2013. 47(0): p. 1201-1209.

34. Nath, P. and P.K. Sarker, Effect of GGBFS on setting, workability and early strength properties of fly ash geopolymer concrete cured in ambient condition. Construction and Building Materials, 2014. 66(0): p. 163-171.

35. Al-Majidi, M.H., Lampropoulos, A., Cundy, A., and Meikle, S., Development of geopolymer mortar under ambient temperature for in situ applications. Construction and Building Materials, 2016. 120: p. 198-211.

36. ASTM C230/C230M-14, Standard Specification for Flow Table for Use in Tests of Hydraulic Cement, ASTM International, West Conshohocken, PA, 2014

37. Safdar, M., T. Matsumoto, and K. Kakuma, Flexural behavior of reinforced concrete beams repaired with ultra-high performance fiber reinforced concrete (UHPFRC). Composite Structures, 2016. 157: p. 448-460. 
38. Beushausen, H. and M. Alexander, Failure mechanisms and tensile relaxation of bonded concrete overlays subjected to differential shrinkage. cament concrete research, 2006. 36: $p$. 1908-14.

39. Dittmer, $\mathrm{T}$. and H. Beushausen, The effect of coarse aggregate content and size on the age at cracking of bonded concrete overlays subjected to restrained deformation. Construction and Building Materials, 2014. 69: p. 73-82.

40. Al-Majidi, M.H., A. Lampropoulos, and A.B. Cundy,Strengthening of plain concrete beams using Strain Hardening Geopolymer (SHGC) layers. In: 39th IABSE Symposium Engineering the Future, Vancouver, British Columbia, Canada, 19-23 September, 2017.

41. Tsioulou, O.T., A.P. Lampropoulos, and S.E. Dritsos, Experimental investigation of interface behaviour of RC beams strengthened with concrete layers. Construction and Building Materials, 2013. 40: p. 50-59.

42. Santos, P.M.D.d., Assessment of the Shear Strength between Concrete Layers. 2009, Universidade de coimbra.

43. Júlio, E., Dias-da-Costa, D., Branco, F.A.B, and Alfaiate, J.M.V., Accuracy of design code expressions for estimating longitudinal shear strength of strengthening concrete overlays. Engineering Structures, 2010. 32(8): p. 2387-2393.

44. GRECO, Greek retrofitting code (final version). Greek Organization for Seismic Planning and Protection. Athens: Greek Ministry for Environmental Planning and Public Works; 2012 [in Greek]. 2012.

45. Model code, International Federation for Structural Concrete (fib), Vol. 1-Bulletin 55, Vol. 2Bulletin 56. 2010, Lausanne.

46. Eurocode 2, CEN En 1992-1-1, Design of concrete structures-Part 1-1: General rules and rules for buildings. 2004, European Committee for Standardization: Brussels: .

47. ACl Committee 318, Building code requirements for structural concrete (ACl318-99) and commentary (318R-99). 1999, American Concrete Institute: Farmington Hills, MI:.

48. CEB-FIP Model Code, Model code for concrete structures, in Comité Euro-International du Béton, Secretariat Permanent, Case Postale. 1990, Thomas Telford: London.

49. BS 8110-1, Structural use of concrete. Part 1: Code of practice for design and construction, . 1997, British Standard Institute: London. 


\section{List of tables}

Table 1. Mixture proportions of PVAFRGC.

\begin{tabular}{lc}
\hline Material & $\begin{array}{c}\text { Mix proportions } \\
{\left[\mathrm{kg} / \mathrm{m}^{3}\right]}\end{array}$ \\
\hline Fly Ash & 388 \\
\hline Slag & 310 \\
\hline Silica fume & 78 \\
\hline Silica sand & 1052 \\
\hline Potassium Silicate alkaline activator & 93 \\
\hline Water content & 194 \\
\hline Superplasticizer & 7.8 \\
\hline PVA fibre & 26 \\
\hline
\end{tabular}

Table 2. Mechanical and geometrical properties of PVA fibre.

\begin{tabular}{ccccccc}
\hline $\begin{array}{c}\text { Fibre } \\
\text { Type }\end{array}$ & $\begin{array}{c}\text { Length } \\
\left(L_{f}\right) \\
{[\mathrm{mm}]}\end{array}$ & $\begin{array}{c}\text { Diameter } \\
\left(d_{f}\right)[\mathrm{mm}]\end{array}$ & $\begin{array}{c}\text { Aspect } \\
\text { ratio } \\
\left(L_{f} / d_{f}\right)\end{array}$ & $\begin{array}{c}\text { Density } \\
{\left[\mathrm{g} / \mathrm{cm}^{3}\right]}\end{array}$ & $\begin{array}{c}\text { Tensile } \\
\text { strength } \\
f_{t}[\mathrm{MPa}]\end{array}$ & $\begin{array}{c}\text { Elastic } \\
\text { modulus } \\
E_{s}[\mathrm{GPa}]\end{array}$ \\
\hline PVA & 12 & 0.015 & 800 & 1.3 & $\begin{array}{c}1560 \pm \\
23\end{array}$ & 29.5 \\
& & & & & 325 & \\
\hline
\end{tabular}

Table 3. Number of specimens (N.O.S) for each PVAFRGC repaired thickness.

\begin{tabular}{c|c|c|c}
\hline $\begin{array}{c}\text { Retrofitting } \\
\text { techniques }\end{array}$ & Description & N.O.S & Specimen designation \\
\cline { 1 - 2 } $\begin{array}{c}\text { Reference } \\
\text { beam }\end{array}$ & Initial RC beam & 2 & Ref \\
\hline \multirow{3}{*}{$\begin{array}{c}\text { Repaired } \\
\text { RC beams }\end{array}$} & PVAFRGC (25mm cover thickness) & 2 & $\begin{array}{c}\text { Ref-corr } \\
\text { PVAFRGC-R25 }\end{array}$ \\
\cline { 2 - 3 } & PVAFRGC (25mm cover thickness) & 2 & PVAFRGC-R25-corr \\
\cline { 2 - 3 } & PVAFRGC (50mm thickness) & 2 & $\begin{array}{c}\text { PVAFRGC-R50 } \\
\text { PVAFRGC-R50-corr }\end{array}$ \\
\hline
\end{tabular}


Table 4. Test results of control (reference) and repaired beams.

\begin{tabular}{|c|c|c|c|c|c|c|c|}
\hline \multirow[b]{2}{*}{ Specimen ID } & \multicolumn{2}{|c|}{ First crack } & \multicolumn{2}{|c|}{ Ultimate point } & \multicolumn{2}{|c|}{ Failure point } & \multirow[b]{2}{*}{$\begin{array}{l}\text { Failure } \\
\text { mode }\end{array}$} \\
\hline & $\begin{array}{l}\text { Load } \\
{[\mathrm{kN}]}\end{array}$ & $\begin{array}{c}\text { Def } \\
{[\mathrm{mm}]}\end{array}$ & $\begin{array}{l}\text { Load } \\
{[\mathrm{kN}]}\end{array}$ & $\begin{array}{c}\text { Def } \\
{[\mathrm{mm}]}\end{array}$ & $\begin{array}{l}\text { Load } \\
{[\mathrm{kN}]}\end{array}$ & $\begin{array}{c}\text { Def } \\
{[\mathrm{mm}]}\end{array}$ & \\
\hline Ref-1 & 9.00 & 0.74 & 52.50 & 9.10 & 44.63 & 14.50 & FL-CC \\
\hline Ref-2 & 9.40 & 0.73 & 53.40 & 10.65 & 45.39 & 16.00 & FL-CC \\
\hline Ref-corr-1 & 8.80 & 0.73 & 45.20 & 6.86 & 38.68 & 11.00 & FL-CC \\
\hline Ref-corr-2 & 8.50 & 0.73 & 43.30 & 7.03 & 37.15 & 12.13 & FL-CC \\
\hline PVAFRGC-R25-1 & 12.20 & 1.13 & 60.75 & 8.00 & 51.64 & 12.20 & FL-CC \\
\hline PVAFRGC-R25-2 & 13.80 & 0.97 & 61.00 & 9.00 & 51.85 & 16.00 & FL-CC \\
\hline PVAFRGC-R25-corr-1 & 14.21 & 1.08 & 55.00 & 6.81 & 46.75 & -- & FL-CC \\
\hline PVAFRGC-R25-corr-2 & 13.23 & 1.41 & 53.54 & 6.89 & 45.51 & 14.25 & FL-CC \\
\hline PVAFRGC-R50-1 & 15.17 & 1.37 & 60.90 & 7.63 & 51.77 & 11.30 & FL-CC \\
\hline PVAFRGC-R50-2 & 14.80 & 1.59 & 60.20 & 8.33 & 51.17 & 12.60 & FL-CC \\
\hline PVAFRGC-R50-corr-1 & 14.00 & 1.85 & 55.47 & 7.71 & 46.58 & 16.80 & FL-CC \\
\hline PVAFRGC-R50-corr-2 & 14.40 & 1.71 & 56.40 & 8.22 & 47.94 & 12.00 & FL-CC \\
\hline
\end{tabular}

Def $=$ deflection

FL-CC $=$ flexural failure followed by secondary compression concrete failure

Table 5. Maximum load and slip values for the repaired RC beams.

\begin{tabular}{|c|c|c|c|c|c|}
\hline Specimen & $\begin{array}{c}\mathrm{P} \\
{[\mathrm{kN}]}\end{array}$ & $\begin{array}{l}S_{\max } \\
{[\mathrm{mm}]}\end{array}$ & $\begin{array}{c}\mathrm{P}_{(\mathrm{s}=0.2 \mathrm{~mm})} \\
{[\mathrm{kN}]}\end{array}$ & $\begin{array}{c}\mathrm{P}_{(\mathrm{s}=0.8 \mathrm{~mm})} \\
{[\mathrm{kN}]}\end{array}$ & $\begin{array}{c}\mathrm{P}_{(\mathrm{s}=1.5 \mathrm{~mm})} \\
{[\mathrm{kN}]}\end{array}$ \\
\hline PVAFRGC-R25-1 & 60.75 & 0.75 & 33.00 & -- & -- \\
\hline PVAFRGC-R25-2 & 61.00 & 1.11 & 25.00 & 58.70 & -- \\
\hline PVAFRGC-R25-corr-1 & 55.00 & 0.31 & 38.00 & -- & -- \\
\hline PVAFRGC-R25-corr-2 & 53.54 & 0.48 & 40.50 & -- & -- \\
\hline PVAFRGC-R50-1 & 60.90 & 0.73 & 34.00 & -- & -- \\
\hline PVAFRGC-R50-2 & 60.20 & 0.36 & 43.00 & -- & -- \\
\hline PVAFRGC-R50-corr-1 & 55.47 & 0.28 & 25.00 & -- & -- \\
\hline PVAFRGC-R50-corr-2 & 56.40 & 0.98 & 21.00 & 50.00 & -- \\
\hline
\end{tabular}


Table 6. The interface shear strength and shear stress of the repaired beams.

\begin{tabular}{|c|c|c|c|c|c|c|}
\hline Specimen & $\begin{array}{c}\text { Model } \\
\text { Code } 2010 \\
{[29] \text { and }} \\
\text { EC2 [30] } \\
{[\mathrm{MPa}]}\end{array}$ & $\begin{array}{c}\text { ACI-318 } \\
{[31]} \\
{[\mathrm{MPa}]}\end{array}$ & $\begin{array}{c}\text { GRECO } \\
{[28]} \\
{[\mathrm{MPa}]}\end{array}$ & $\begin{array}{c}\text { CEB-FIP } \\
\text { Model } \\
\text { Code } 90 \\
{[32]} \\
{[\mathrm{MPa}]}\end{array}$ & $\begin{array}{l}\tau_{\mathrm{x}}(\text { for } \\
\text { Pmax }) \\
{[\mathrm{MPa}]}\end{array}$ & 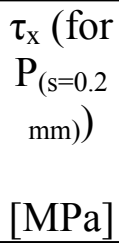 \\
\hline PVAFRGC-R25-1 & 0.91 & 1.79 & 1.51 & 0.81 & 1.69 & 0.92 \\
\hline PVAFRGC-R25-2 & 0.91 & 1.79 & 1.51 & 0.81 & 1.69 & 0.69 \\
\hline PVAFRGC-R25-corr-1 & 0.91 & 1.79 & 1.51 & 0.81 & 1.53 & 1.06 \\
\hline PVAFRGC-R25-corr-2 & 0.91 & 1.79 & 1.51 & 0.81 & 1.49 & 1.13 \\
\hline PVAFRGC-R50-1 & 3 & 3.32 & 1.51 & 0.81 & 1.69 & 0.94 \\
\hline PVAFRGC-R50-2 & 3 & 3.32 & 1.51 & 0.81 & 1.67 & 1.19 \\
\hline PVAFRGC-R50-corr-1 & 3 & 3.32 & 1.51 & 0.81 & 1.54 & 0.69 \\
\hline PVAFRGC-R50-corr-2 & 3 & 3.32 & 1.51 & 0.81 & 1.57 & 0.58 \\
\hline
\end{tabular}




\section{List of figures' captions}

Figure 1. Testing set up; a) direct tensile test and b) flexural strength test.

Figure 2. a) Stress-strain results for direct tensile tests $(n=4)$ and $\mathbf{b})$ load-deflection results for flexural strength tests $(n=3)$. The darker line in each graph shows the average performance of 4 or 3 specimens.

Figure 3. Reference beam-geometry and reinforcement details (all dimensions in $\mathrm{mm}$ ).

Figure 4. Casting the substrate $\mathrm{RC}$ beams for repair purposes.

Figure 5. Preparation of the concrete surface; a) Roughening the concrete surface, and b) cleaning the reinforcement steel.

Figure 6. a) Initial beams ready for casting the repair layer at $25 \mathrm{~mm}$ thickness and b) $50 \mathrm{~mm}$ layer thickness.

Figure 7. Schematic diagram of repair technique.

Figure 8. Accelerated corrosion system; a) Schematic diagram of corrosion pool; b) $25 \mathrm{~mm}$ repair layer and c) $50 \mathrm{~mm}$ repair layer.

Figure 9. Set-up for accelerating reinforcement corrosion in RC beam specimens; a) Power supply and b) specimens under the accelerated corrosion process.

Figure 10. Stages of removal and cleaning of corroded steel coupons.

Figure 11. Loading setup of experimental beams (all dimensions in $\mathrm{mm}$ ).

Figure 12. Strain gauges layout (all dimensions in $\mathrm{mm}$ ).

Figure 13. Detail of lateral LVDT set up.

Figure 14. Tensile side of the control (right) and repaired RC beams (left) after exposure to induced current corrosion.

Figure 15. The corrosion of tensile steel bears after specimen demolition - from left to right: $\mathrm{RC}$ beam repaired with $50 \mathrm{~mm}$ of PVAFRGC; RC beam repaired with $25 \mathrm{~mm}$ of PVAFRGC; control RC beam.

Figure 16. a) Side corrosion crack pattern for the corroded control beams and b) PVAFRGCcorroded beams.

Figure 17. Mode of failure of non-corroded and corroded of initial RC beam and repaired RC beams.

Figure 18. Load-deflection curves of reference beams. 
Figure 19. Load-deflection curves of repaired beam with $25 \mathrm{~mm}$ thickness of PVAFRGC material overlay.

Figure 20. Load-deflection curves of repaired beam with $50 \mathrm{~mm}$ thickness of PVAFRGC material overlay.

Figure 21. Load against deflection curve comparisons; a) non-corroded and corroded initial control beams, b) repaired RC beams with $25 \mathrm{~mm}$ of PVAFRGC layer and c) repaired RC beams with $50 \mathrm{~mm}$ of PVAFRGC layer.

Figure 22. Comparison of the effect of the repair layer on the load-carrying capacity.

Figure 23. Load vs slip relationship of repaired RC beams with $25 \mathrm{~mm}$ PVAFRGC overlay.

Figure 24. Load vs slip relationship of repaired RC beams with $50 \mathrm{~mm}$ PVAFRGC overlay.

Figure 25. Interface slip measurements at peak load for repaired RC beams with $25 \mathrm{~mm}$ PVAFRGC overlay.

Figure 26. Interface slip measurements at peak load for repaired RC beams with $50 \mathrm{~mm}$ PVAFRGC overlay. 


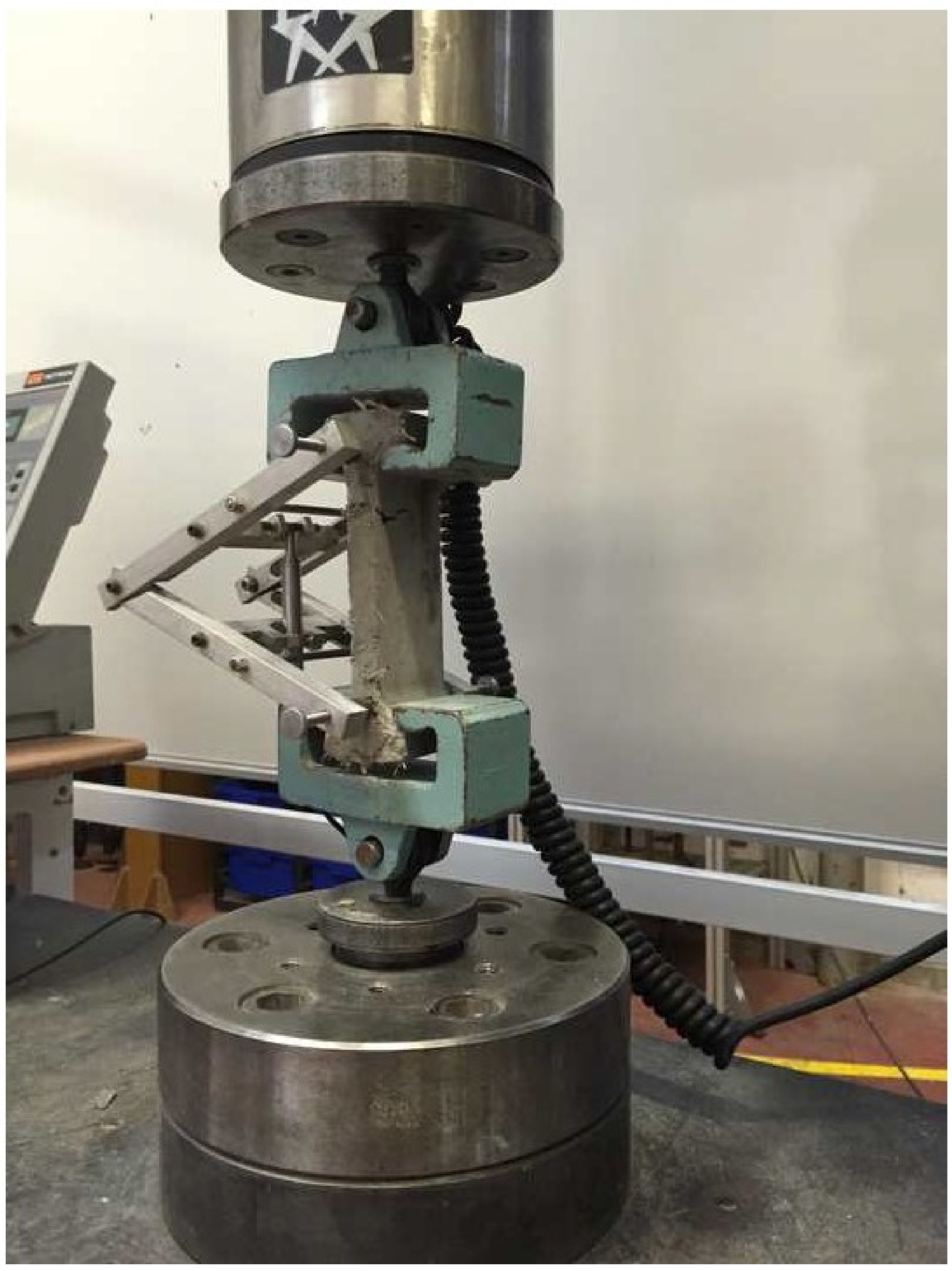


Fig. 1b

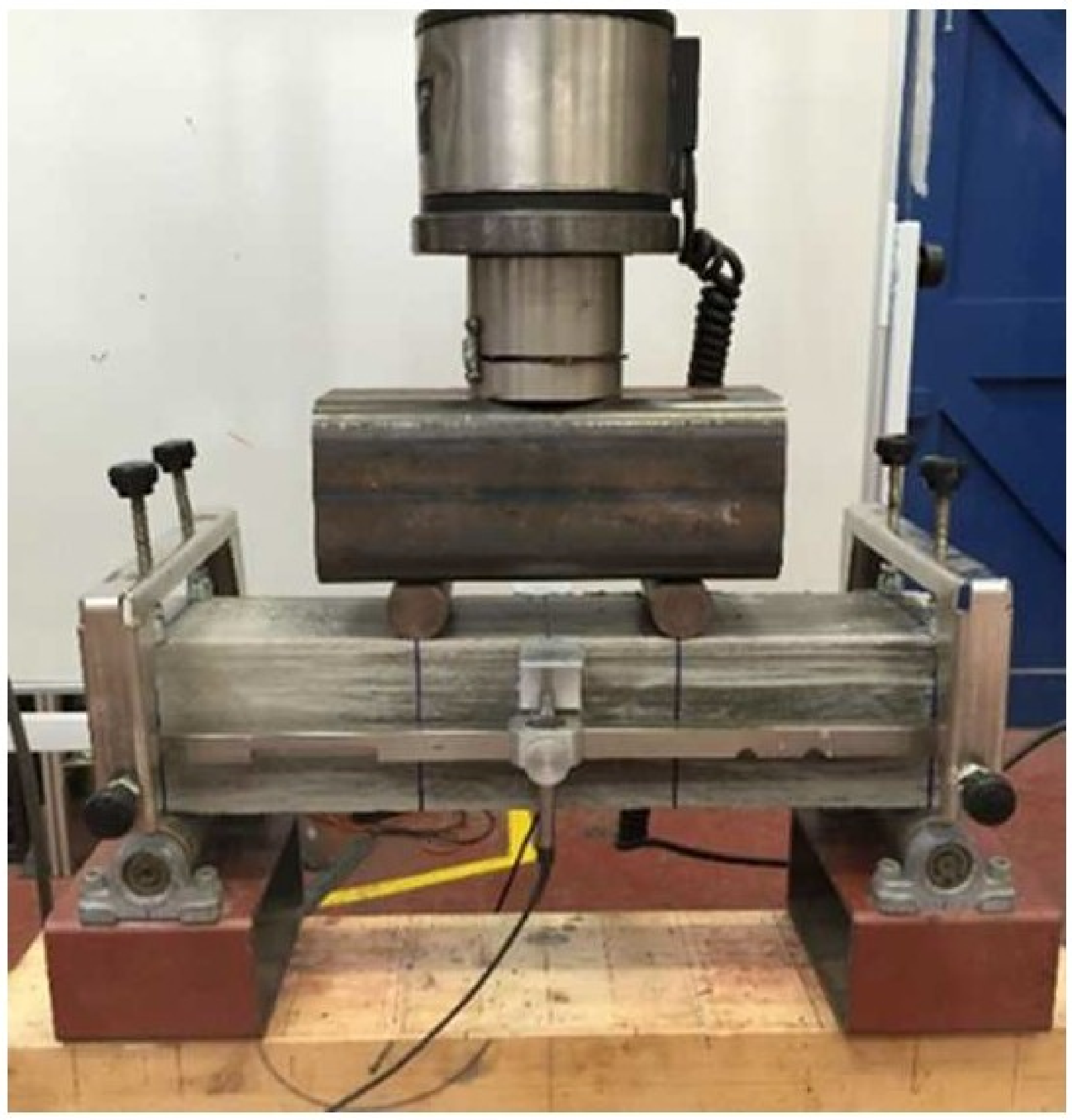




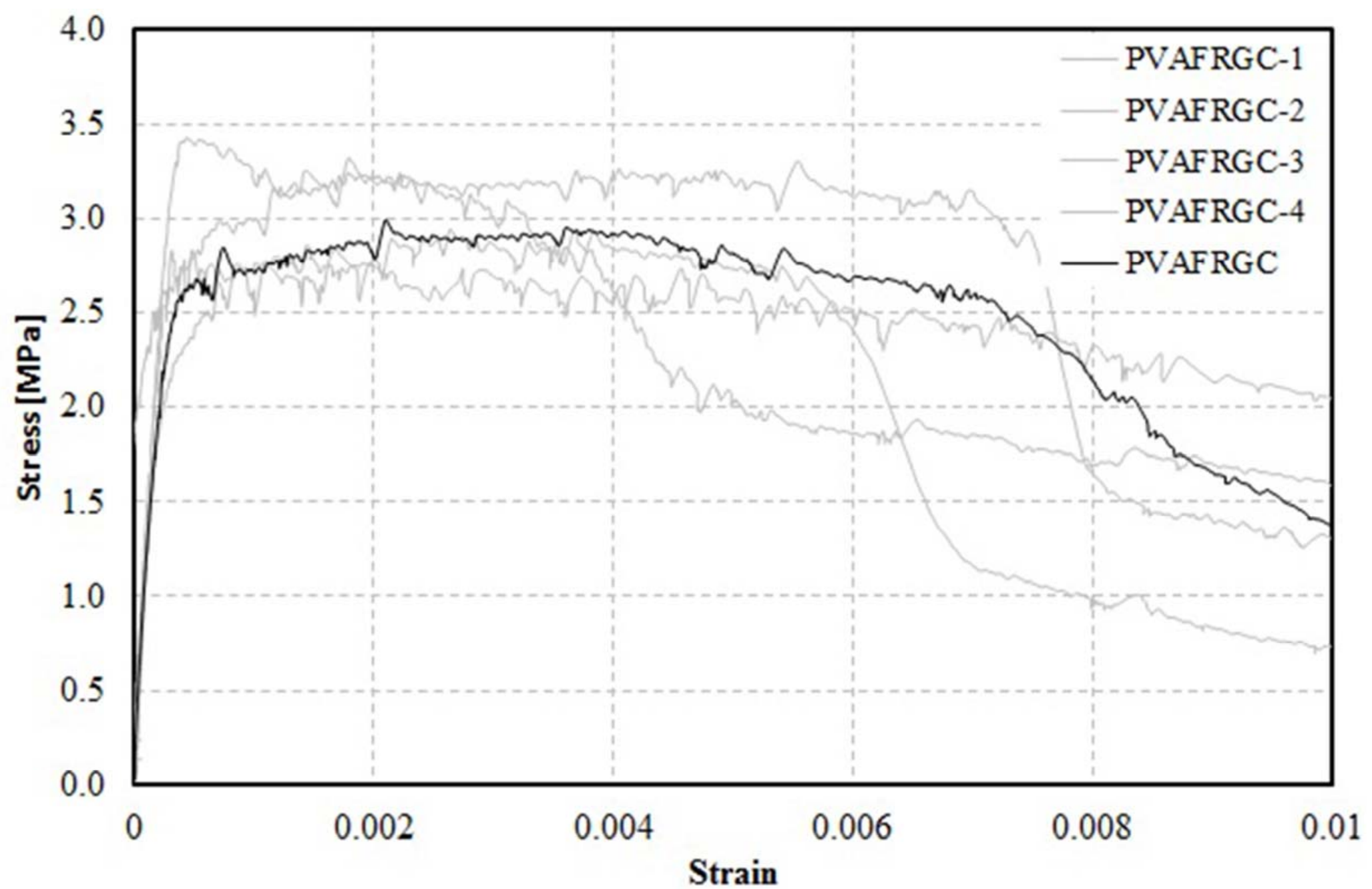


Fig. 2b

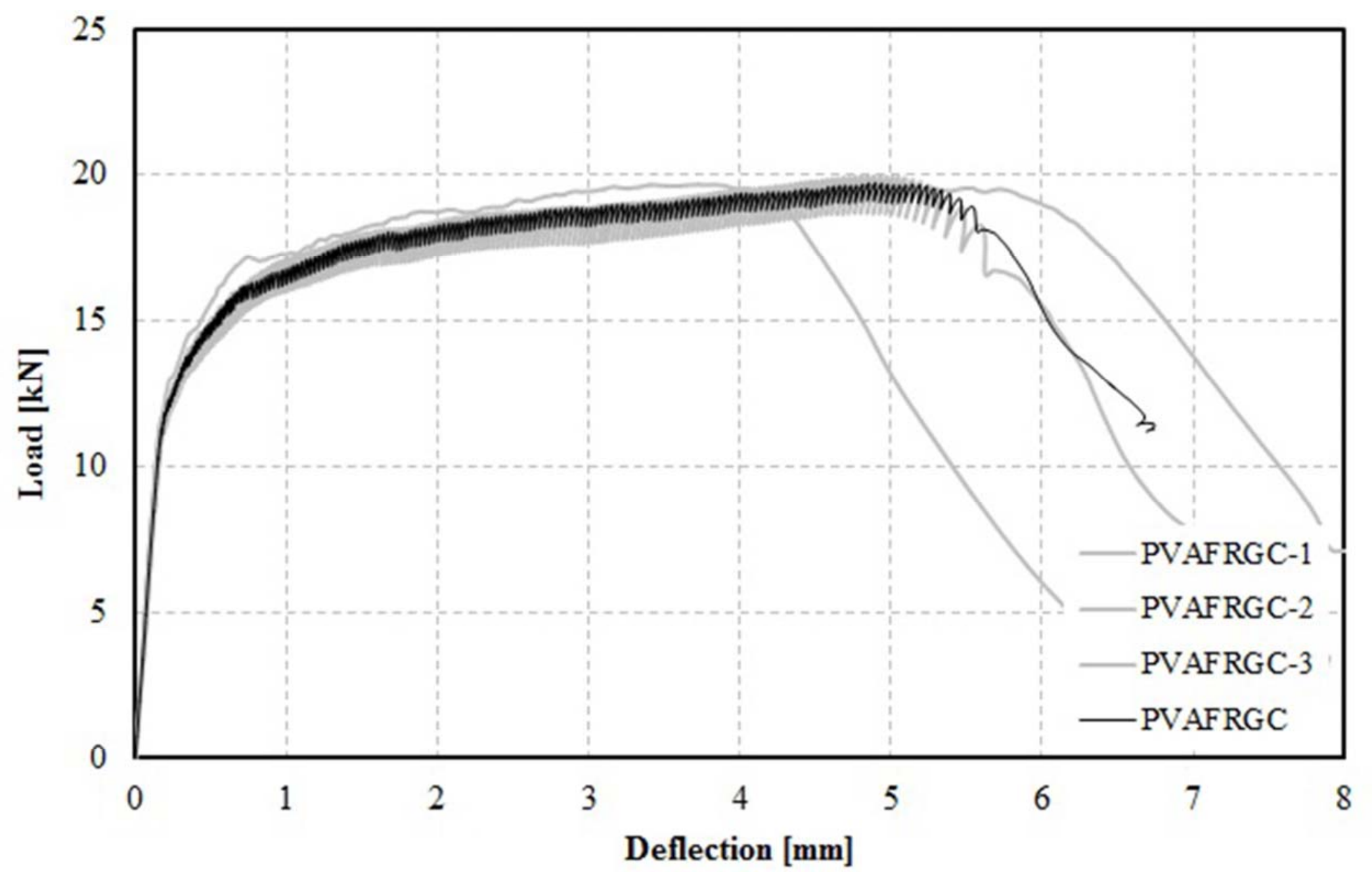




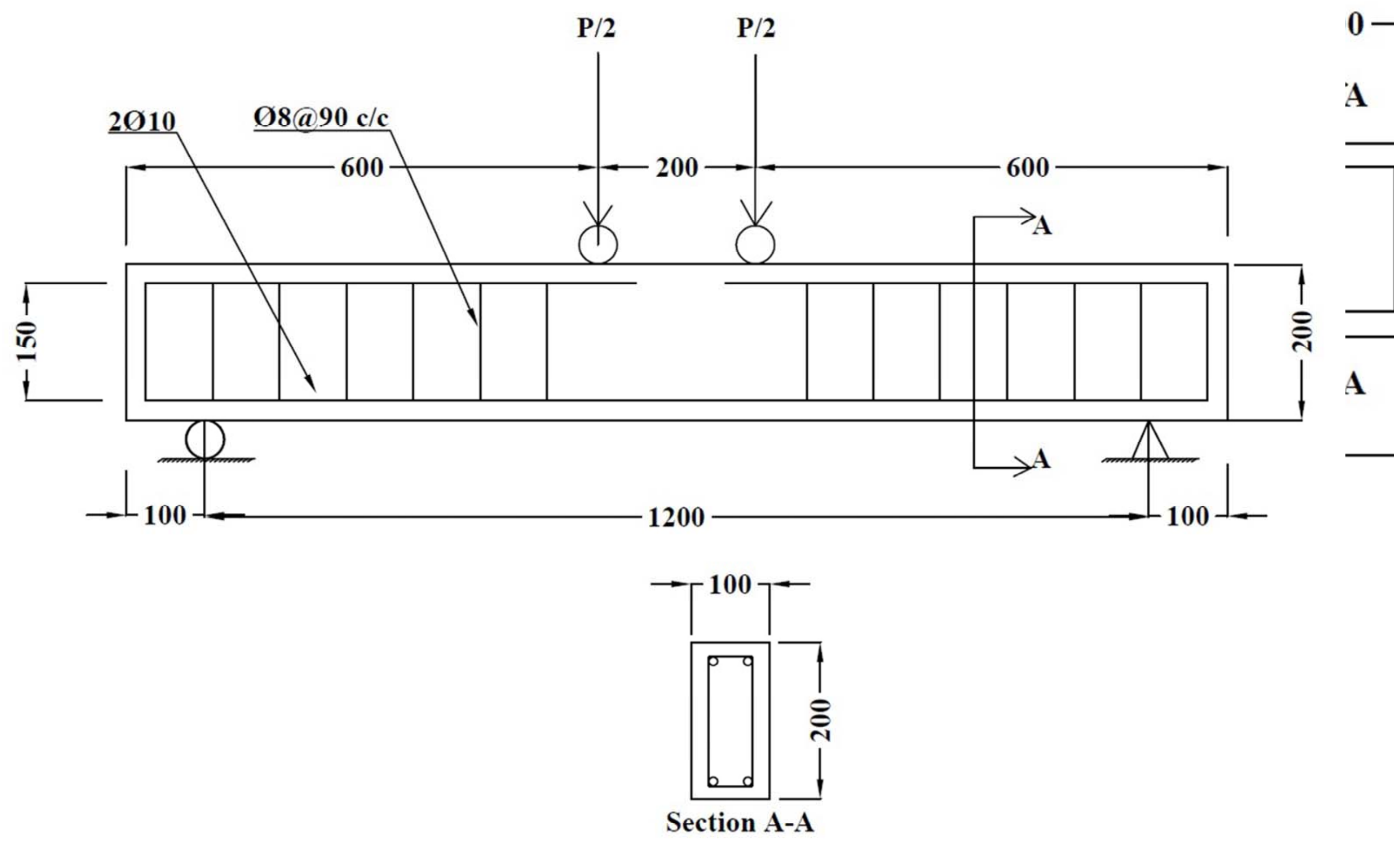




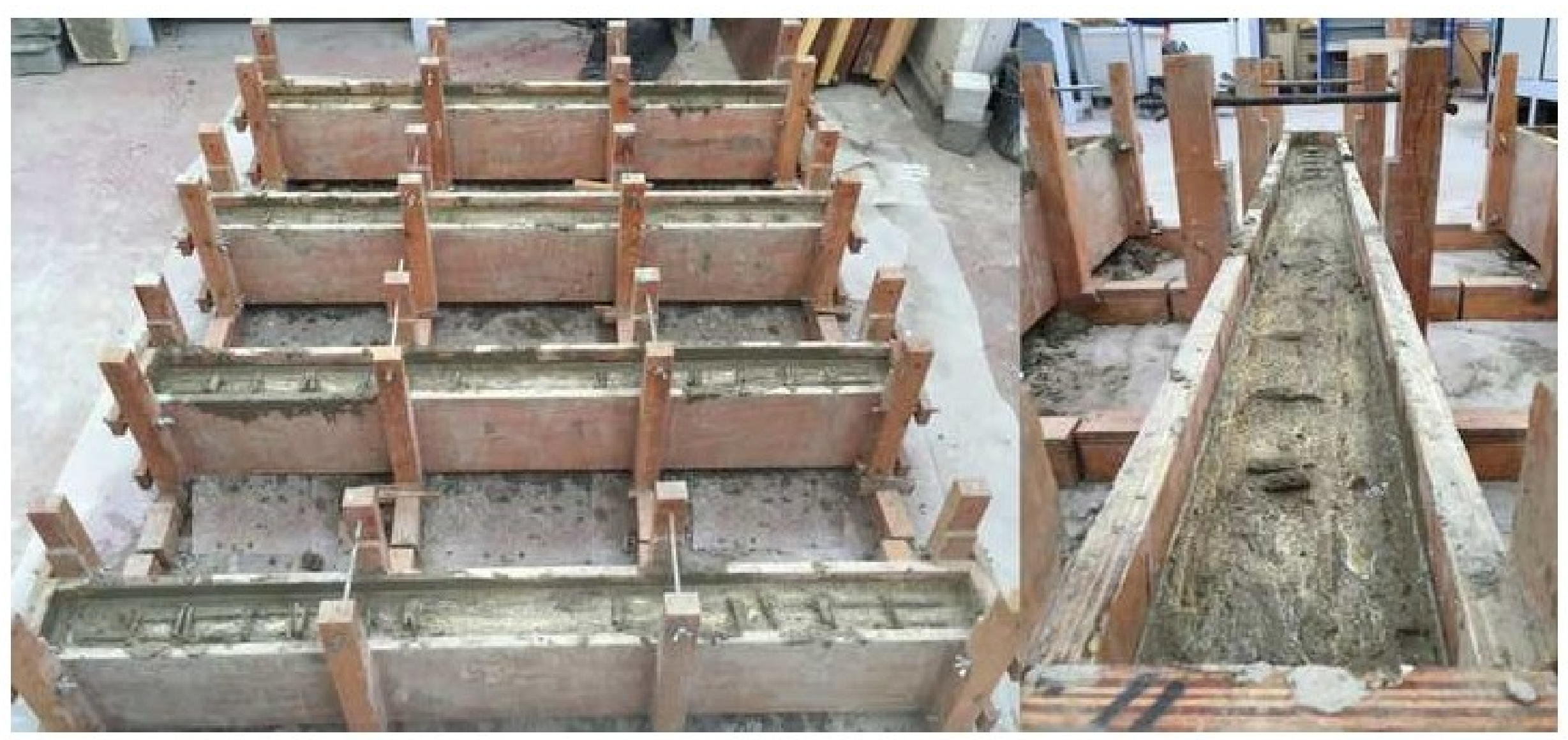




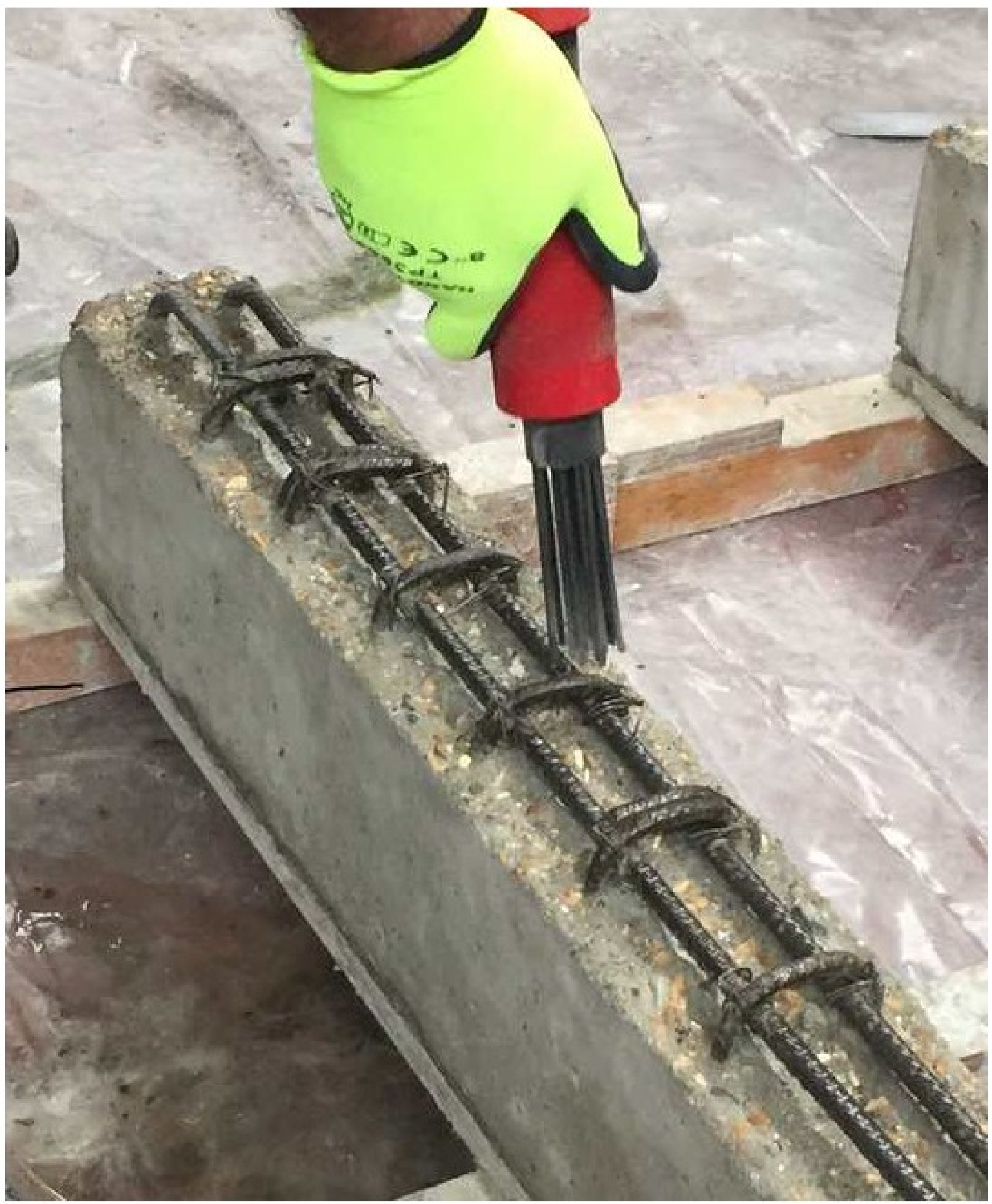




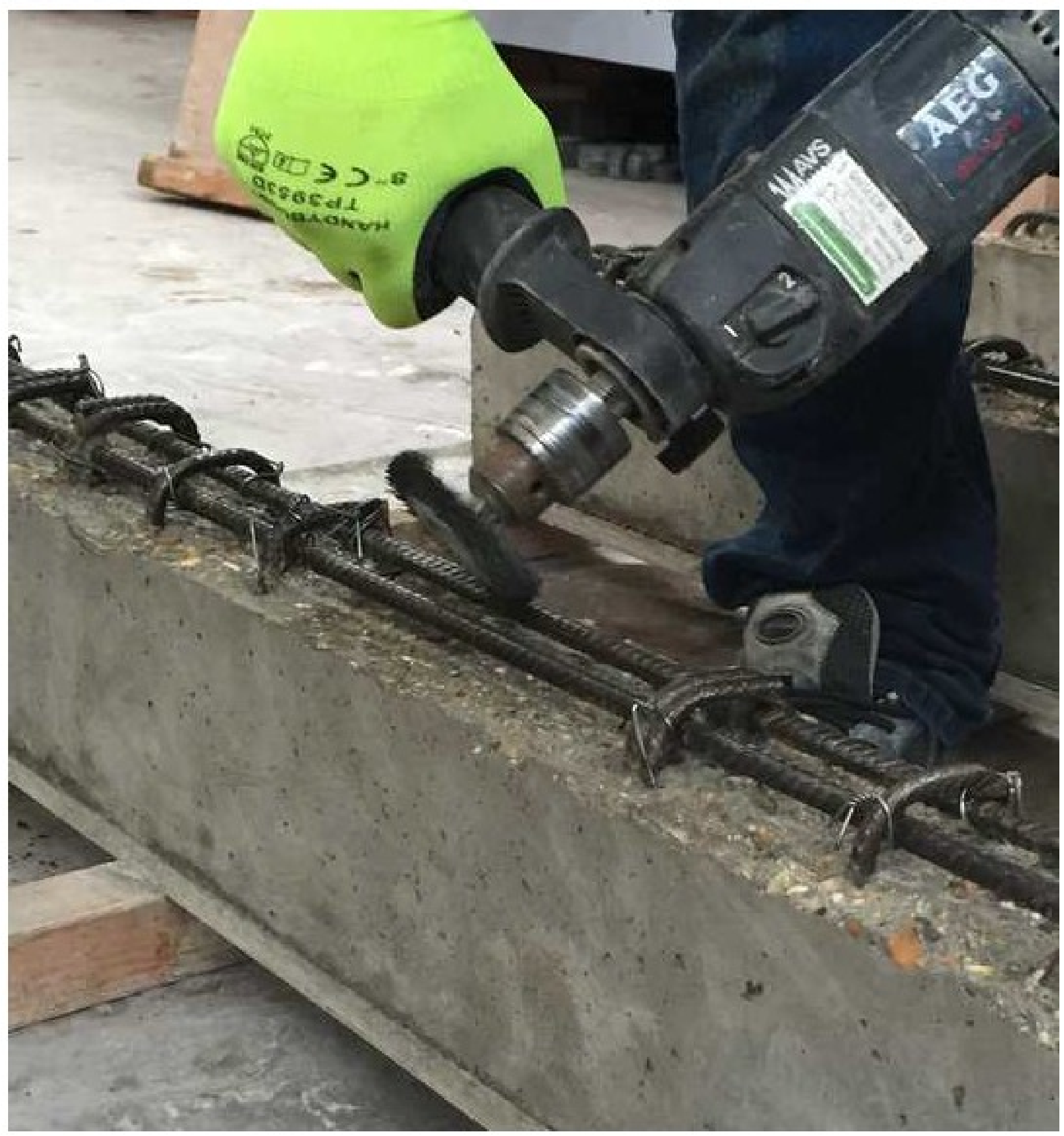




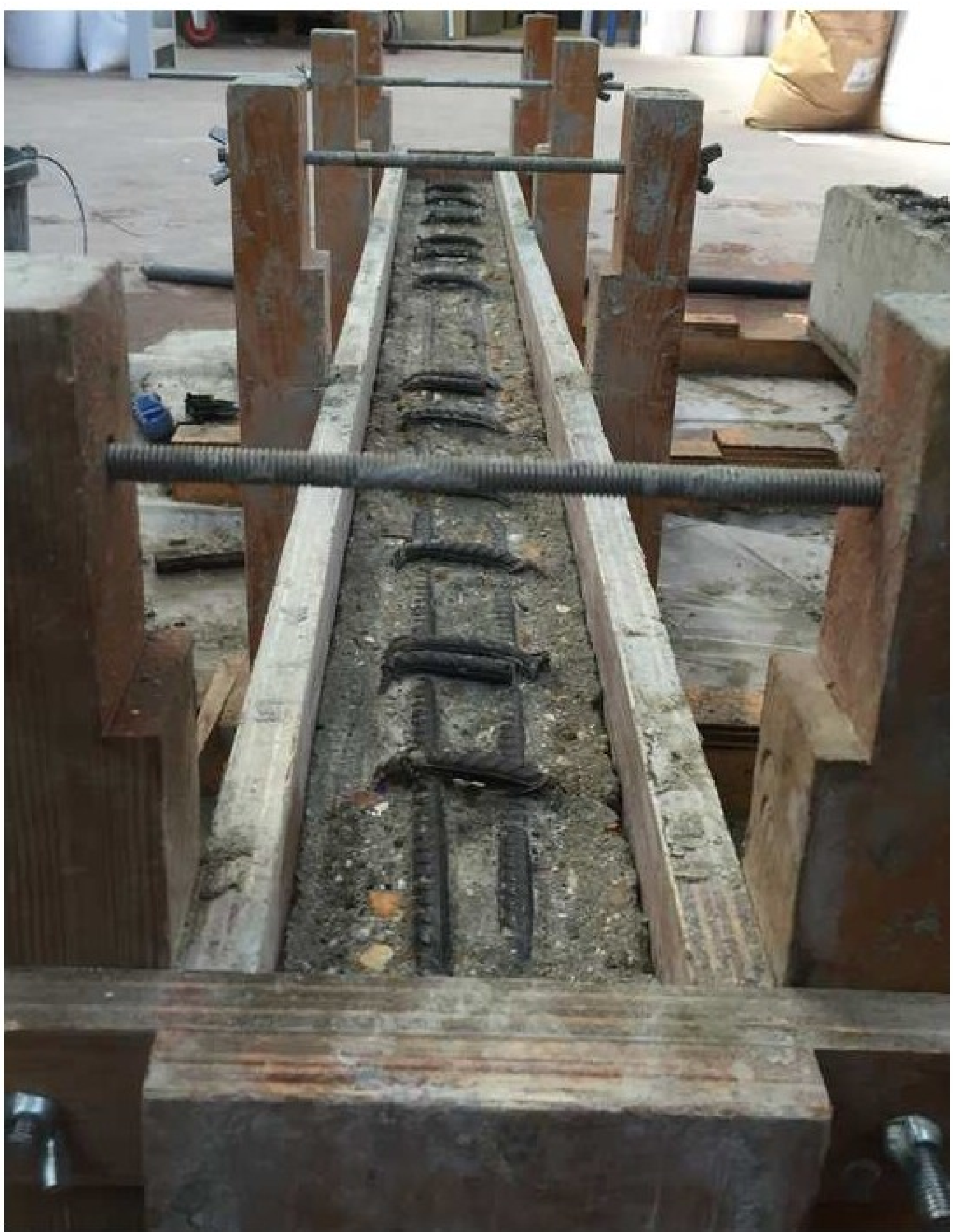




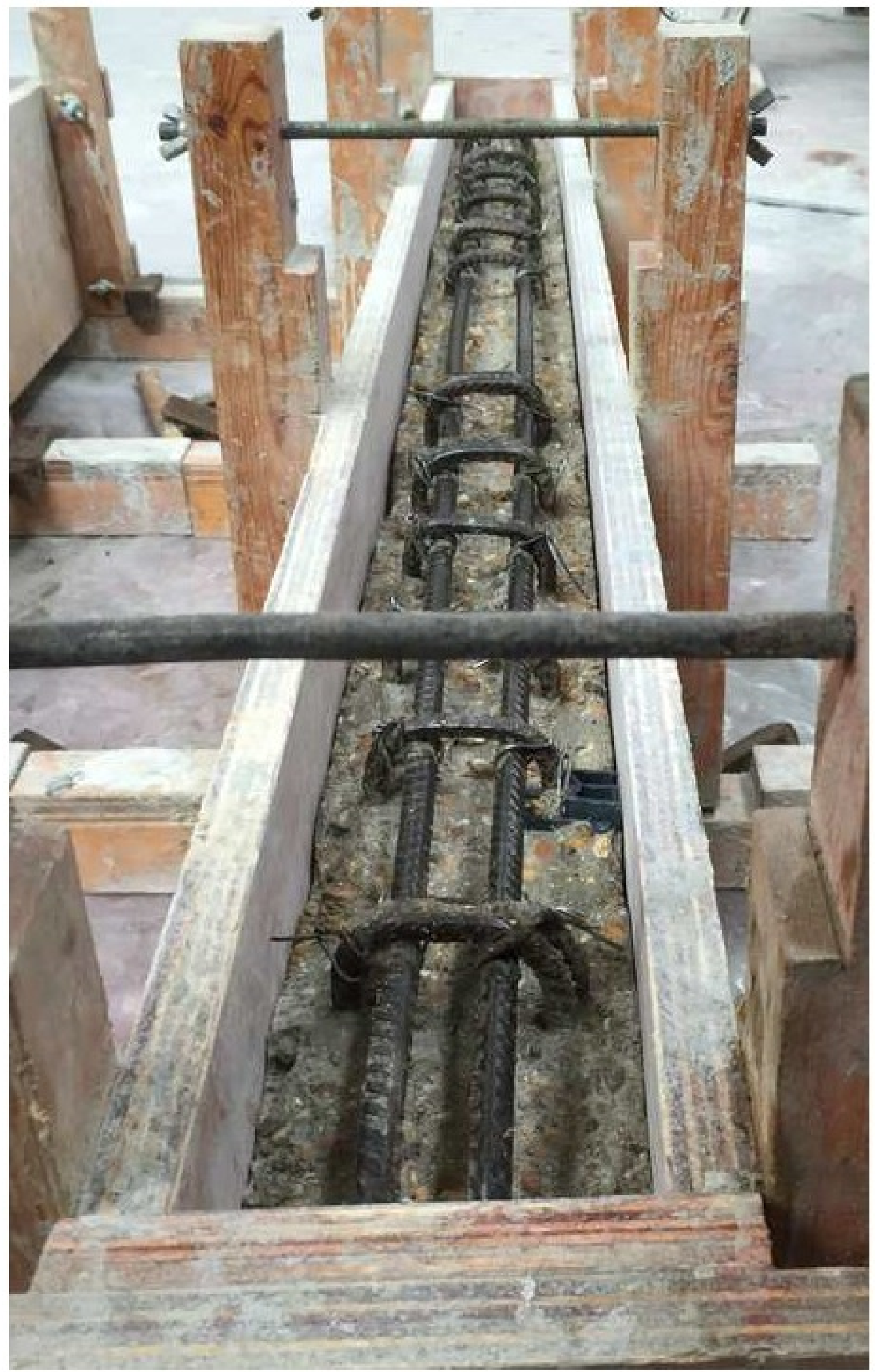


Fig. 7

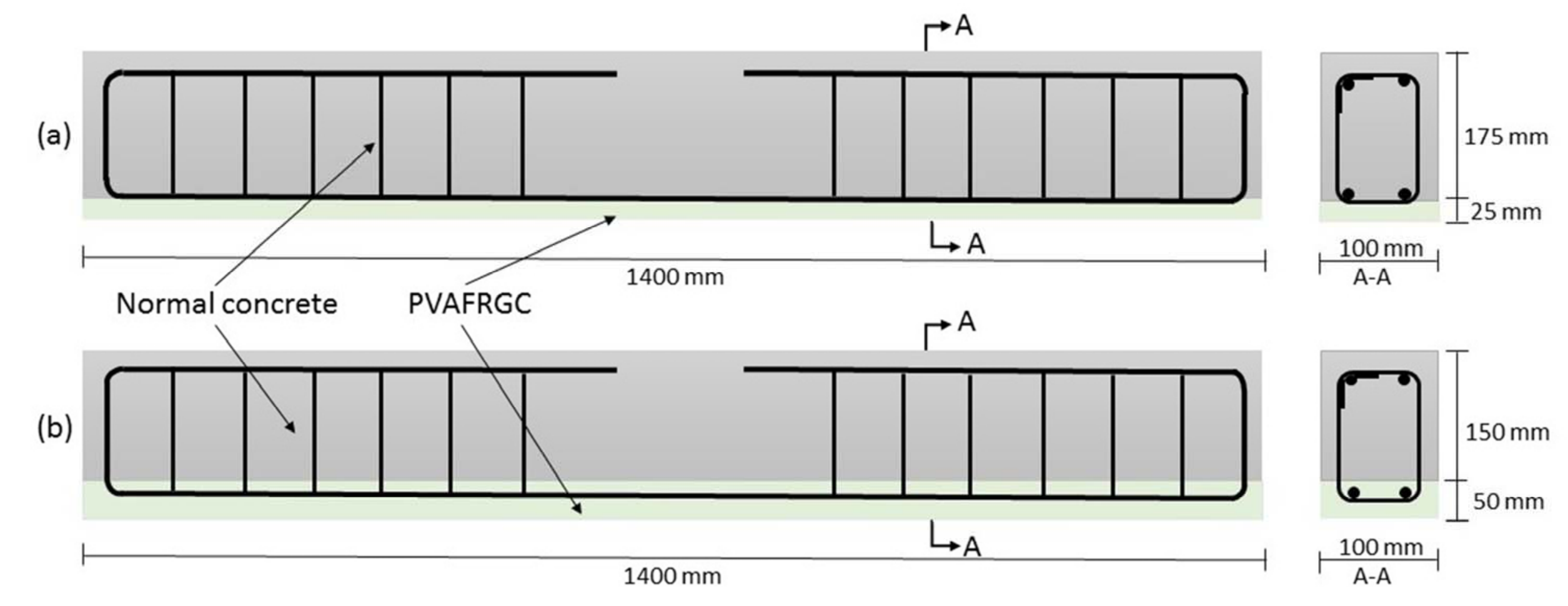


Fig. 8

(a)

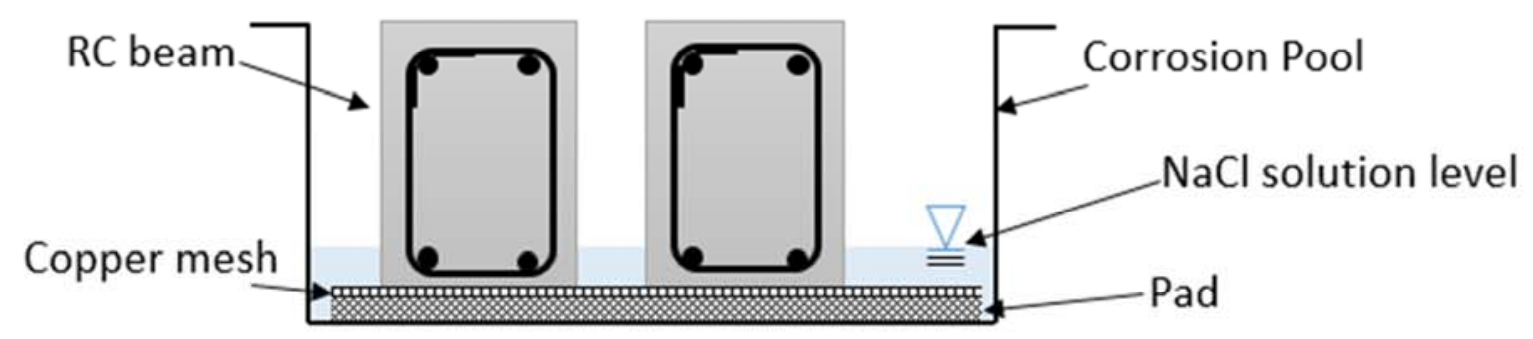

(b)

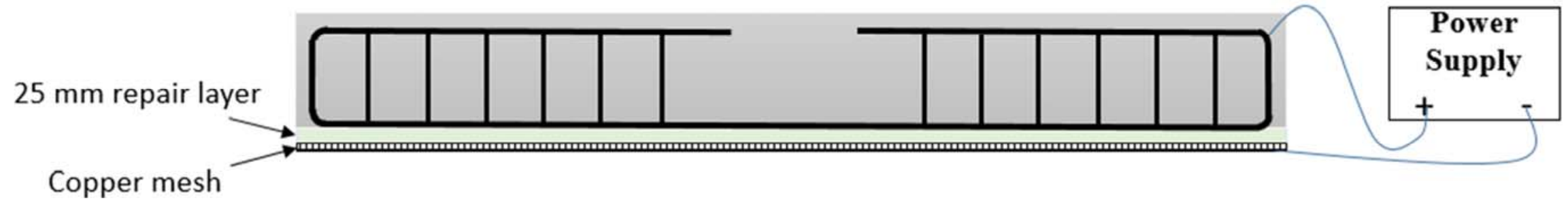

(c)

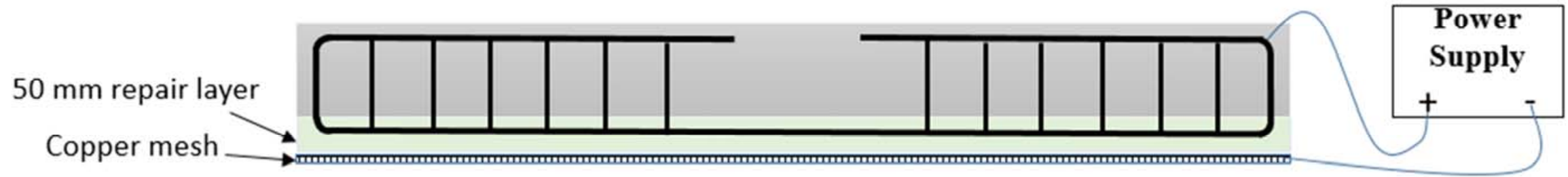




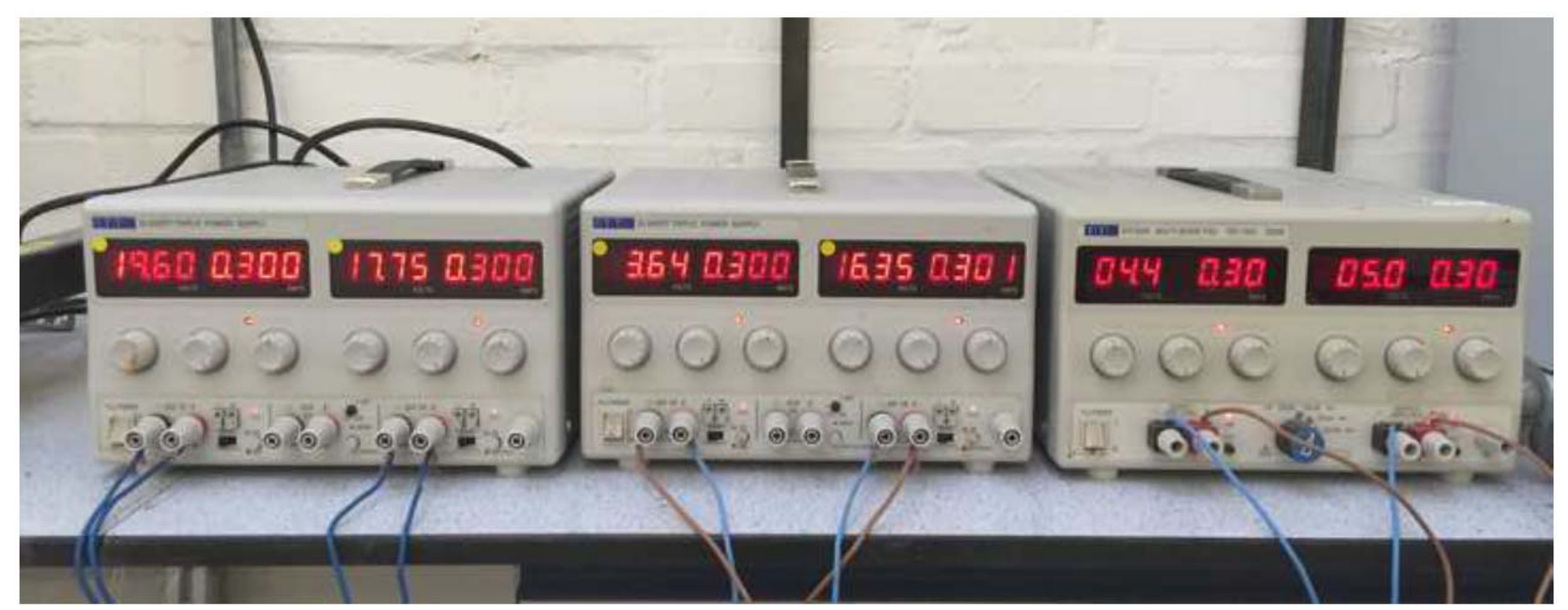




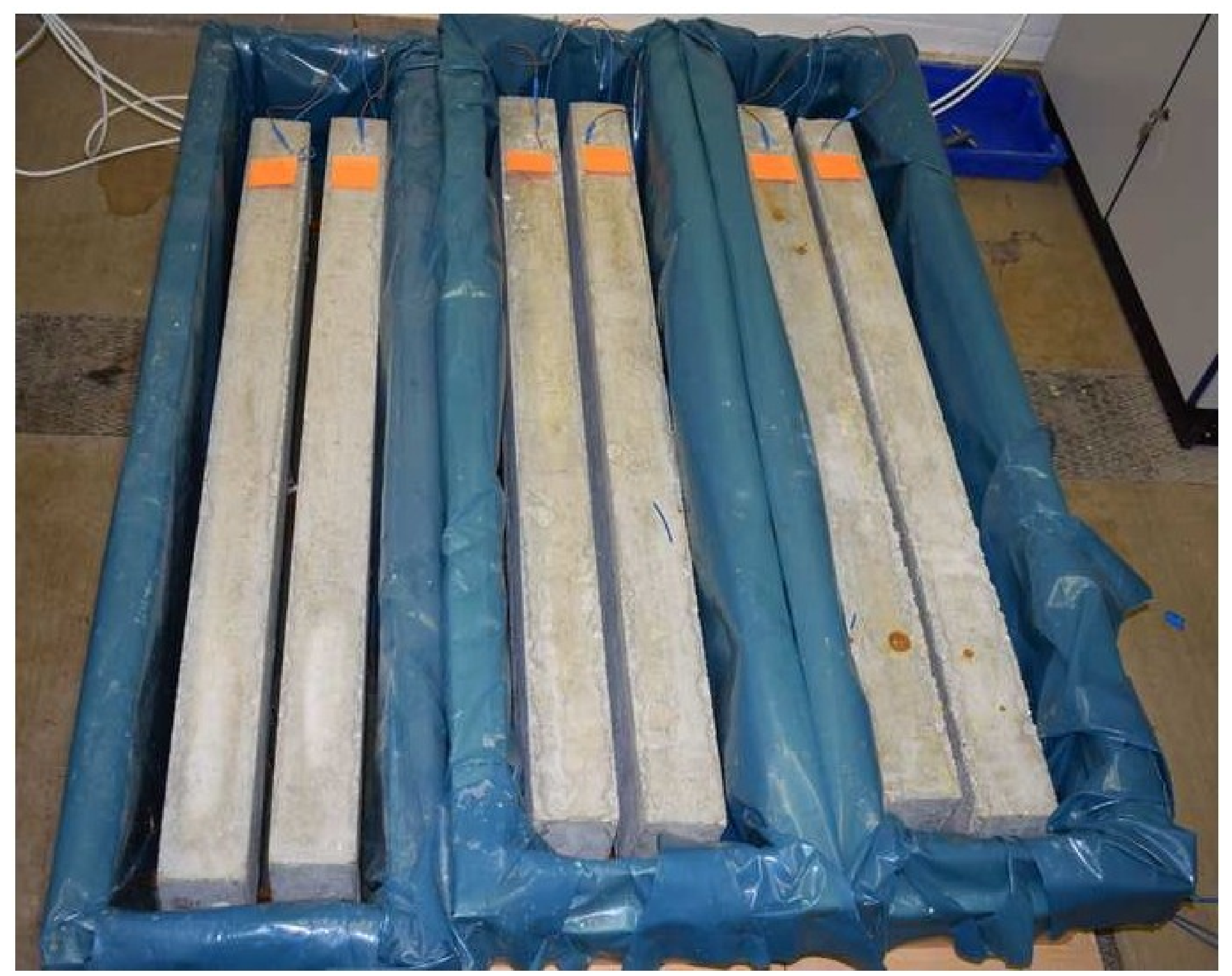



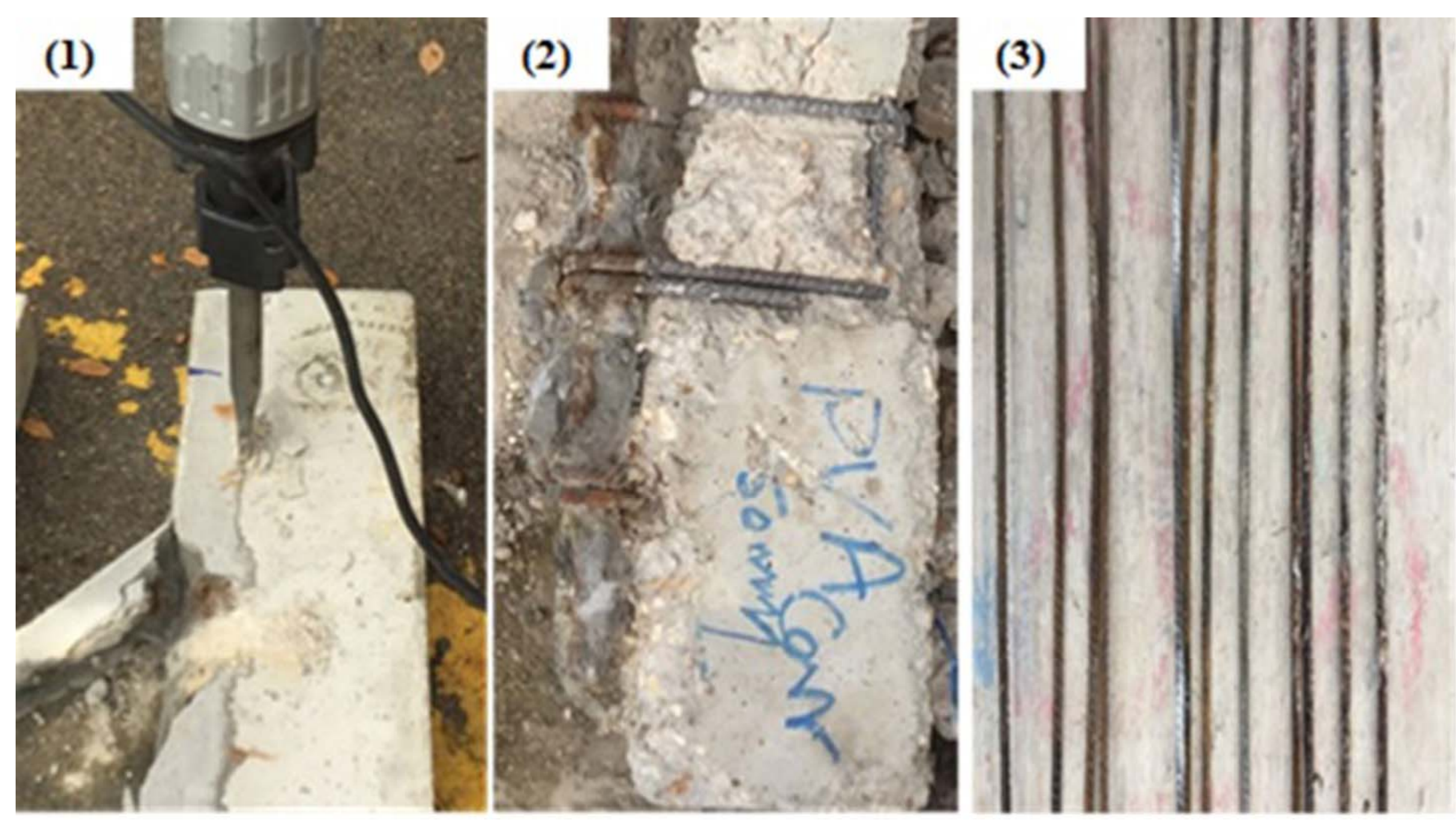


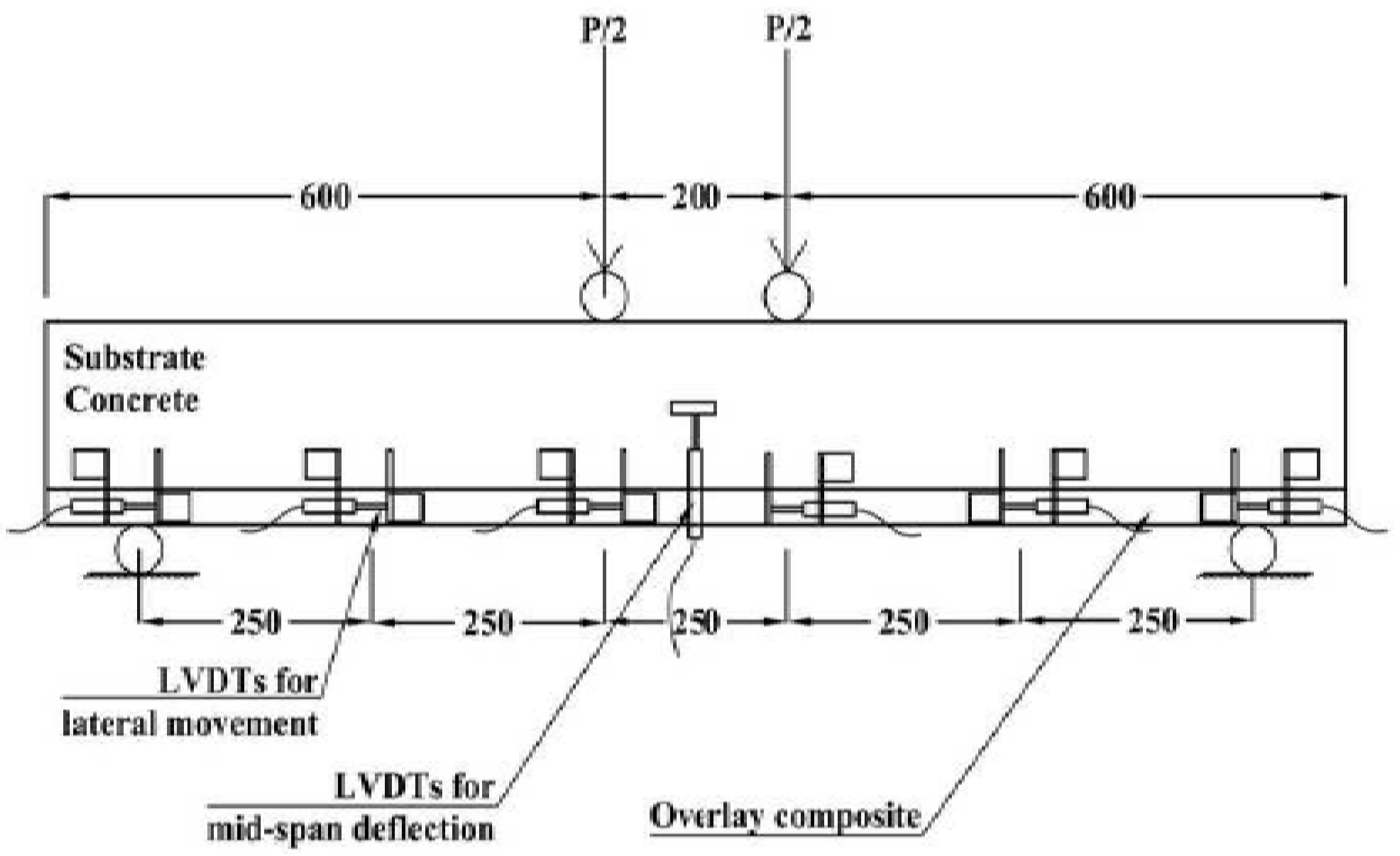




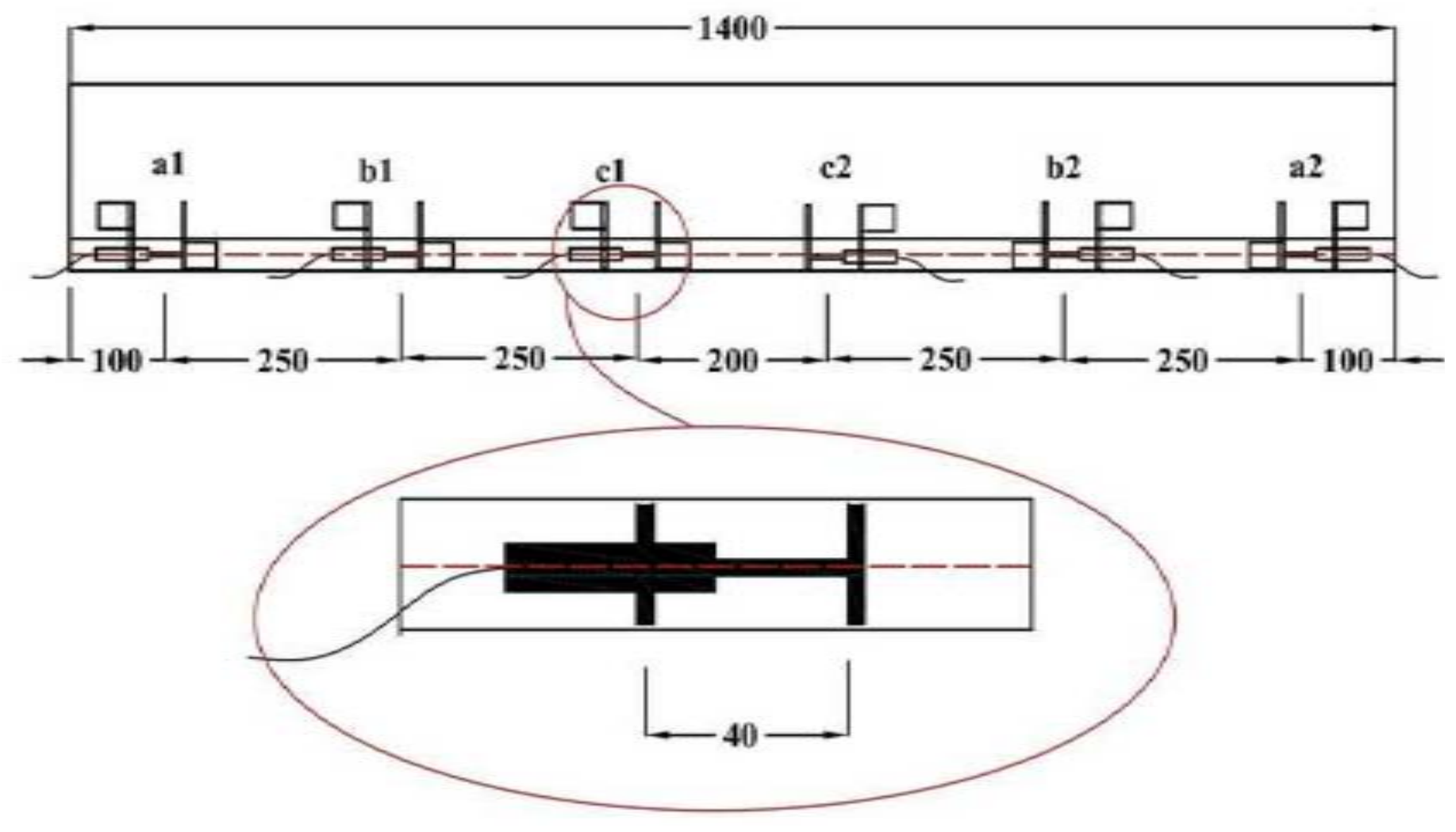




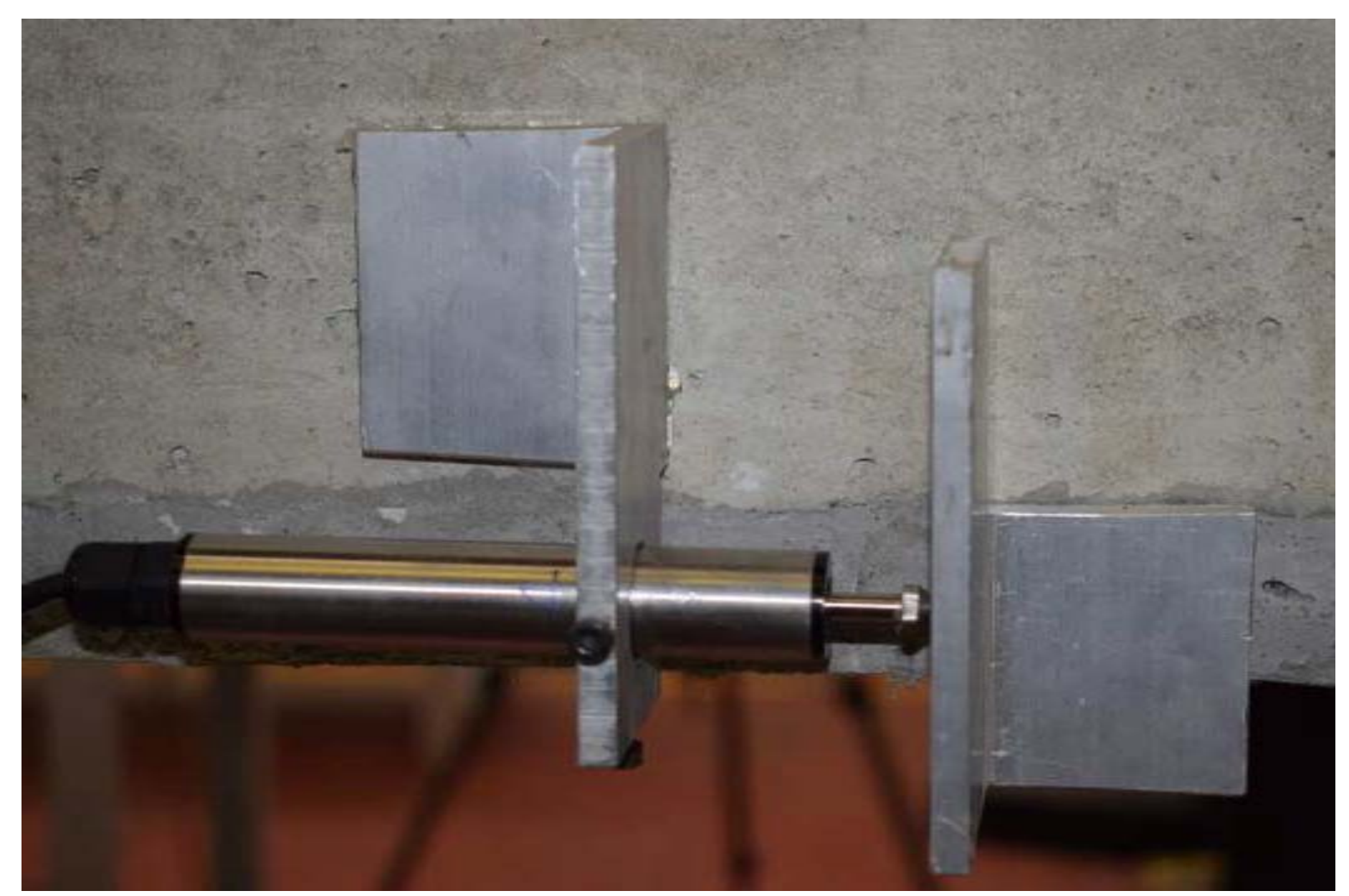




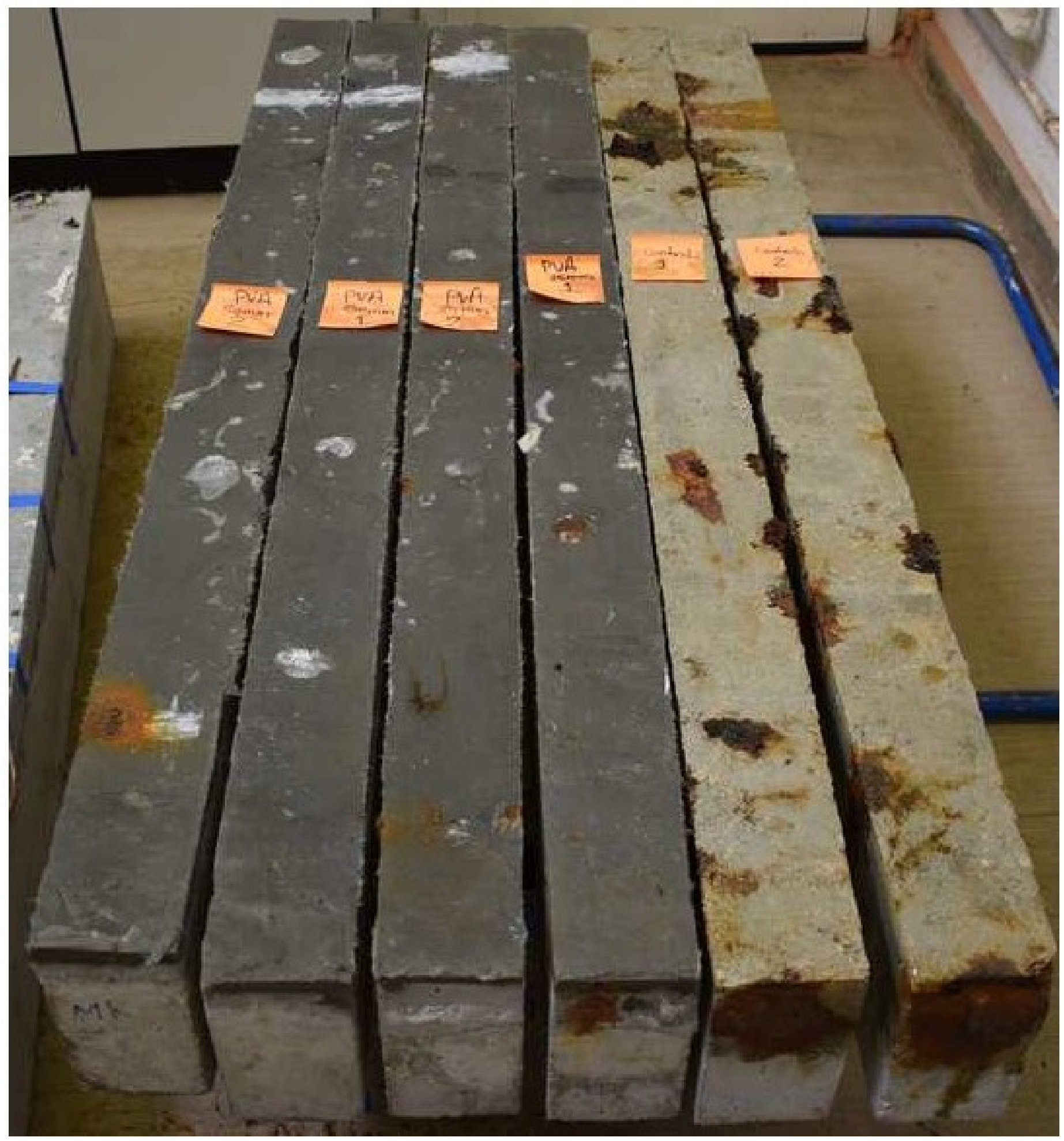




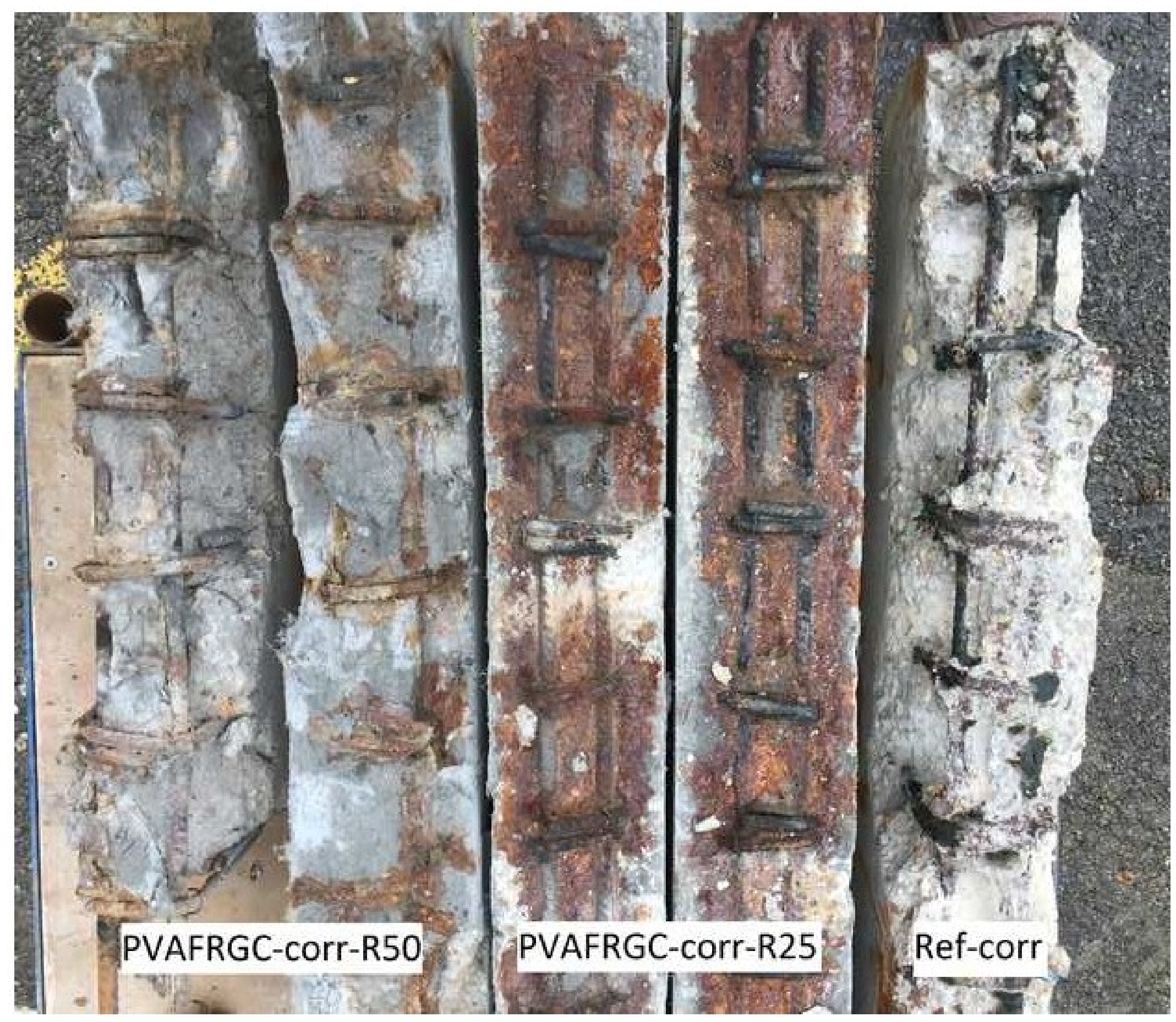




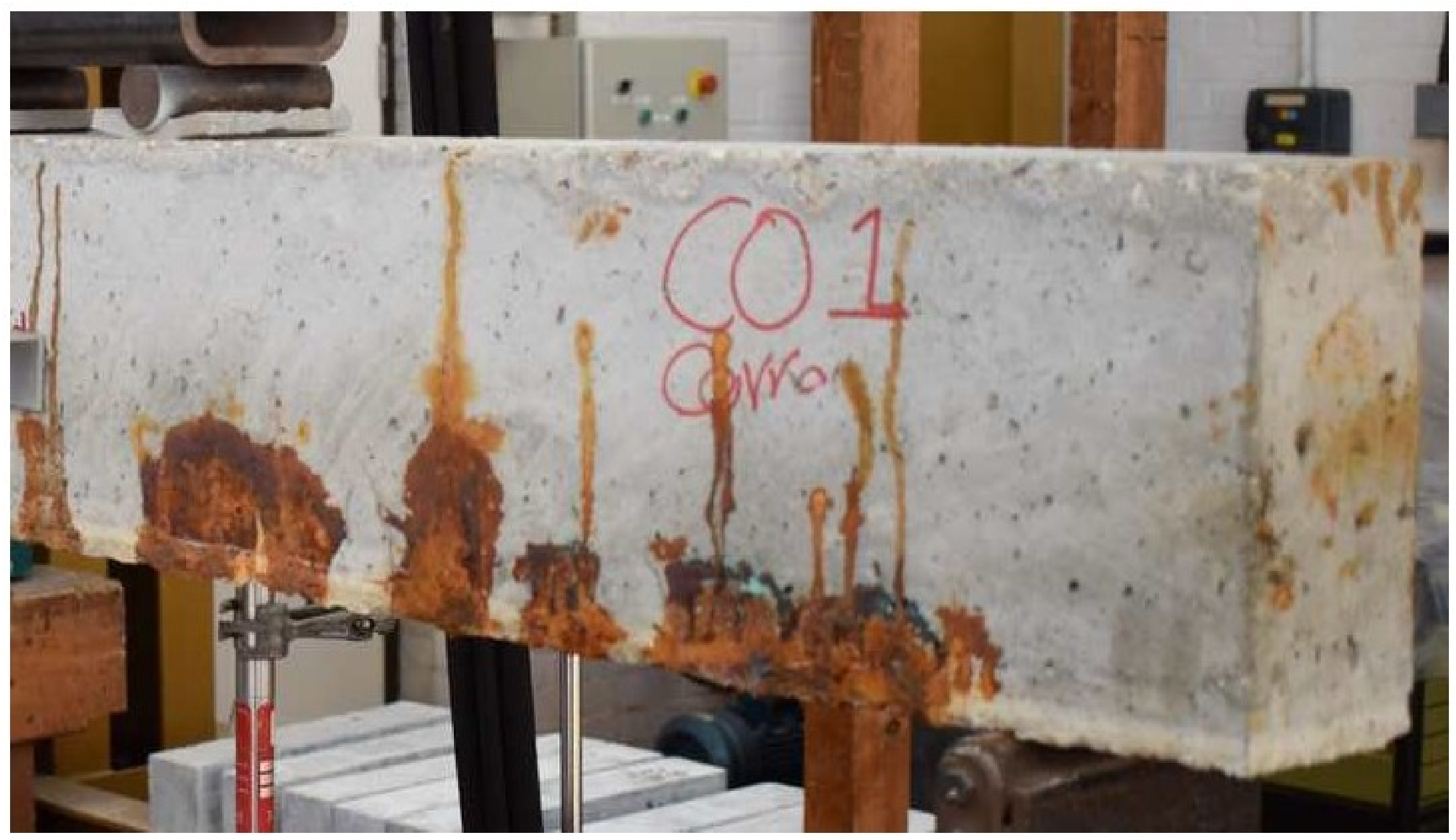




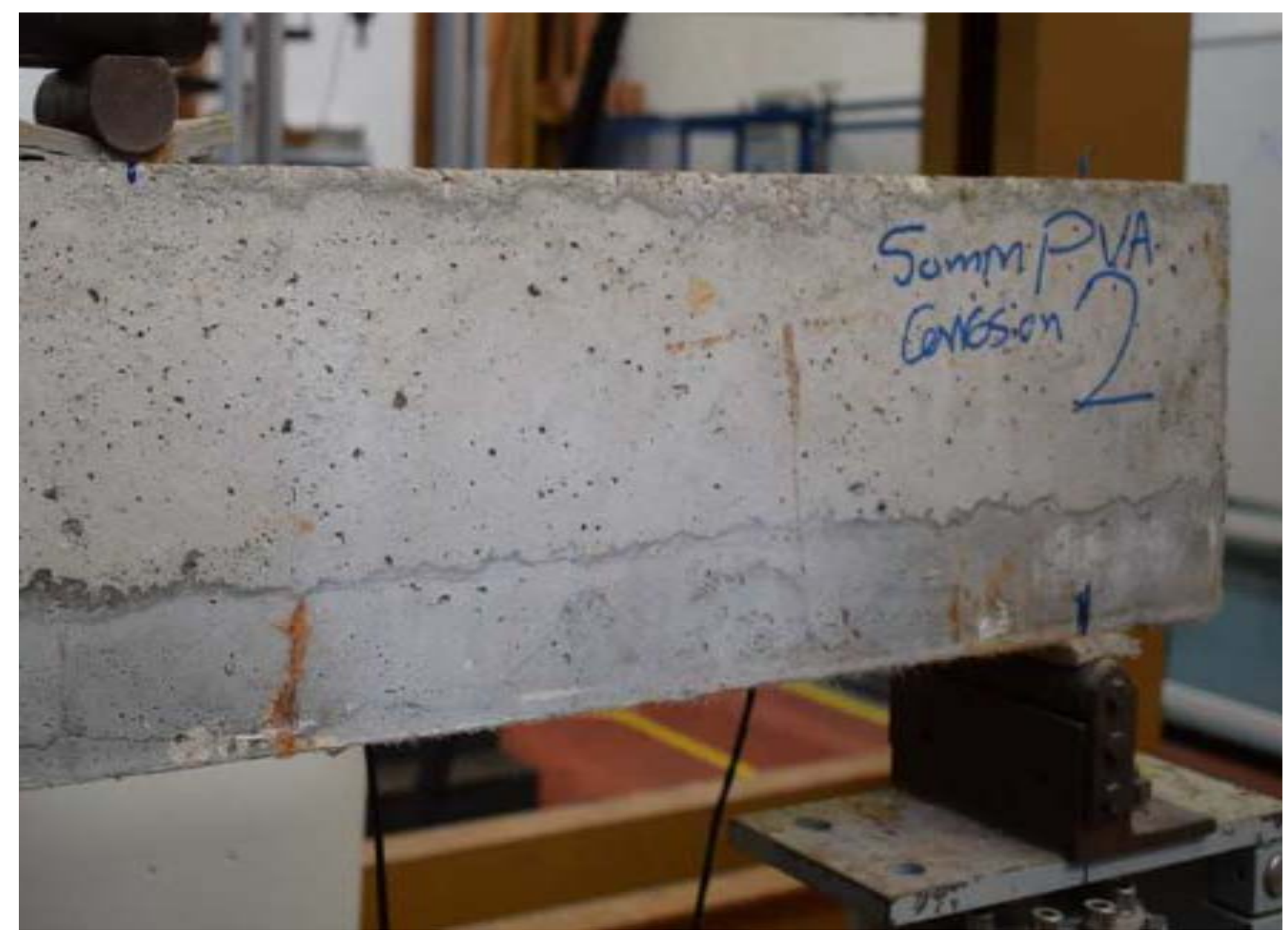




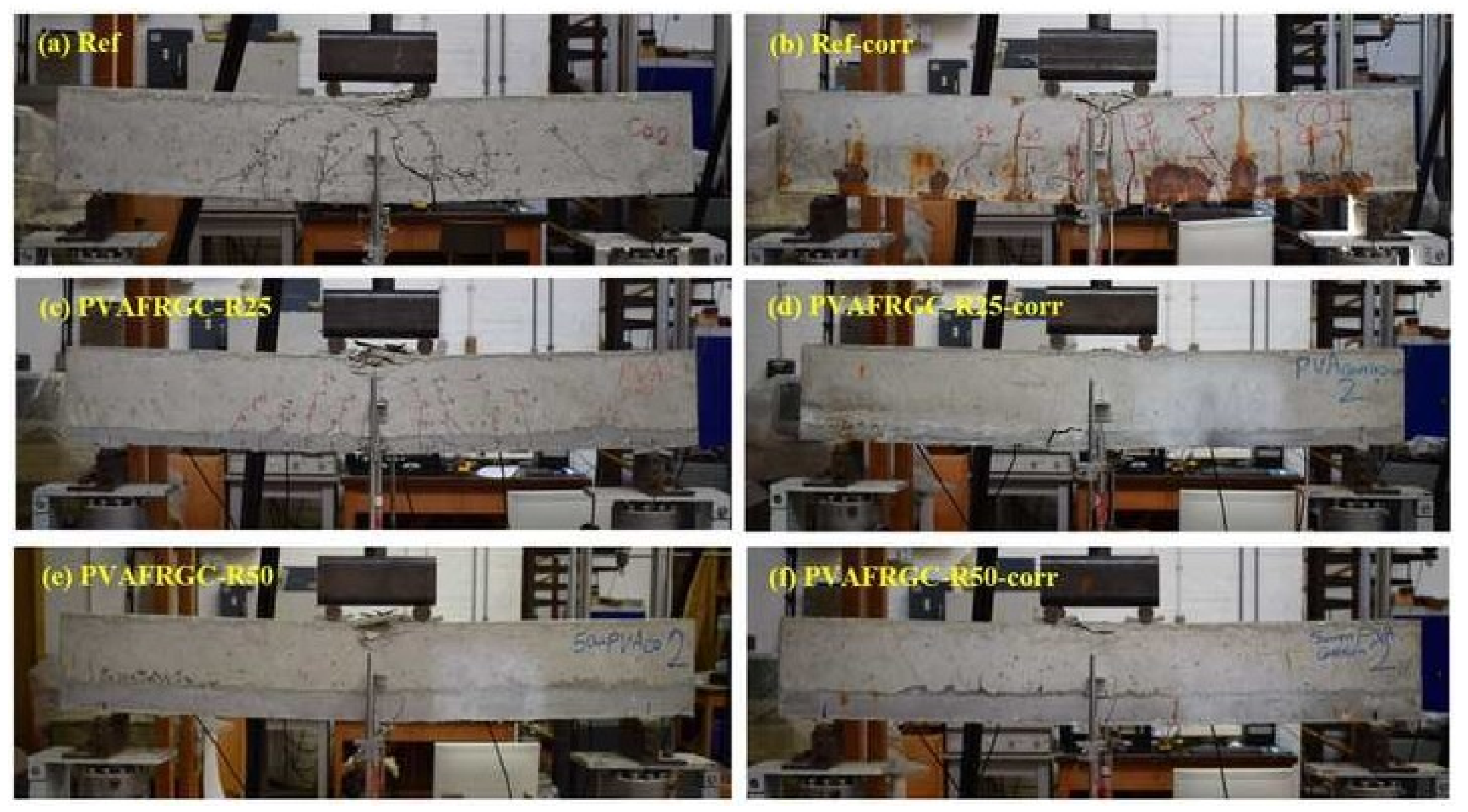


Fig.18a

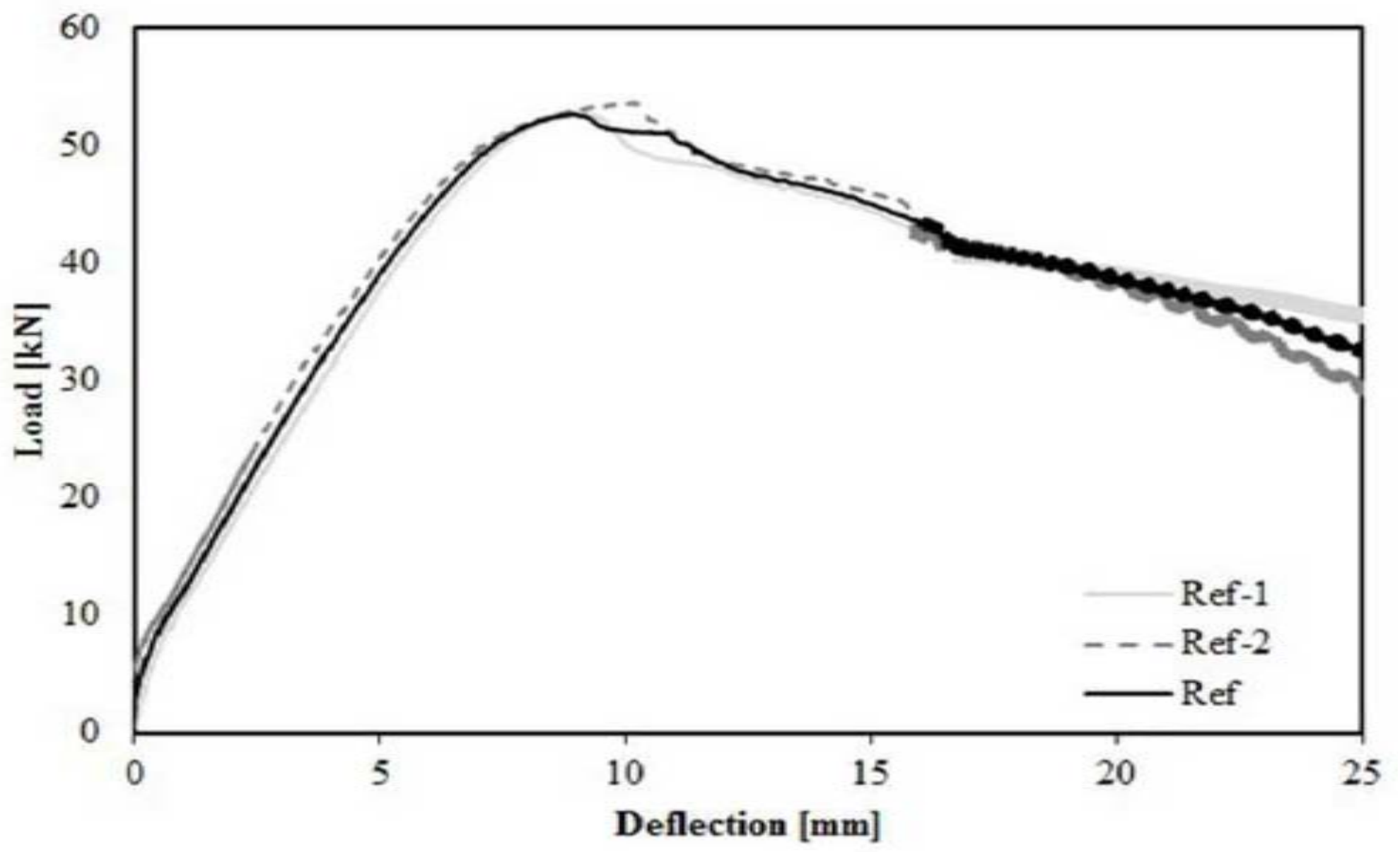


Fig.18b

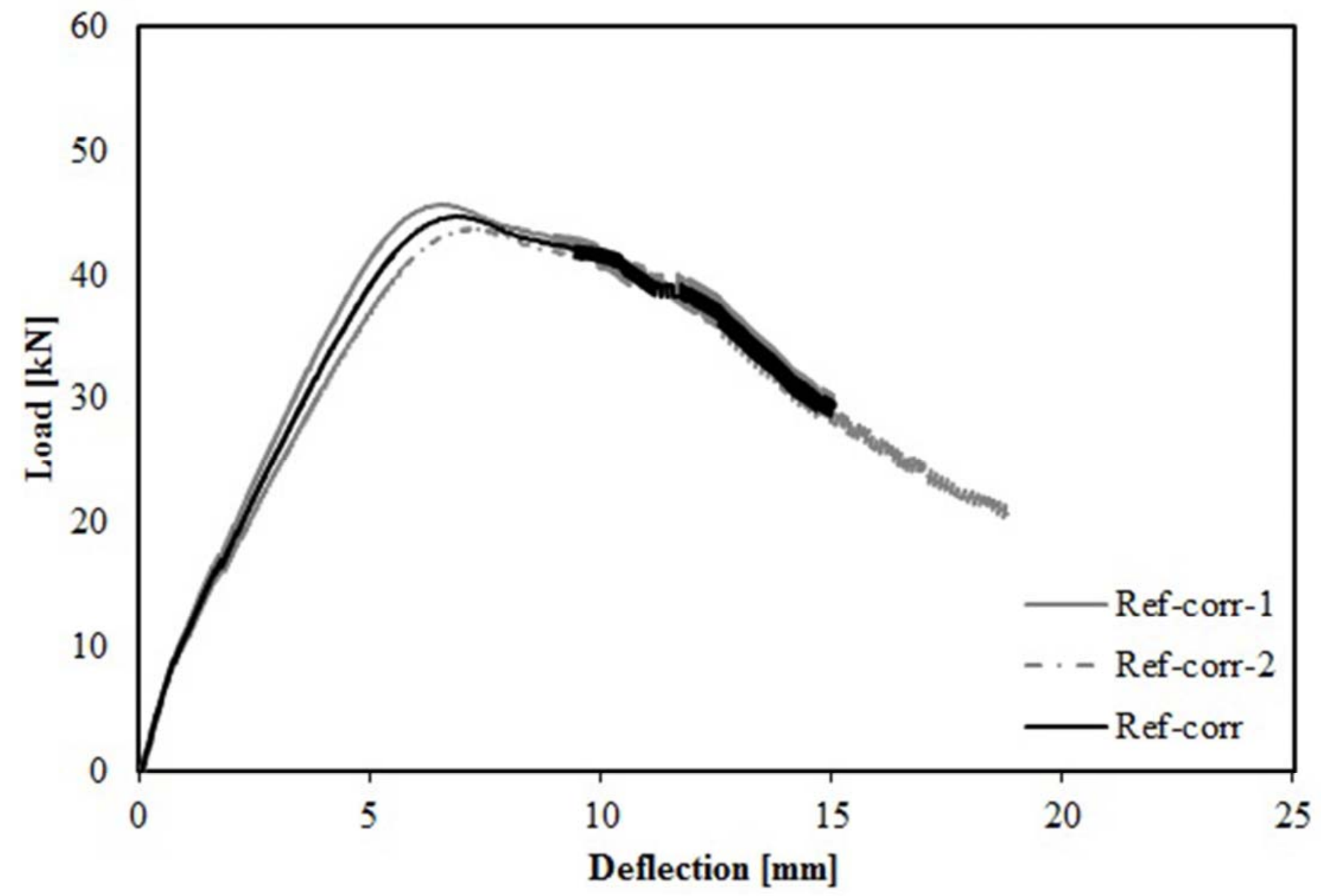




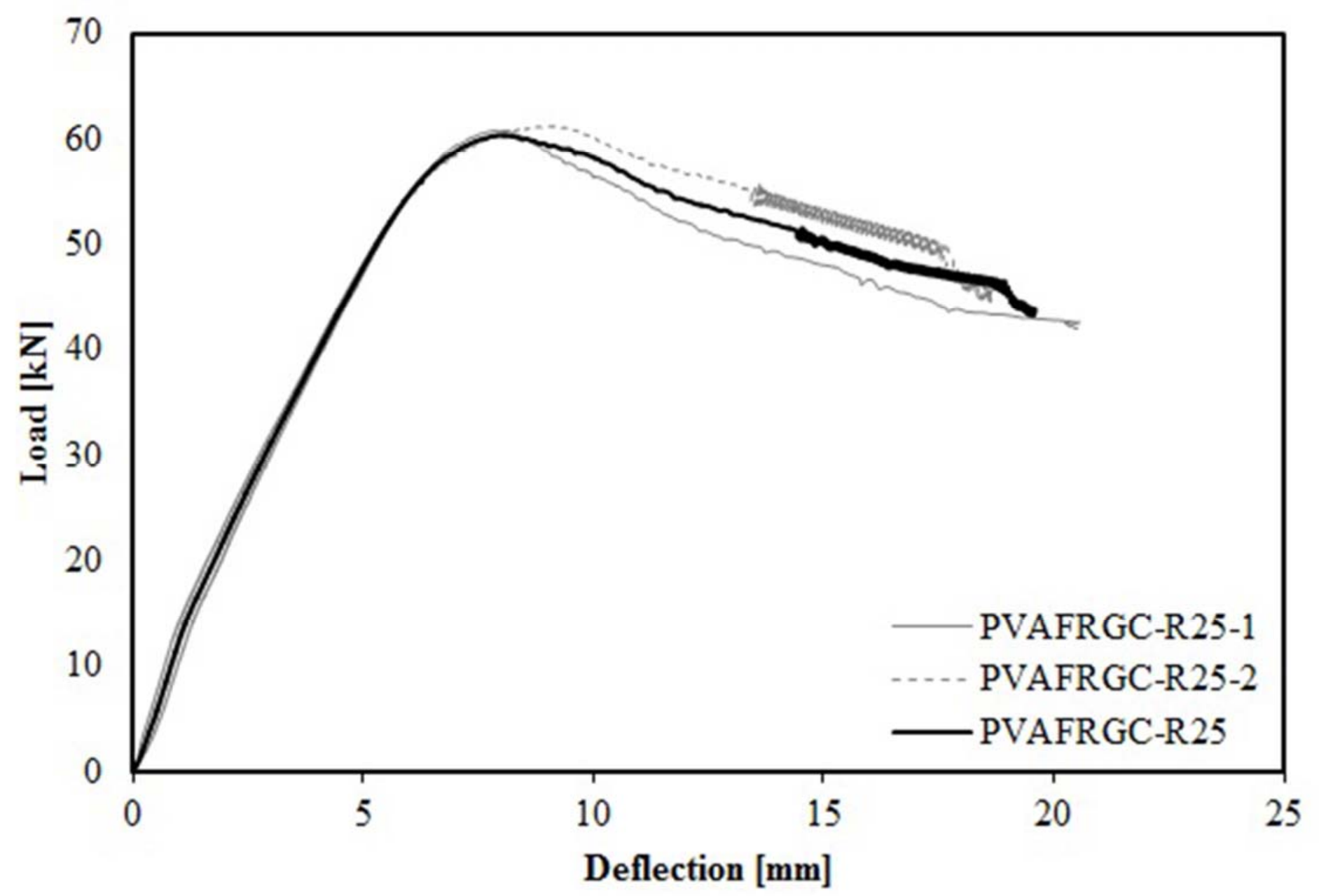




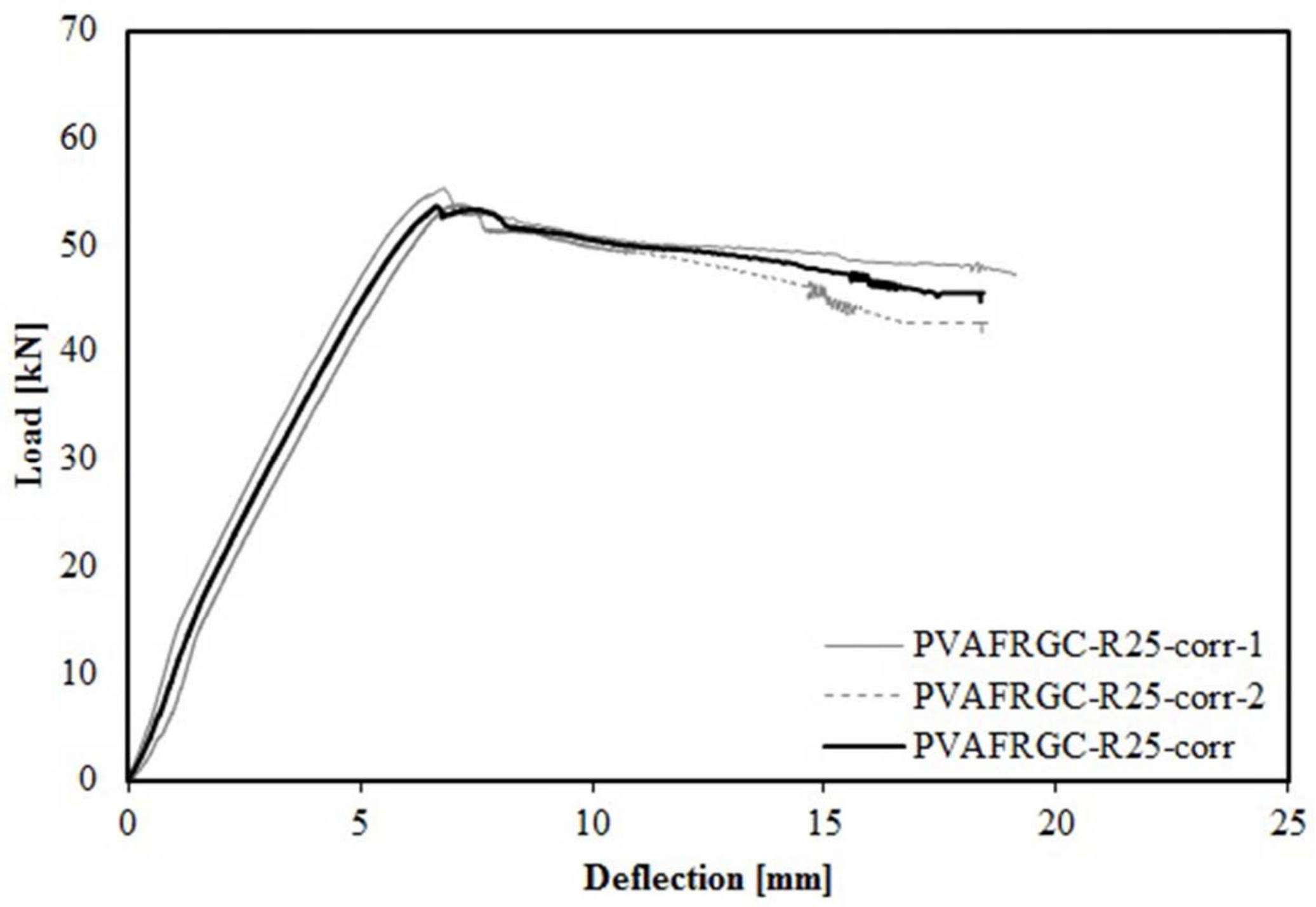




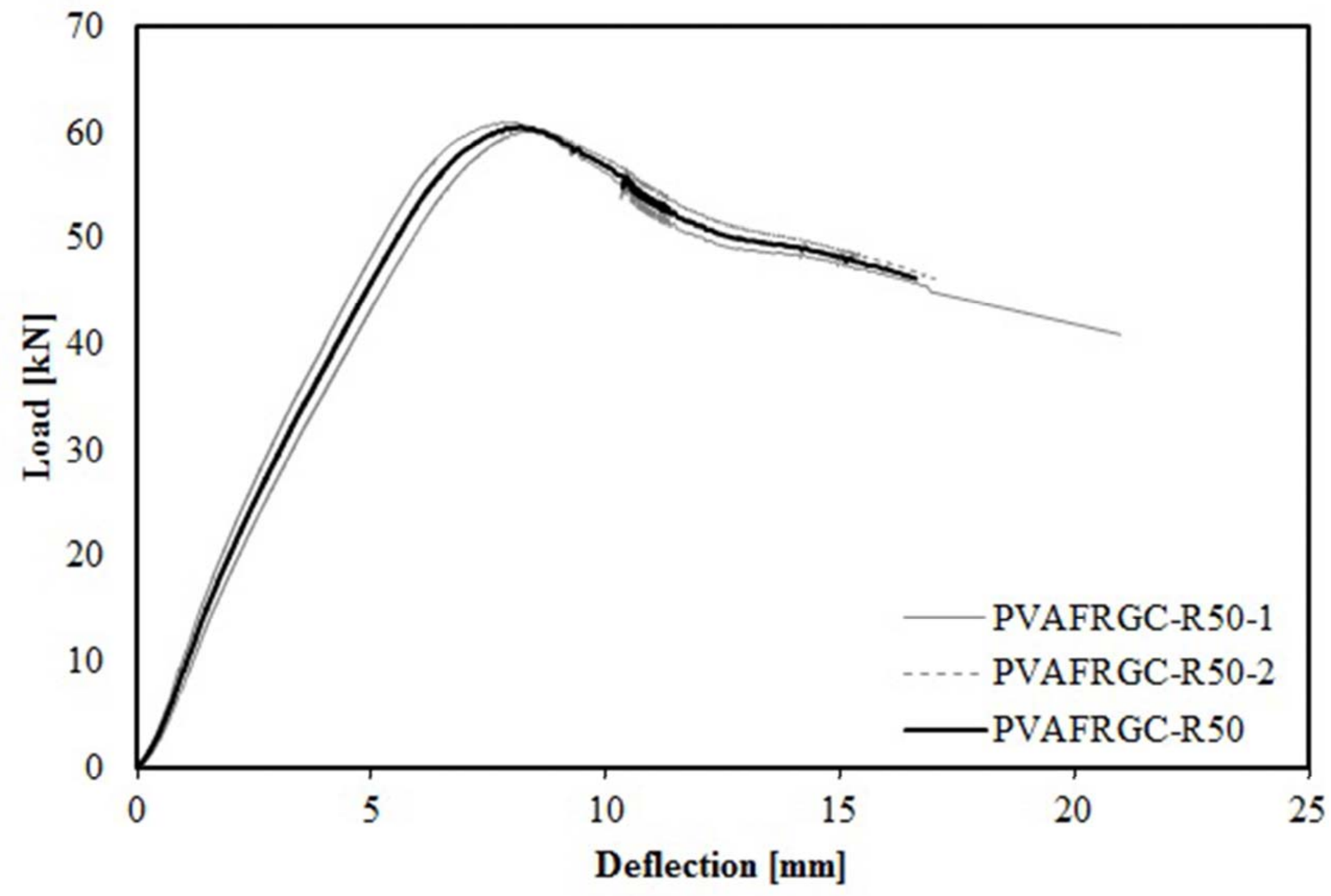




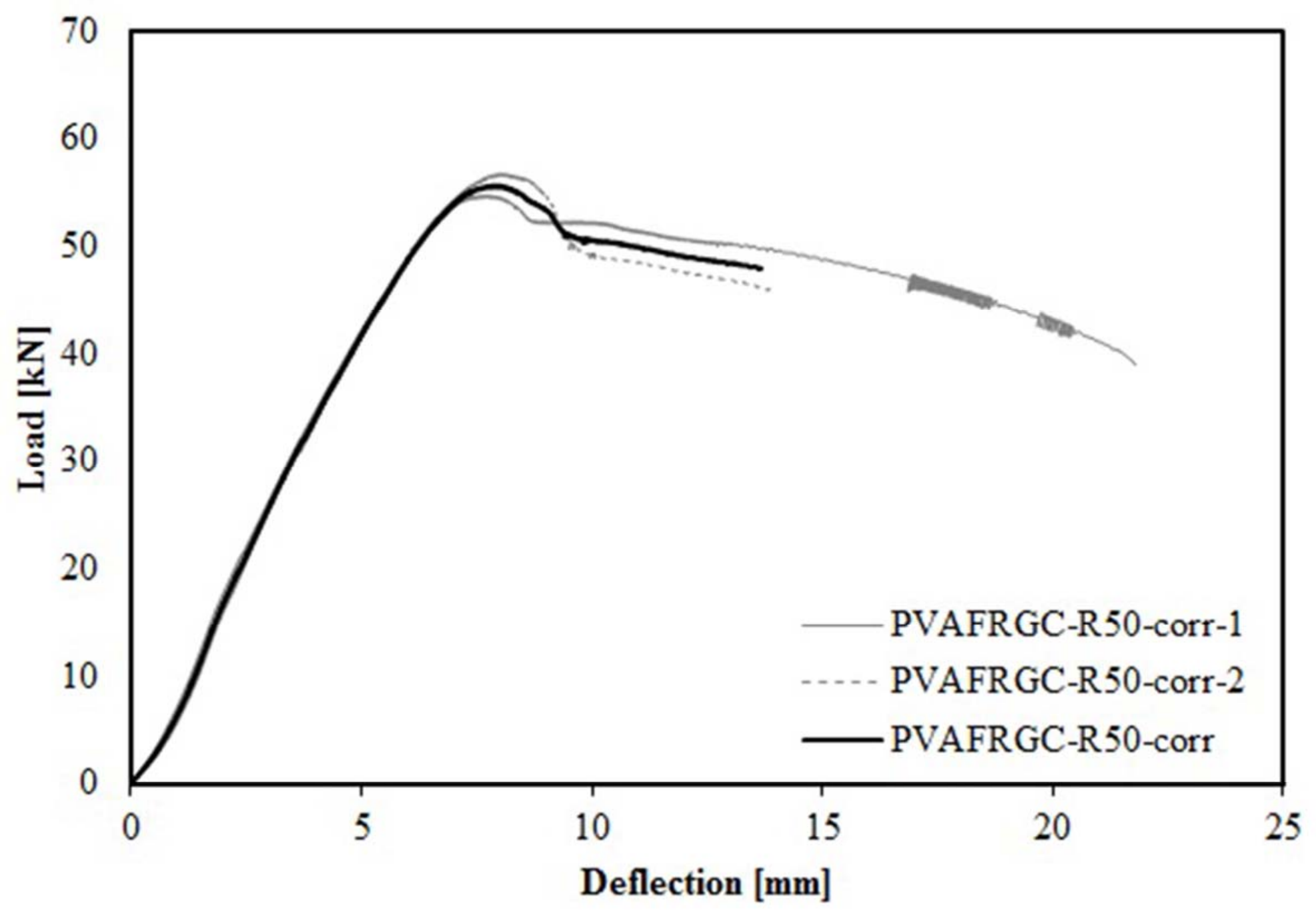




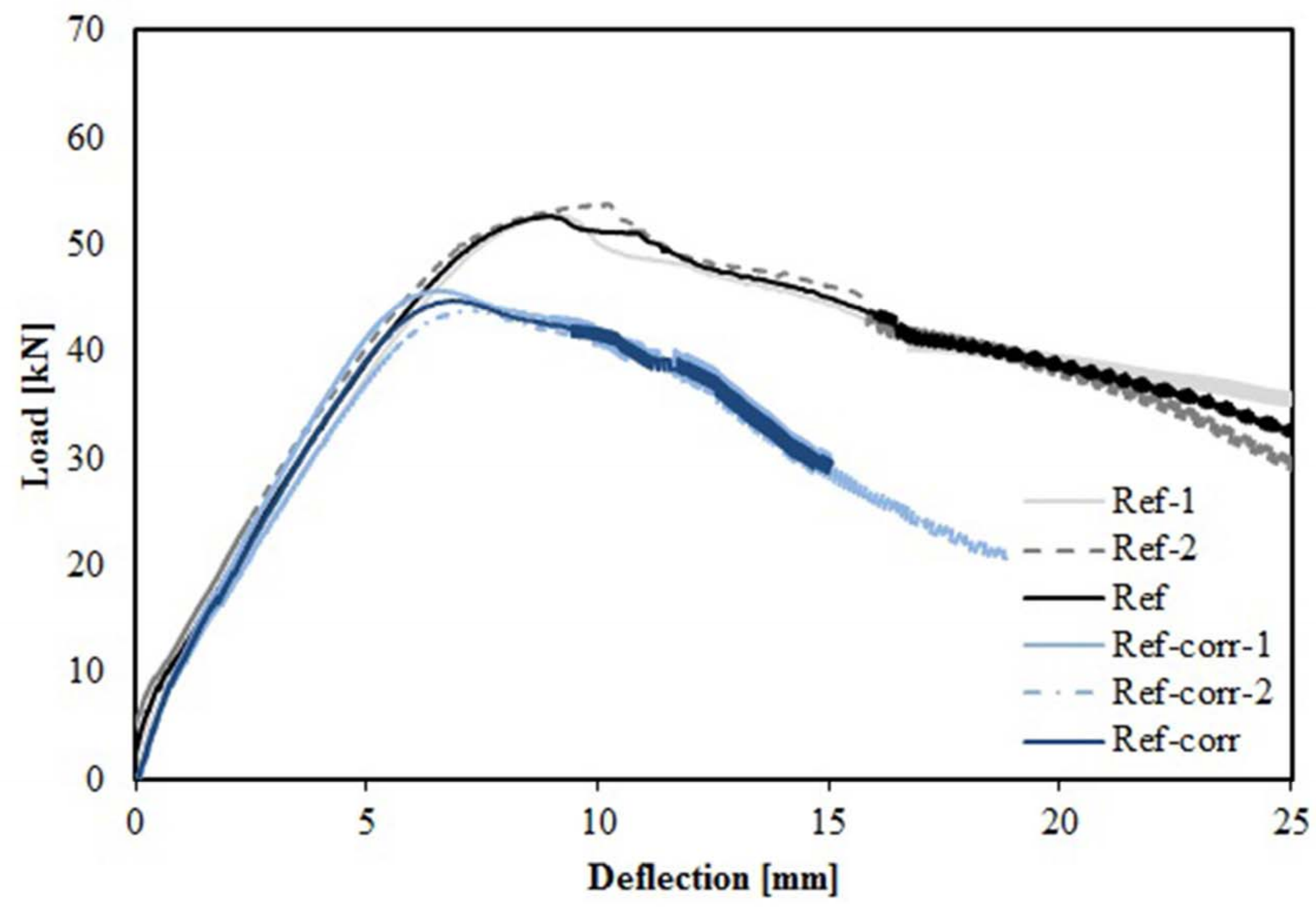




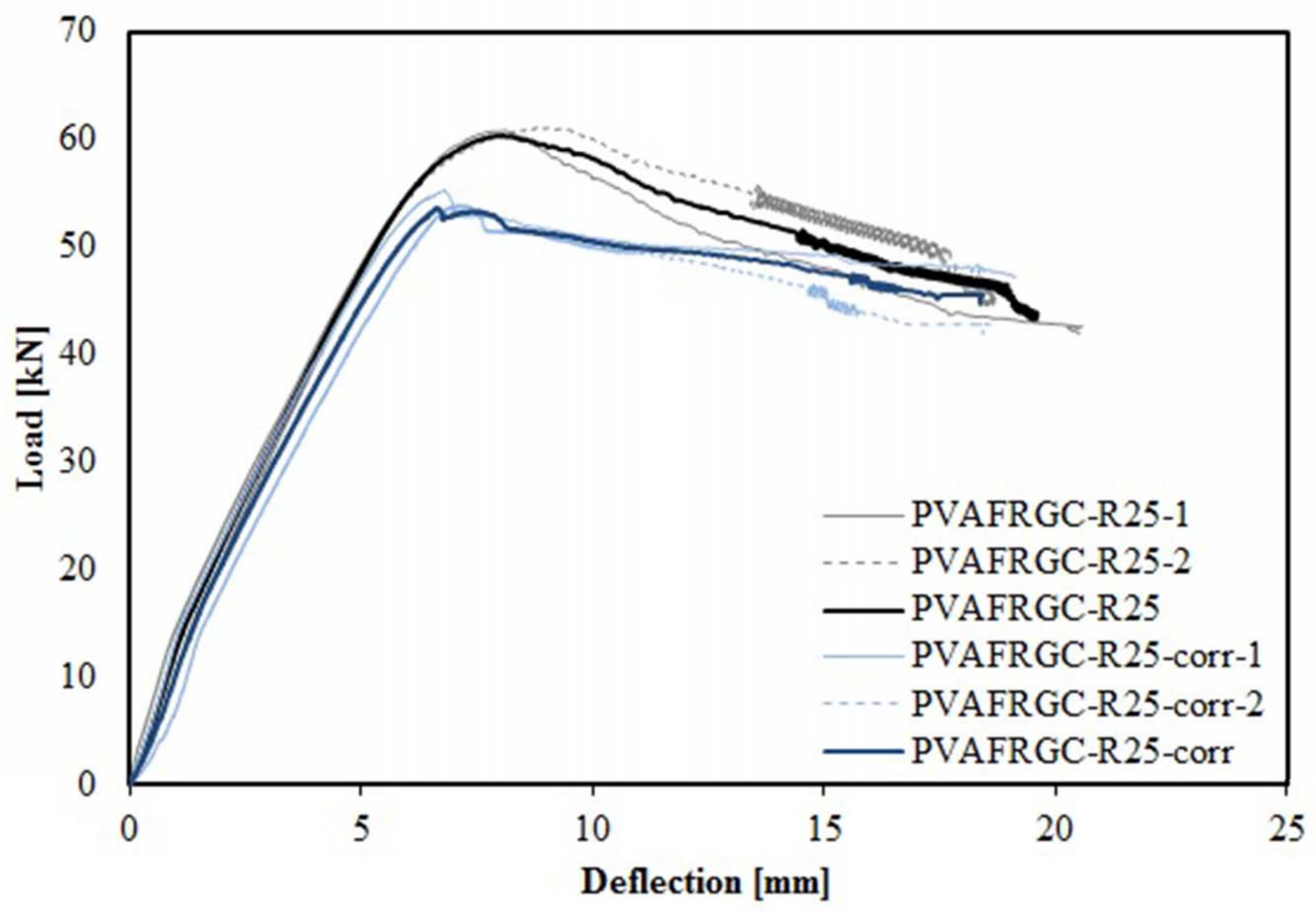




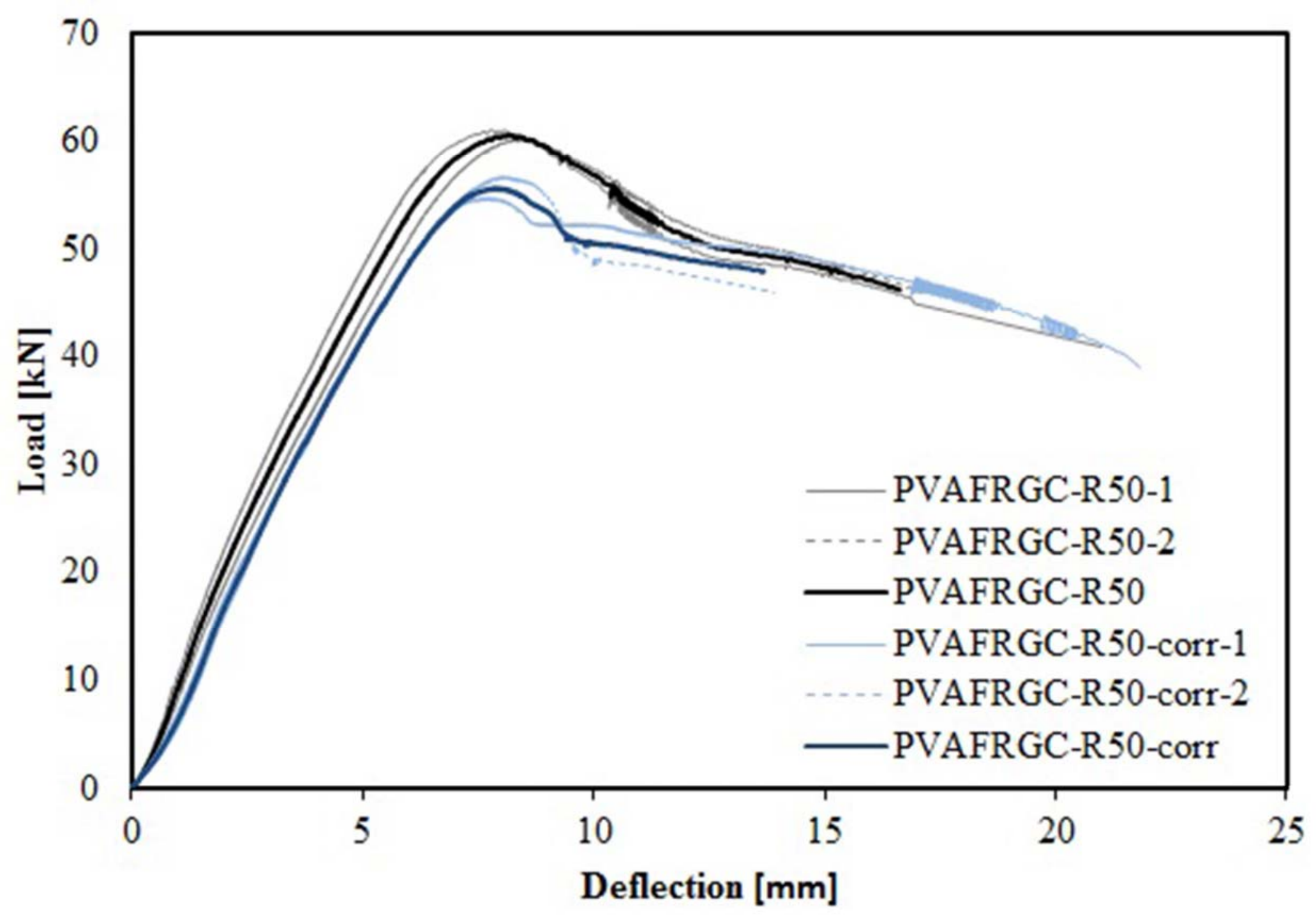


Fig.22

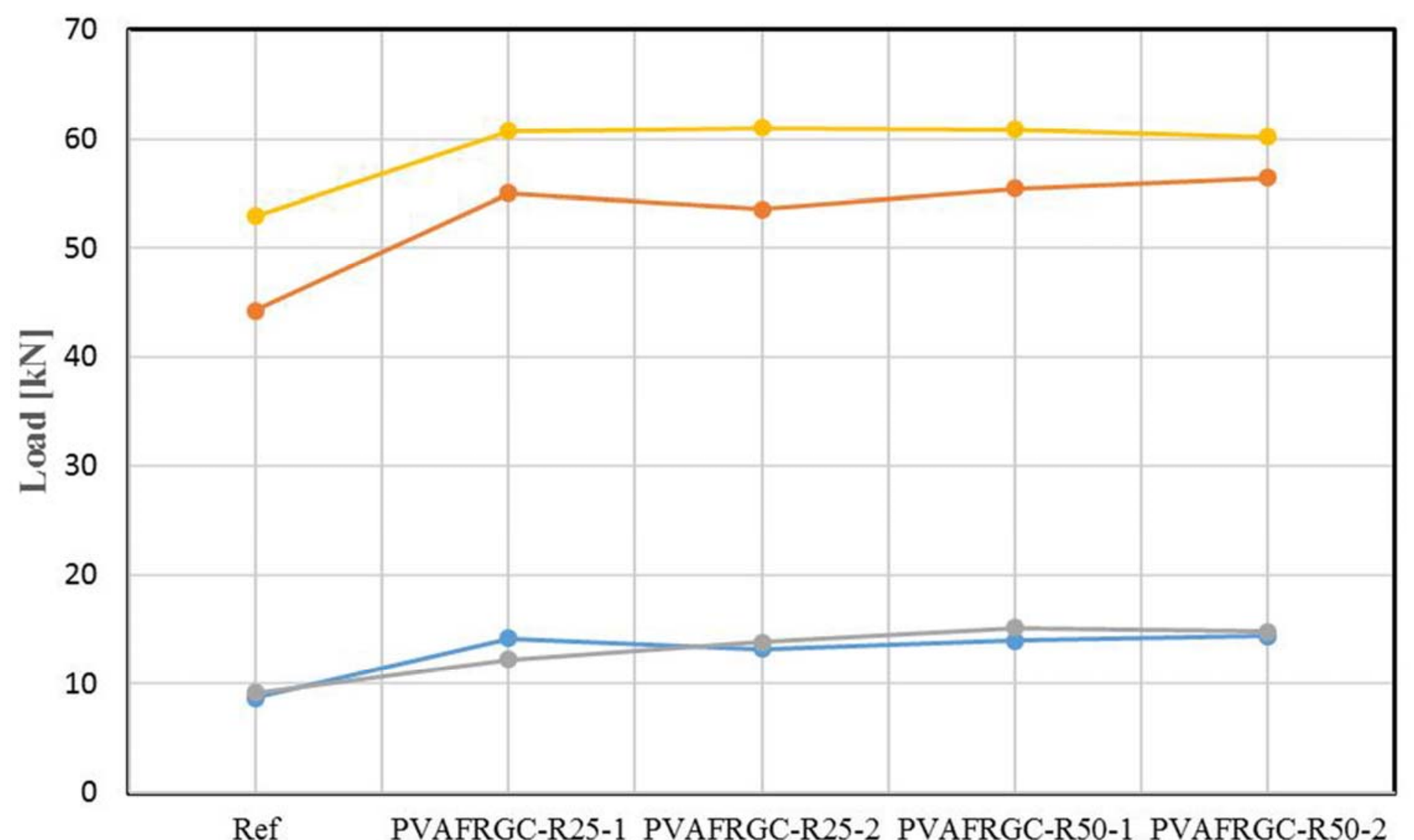

$\multimap$ First crack load corroded $\quad \longrightarrow$ Peak load corroded $\quad \longrightarrow$ First crack load $\longrightarrow$ Peak load 


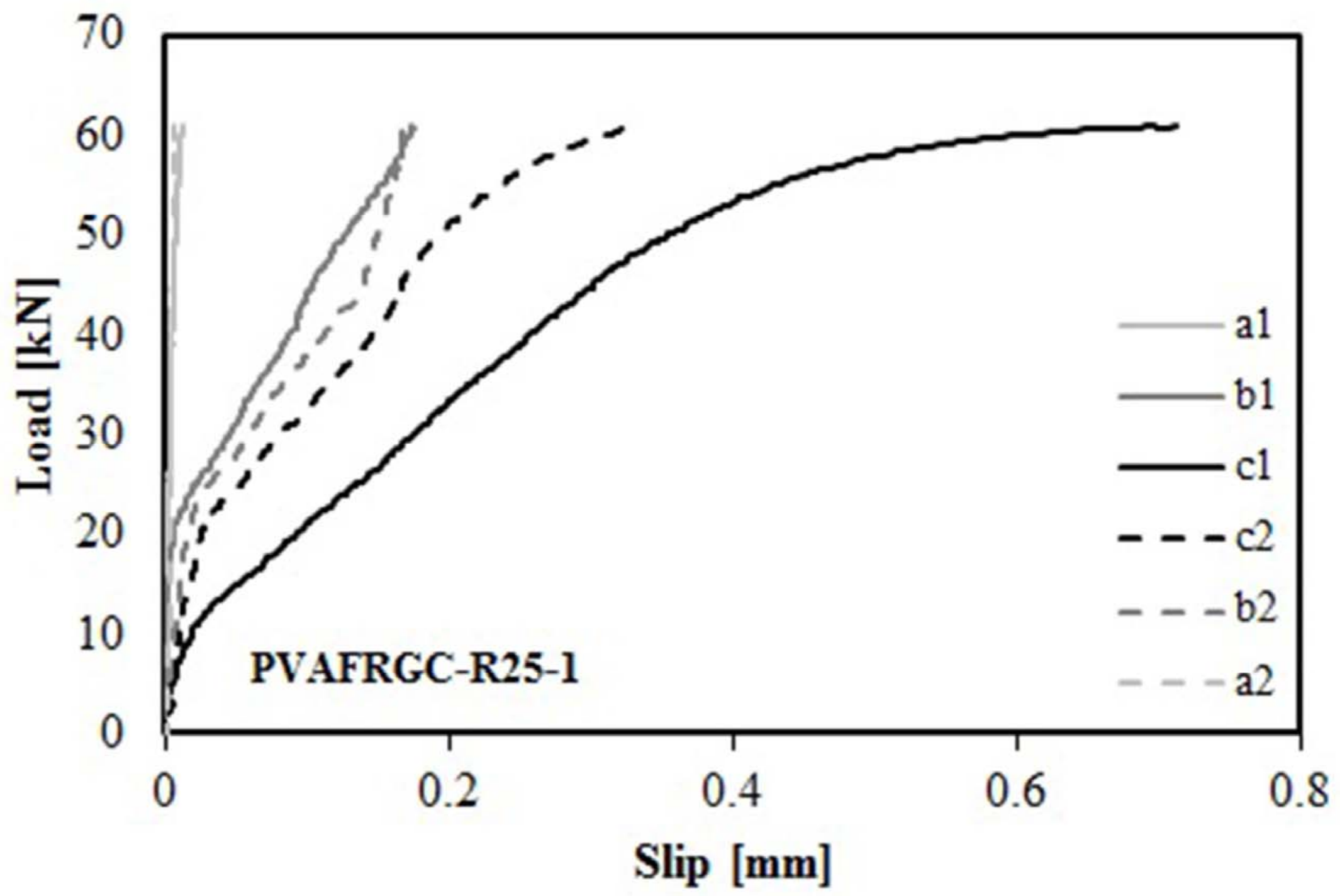


Fig.23b

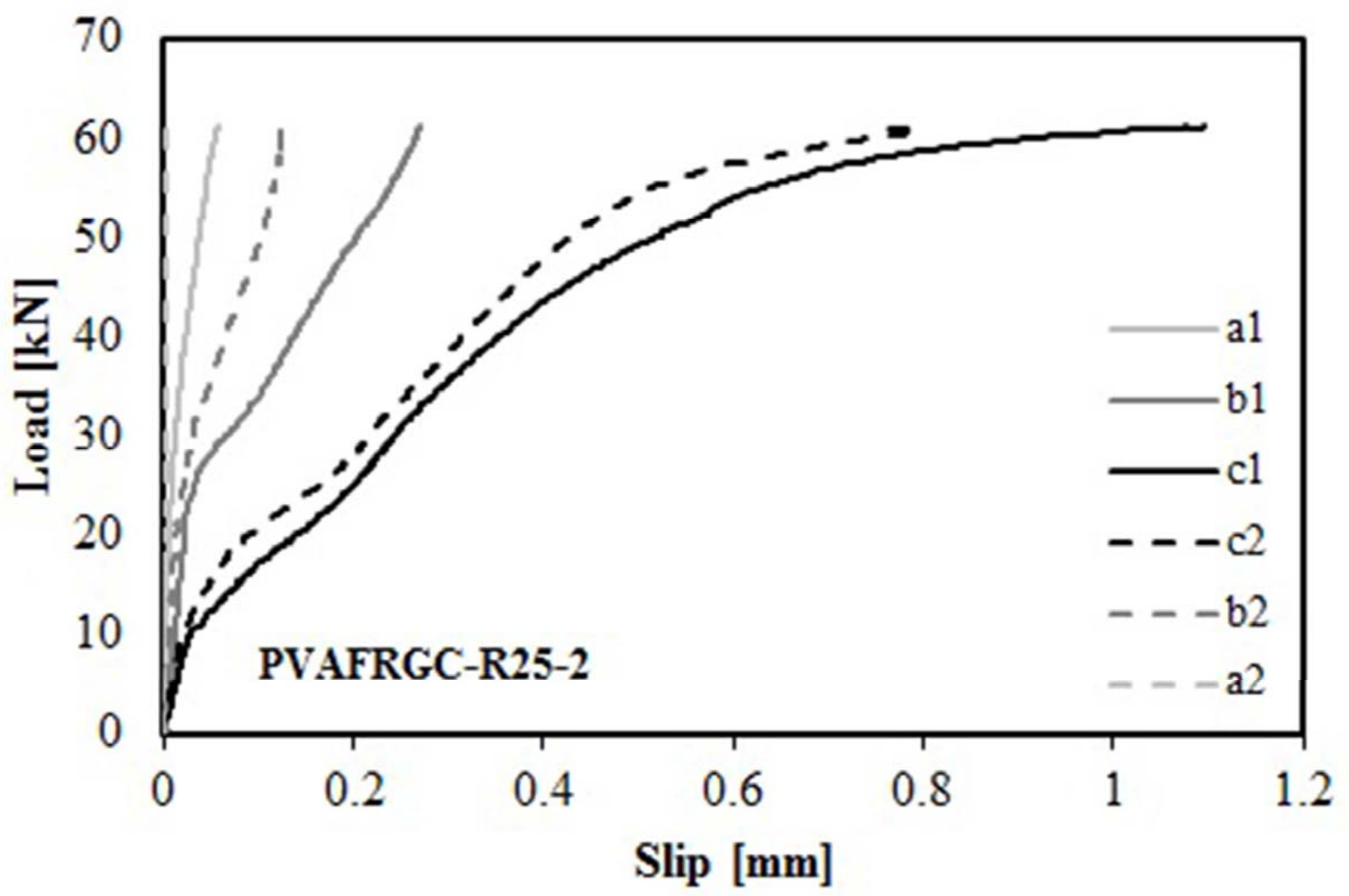




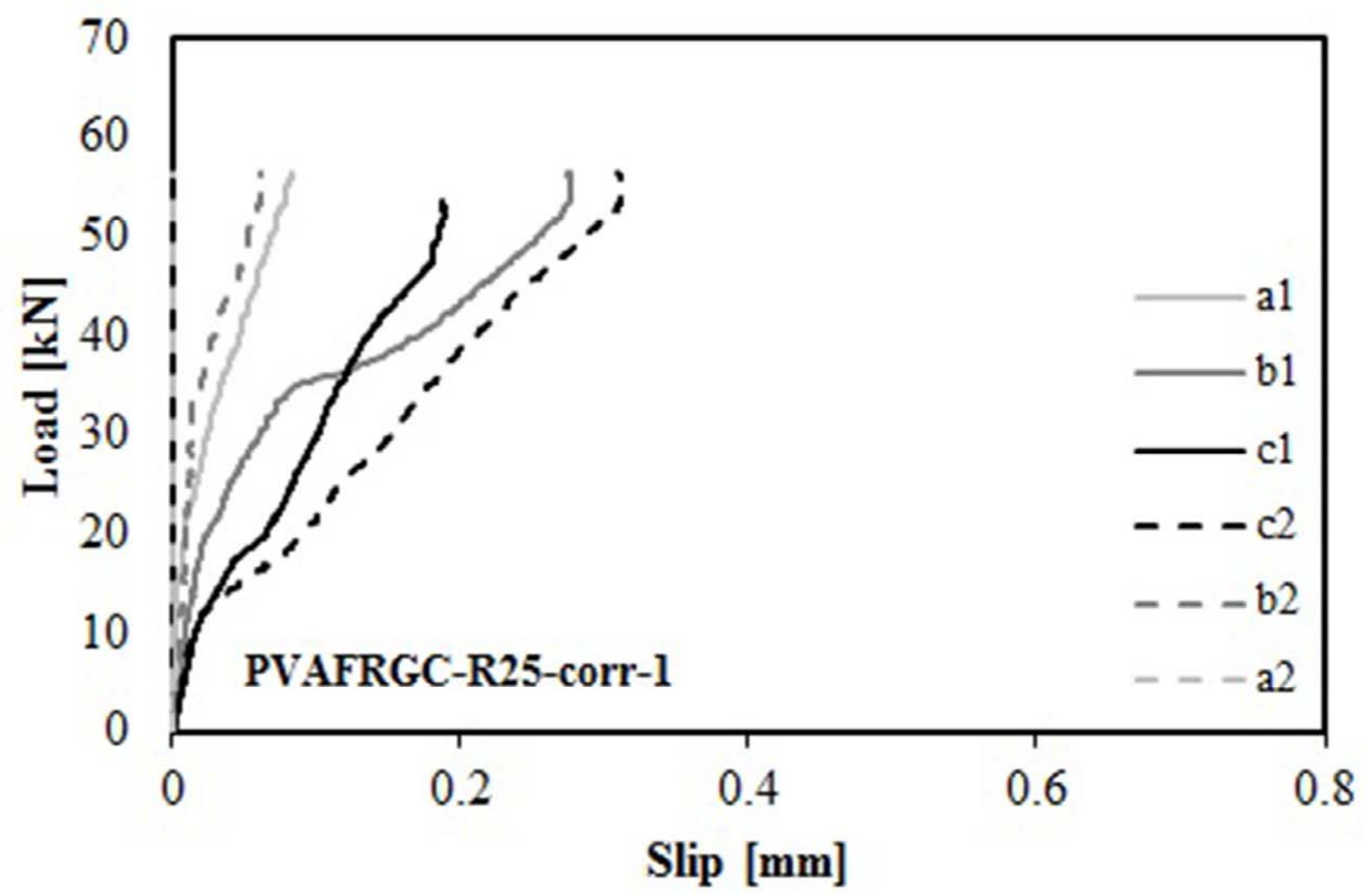




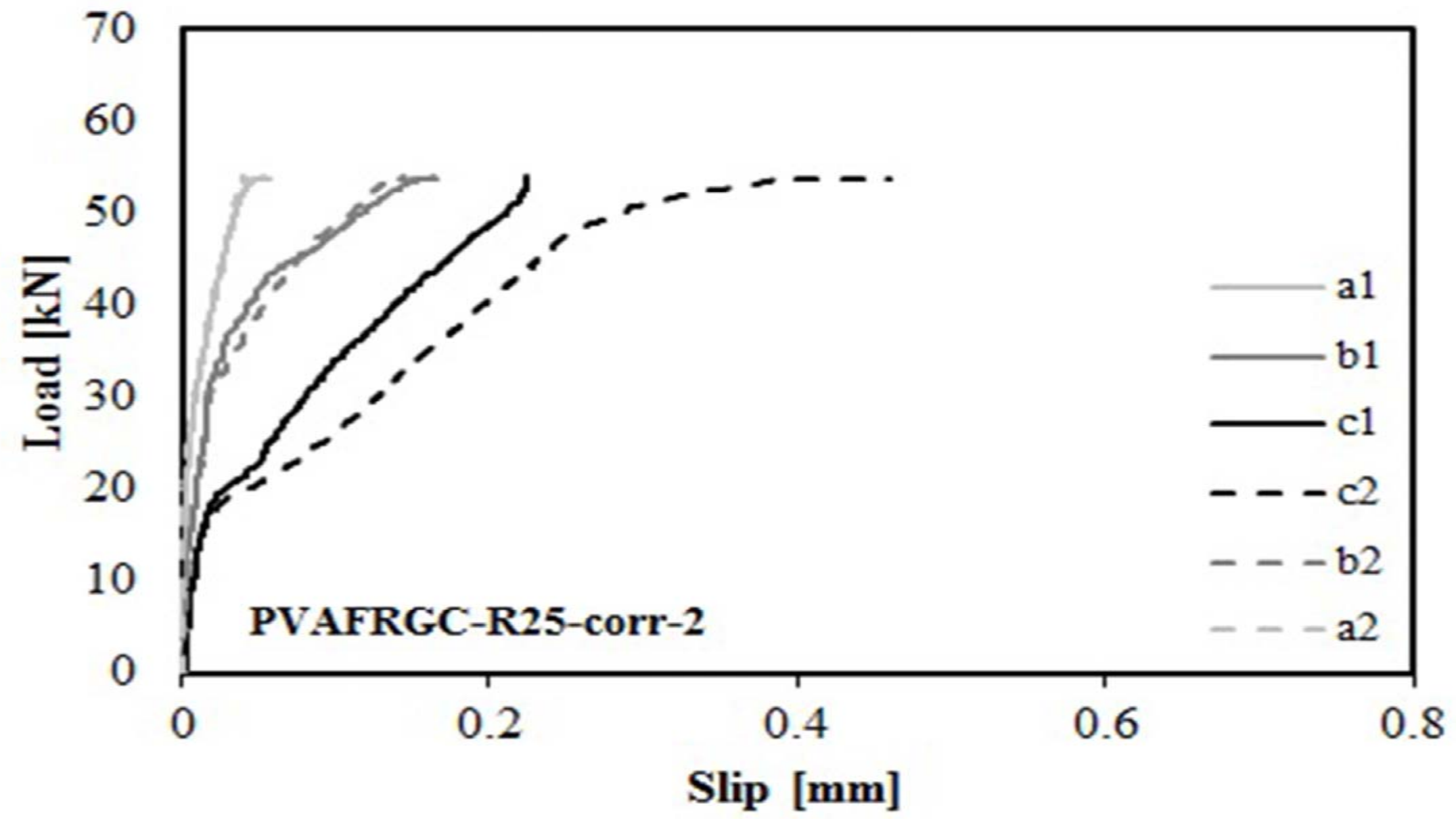




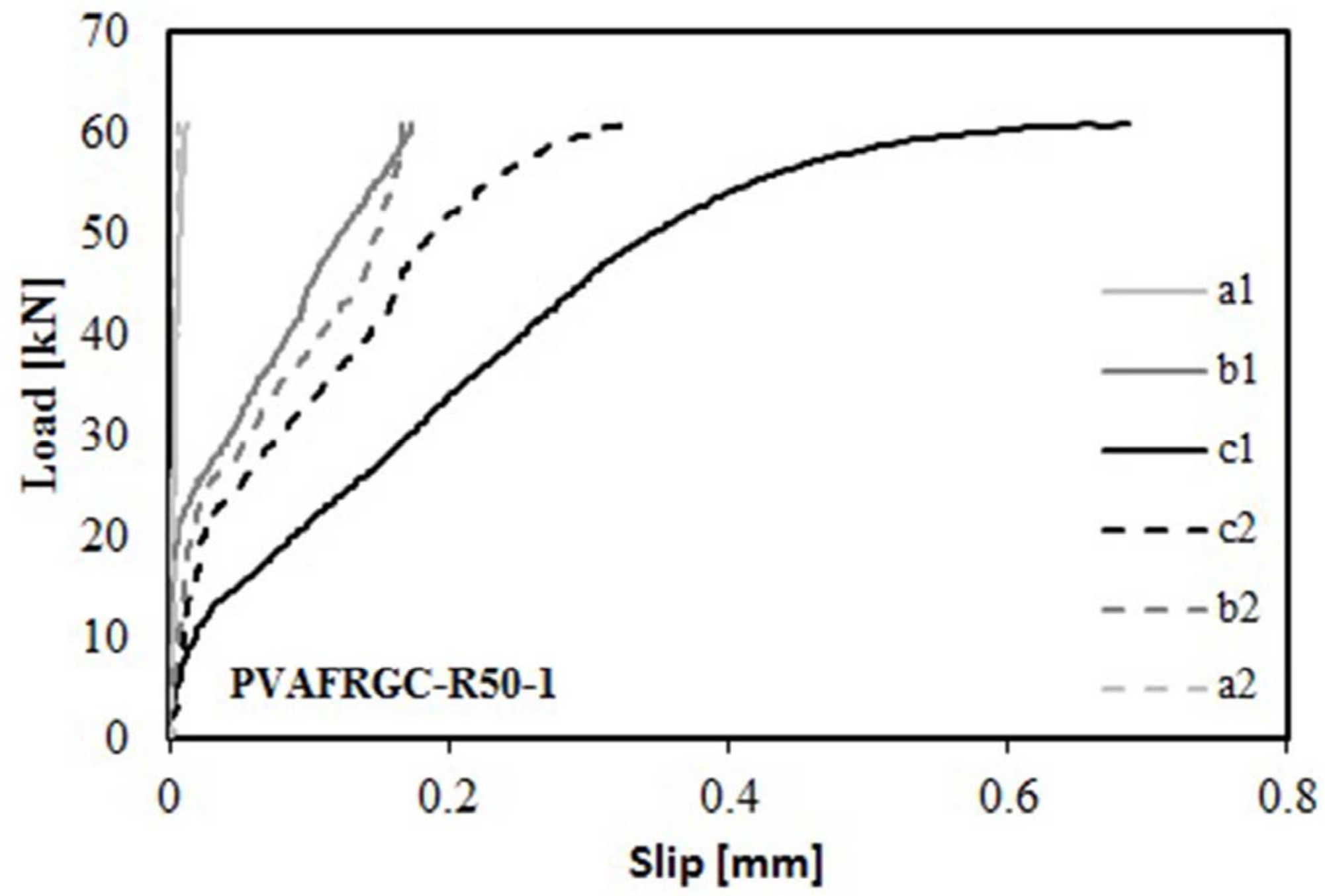




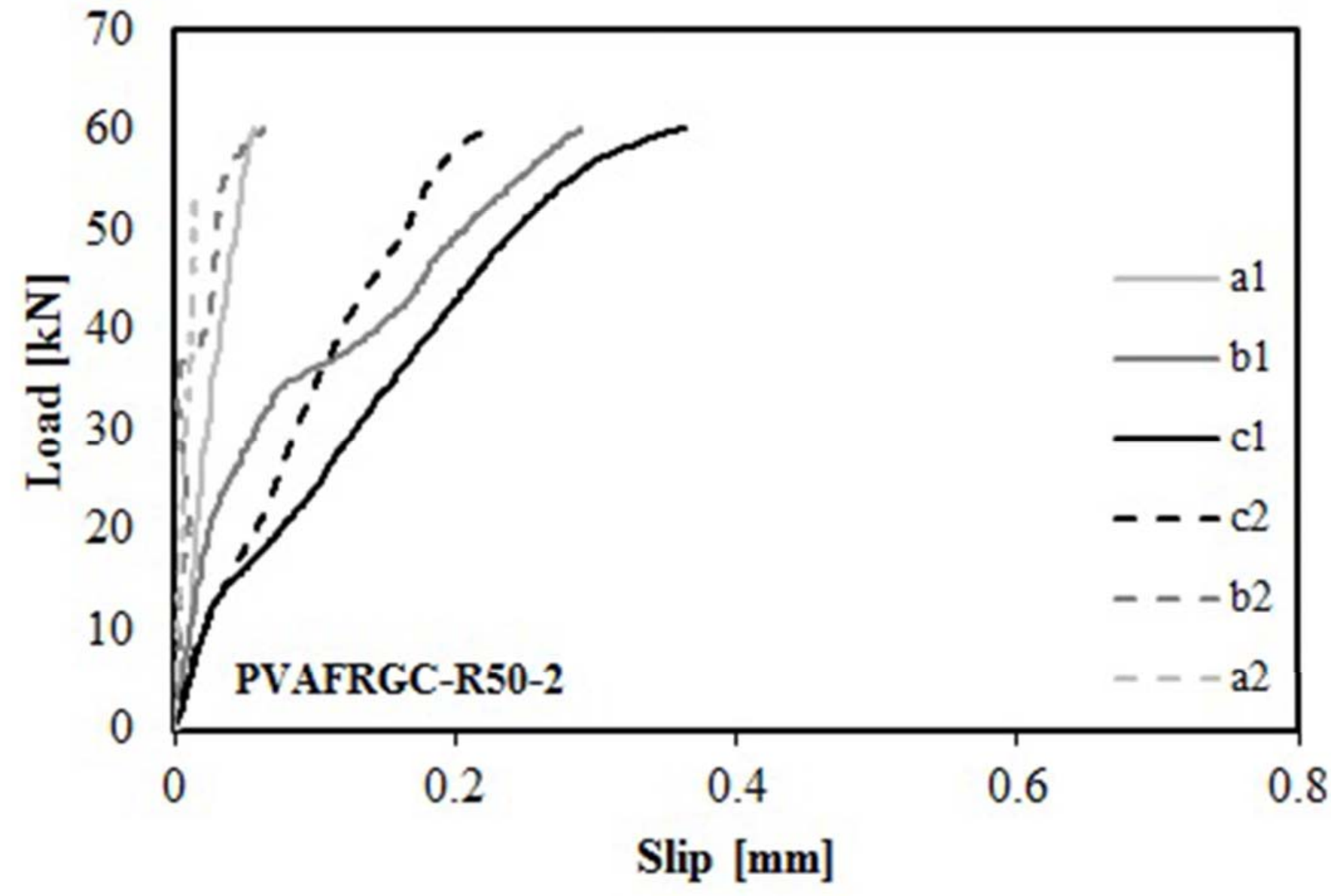




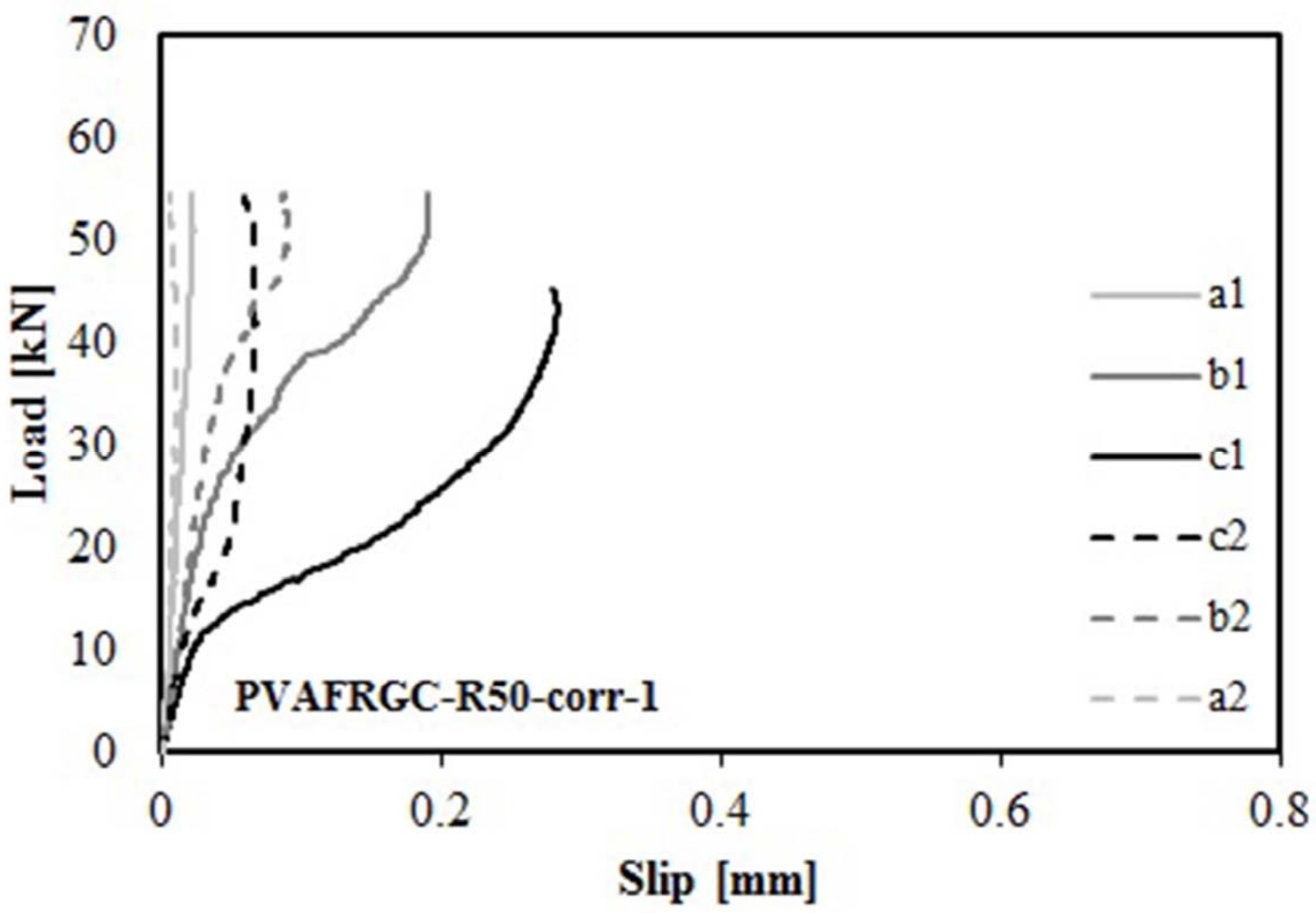




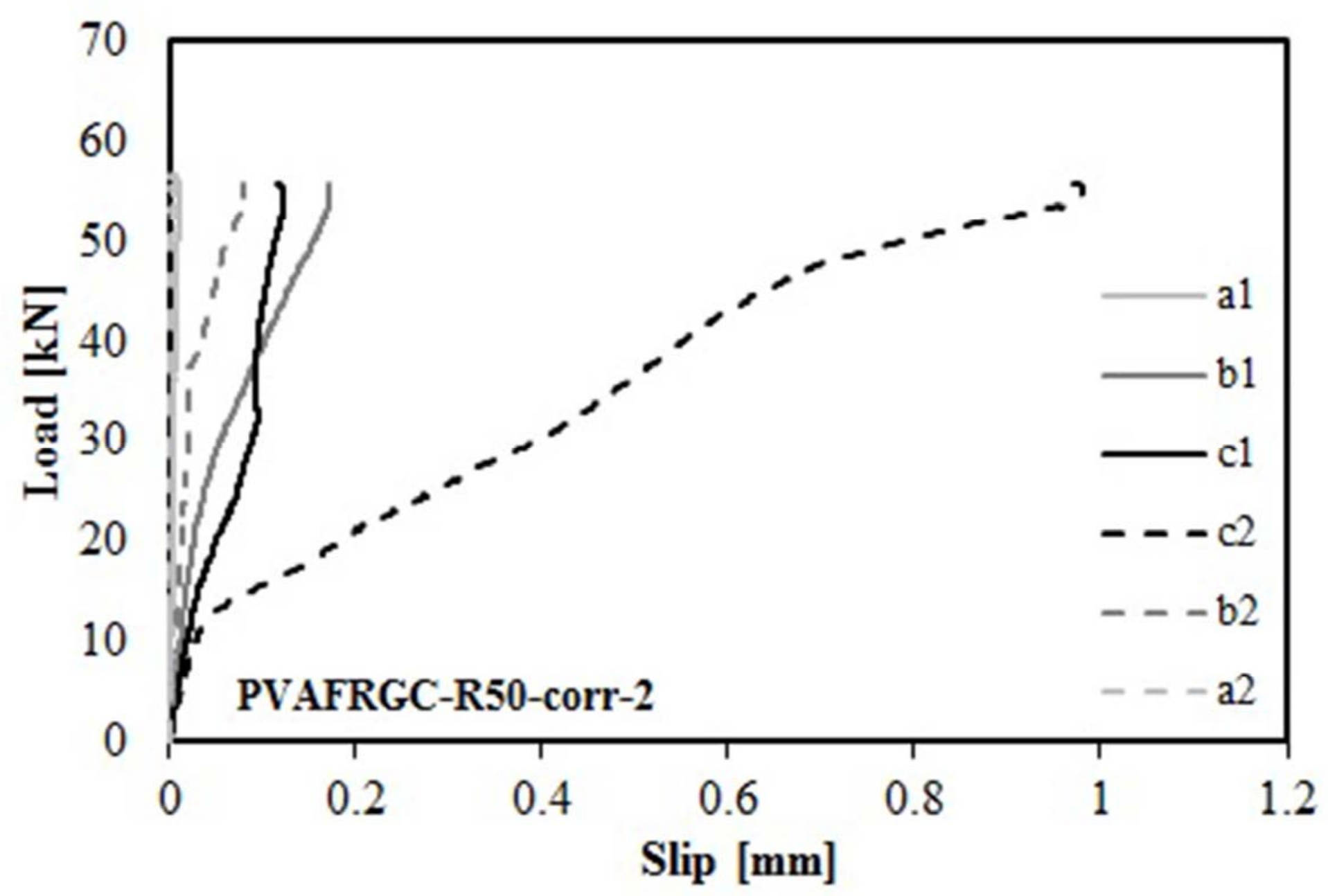


Fig. 25

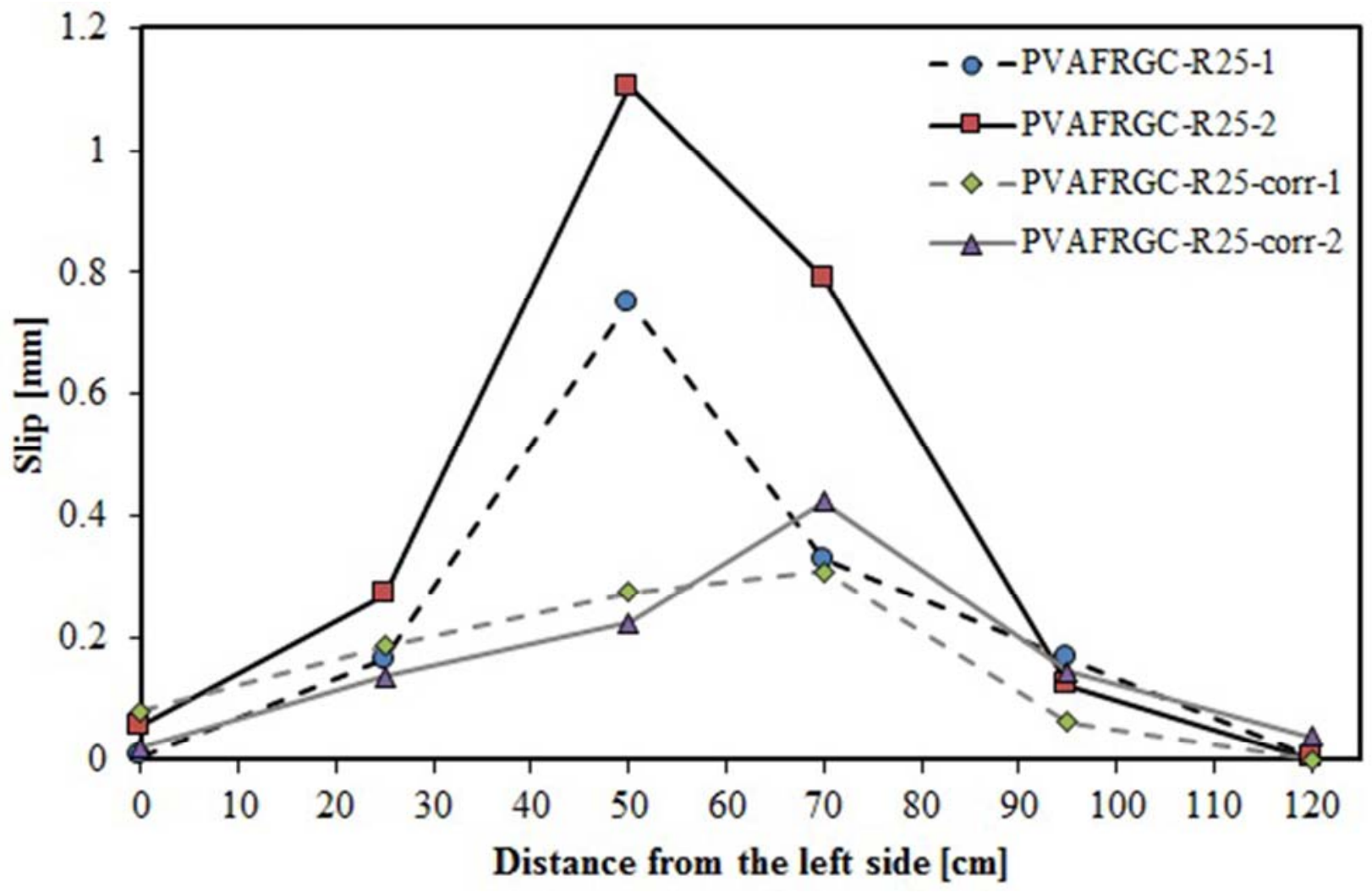




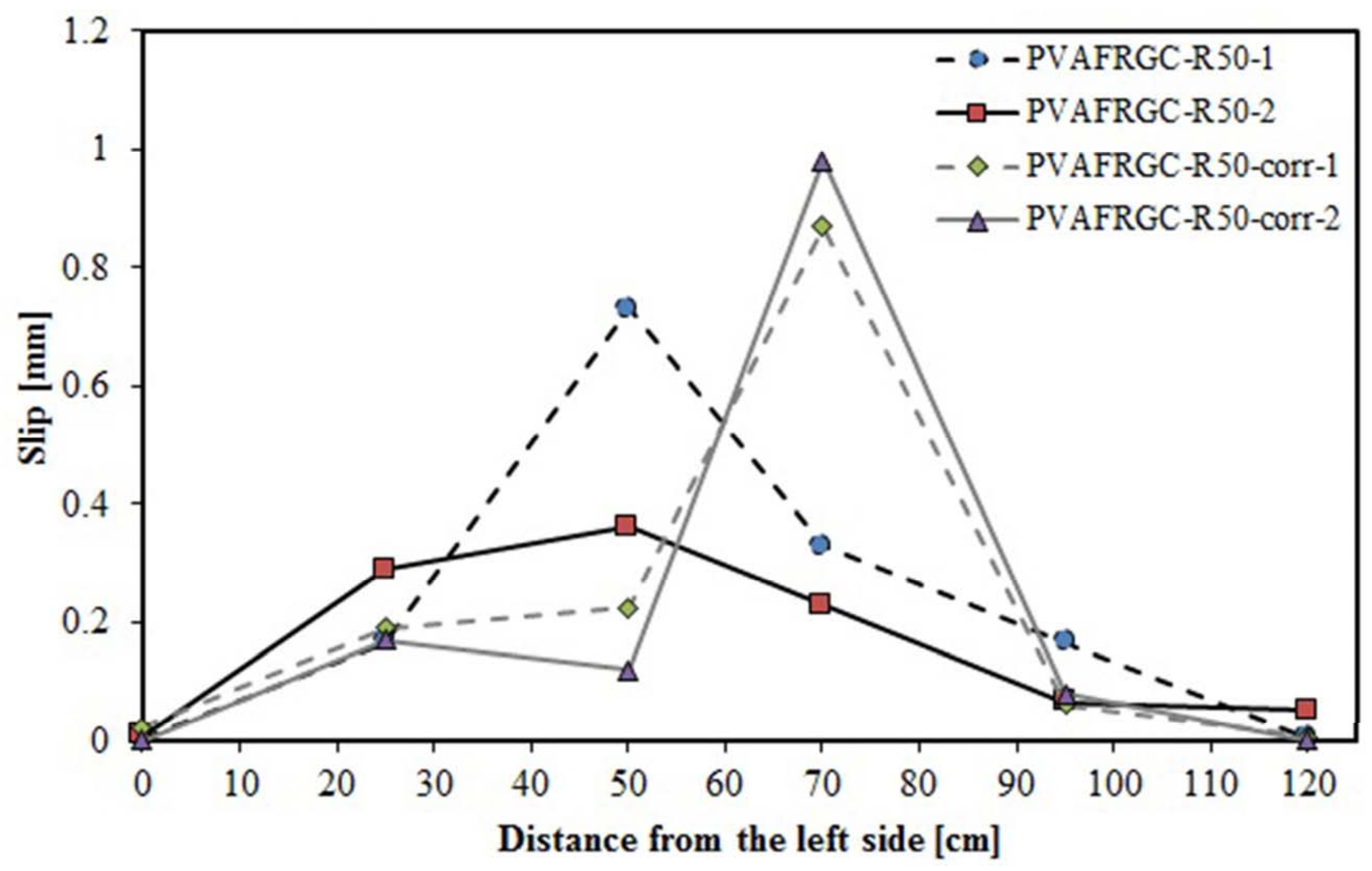

